ROBMILSON SIMÕES GUNDIM

DESENVOLVIMENTO E APLICAÇÃO DE METODOLOGIA PARA AUXÍLIO DA ENGENHARIA EM AUTOMAÇÃO RESIDENCIAL MAEAR

São Paulo 
ROBMILSON SIMÕES GUNDIM

DESENVOLVIMENTO E APLICAÇÃO DE METODOLOGIA PARA AUXÍLIO DA ENGENHARIA EM AUTOMAÇÃO RESIDENCIAL MAEAR

São Paulo 
ROBMILSON SIMÕES GUNDIM

\title{
DESENVOLVIMENTO E APLICAÇÃO DE METODOLOGIA PARA AUXÍLIO DA ENGENHARIA EM AUTOMAÇÃO RESIDENCIAL MAEAR
}

\author{
Dissertação apresentada à Escola \\ Politécnica da Universidade de São \\ Paulo para obtenção do título de \\ Mestre em Engenharia \\ Área de Concentração: \\ Departamento de Engenharia de \\ Energia e Automação Elétricas \\ Orientador: \\ Prof. Dr. Sergio Luiz Pereira
}

São Paulo 


\section{DEDICATÓRIA}

Dedico este trabalho a meus pais; Manoel e Júlia e aos filhos; Gabriela, Igor e Gustavo. Geração e continuidade. 


\section{AGRADECIMENTOS}

\section{A Deus.}

Ao Prof. Dr. Sergio Luiz Pereira e a secretária do Grupo de Automação Elétrica em Sistemas Industriais - GAESI, Sra.Luzia, pela orientação e constante estímulo transmitido durante todo o trabalho.

Existem pessoas que são especiais, pois cruzam o nosso caminho e nos auxiliam a orientá-lo em busca de nossos objetivos, fazendo com que nós possamos nos transformar em pessoas melhores.

A todas estas pessoas, Muito obrigado. 


\section{RESUMO}

Este trabalho apresenta uma revisão bibliográfica sobre a teoria e a prática da Automação Residencial (AR) e também apresenta uma proposta de uma metodologia para auxílio da engenharia em AR intitulada MAEAR - Metodologia para Auxílio da Engenharia em Automação Residencial. Este trabalho apresenta também uma análise entre as principais teorias de controle desenvolvidas para a automação industrial, e a correlação das mesmas sobre sistemas de automação predial e residencial, assim como uma comparação dos níveis de automação industrial e residencial existentes. Os testes de validação da metodologia MAEAR proposta também são apresentadas neste trabalho.

Palavras chaves: Automação Residencial (AR). Níveis de automação. MAEAR Metodologia para Auxílio da Engenharia em Automação Residencial. 


\begin{abstract}
This work presents a bibliographical revision about the theory and the practice of Home Automation (HA) and also presents a proposal of a methodology for aid of engineering in HA entitled MAEAR - Methodology for Aid of Engineering in Home Automation. This work also presents an analysis between the main theories of controls developed to industrial automation, and the correlation it with systems of building automation and home automation, as well as a comparative of levels of industrial automation and home automation. The tests of validation of methodology MAEAR proposal also are presented in this work.
\end{abstract}

Keywords: Home Automation (HA). Automation level. MAEAR - Methodology for Aid of Engineering in Home Automation. 


\section{LISTA DE ILUSTRAÇÕES}

Figura 1.1 - Breve Histórico da Automação Residencial.

18

Figura 1.2 - Estimativa das Receitas Anuais do Mercado de Automação Residencial dos EUA. 19

Figura 1.3 - Estimativa do Crescimento do Mercado de Soluções de Comunicações e Redes nos EUA

Figura 1.4 - Estimativa do Crescimento dos Provedores de Redes de Banda Larga nos EUA. 22

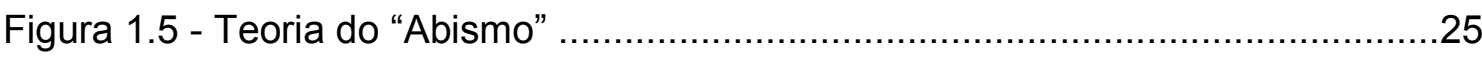

Figura 2.1 - Classificação dos Sistemas Físicos de Automação..............................28

Figura 2.2 - Sistema de controle em malha aberta...........................................30

Figura 2.3 - Sistema com controle manual...................................................... 31

Figura 2.4 - Sistema com controle automático a programa..................................31

Figura 2.5 - Sistema com controle em malha fechada.......................................32

Figura 2.6 - Abrangência da Automação Residencial........................................35

Figura 2.7 - Pirâmide da Automação Industrial............................................36

Figura 2.8 - Níveis de automação residencial segundo a HAA - Home Automation

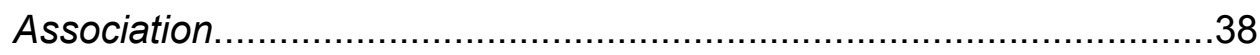

Figura 2.9 - Possibilidades de cargas para sensores de presença........................42

Figura 2.10 - Sensores de presença com tecnologia por raios infravermelhos........43

Figura 2.11 - Sensor de presença com tecnologia por raios ultra-sônicos...............44

Figura 2.12 - Sensor de presença com tecnologia dual....................................45

Figura 2.13 - Sensores com fotocélula.......................................................45

Figura 2.14 - Sensores de presença com fotocélula ......................................46

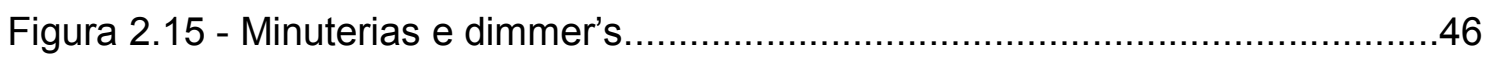

Figura 2.16 - Relé Eletromagnético.....................................................47

Figura 2.17 - Projeto do $1^{\circ}$ relé de impulso - 1950 - Piero Giordanino - Patenteado pela empresa Finder......................................................... 48

Figura 2.18 - Exemplo de seqüência de relé de impulso.....................................48

Figura 2.19 - Modelos de relés de impulso........................................................49

Figura 2.20 - Módulos de controle X10 ..................................................50 
Figura 2.21 - Rede Internet pela rede elétrica.......................................................

Figura 2.22 - Modelo de central de controle iluminação...........................................53

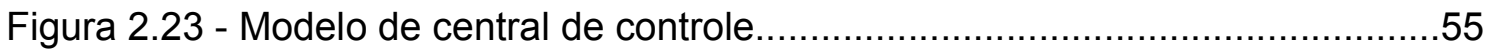

Figura 2.24 - Conceito do sistema de automação centralizado IHC.........................56

Figura 2.25 - Conceito da rede de comunicação BUS - instabus EIB .......................60

Figura 2.26 - Conceito da expansão da rede de comunicação BUS - instabusEIB..62

Figura 2.27- Módulos de sensores e atuadores IHouse ..........................................66

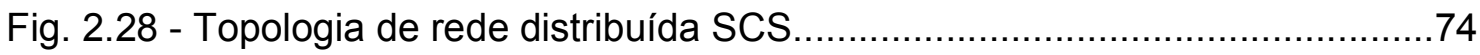

Fig. 2.29 - Exemplo de configuração de dispositivo SCS...........................................74

Fig. 2.30 - Princípio de comunicação entre dispositivos SCS.....................................75

Figura 3.1 - Fluxograma da Metodologia para Auxílio da Engenharia em Automação

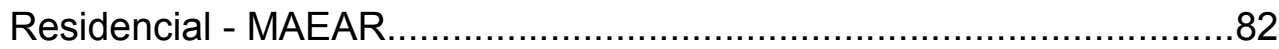

Figura 4.1 - Possibilidades de metodologia para a implantação de projetos residenciais com AR .................................................................

Figura 4.2 - Planta Baixa para simples visualização da Edificação 6 .......................101 


\section{LISTA DE TABELAS}

Tabela 2.1 - Classificação da automação residencial I...........................................40

Tabela 2.2 - Classificação da automação residencial II.........................................41

Tabela 2.3 - Quadro comparativo entre as tecnologias apresentadas I..................77

Tabela 2.4 - Quadro comparativo entre as tecnologias apresentadas II..................78

Tabela 3.1 - Tabela de referência para avaliação métrica proposta dos níveis de

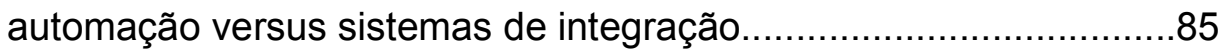

Tabela 3.2 - Tabela resumo para determinar a magnitude e o índice de integração em edificações residenciais.

Tabela 4.1 - Tabela de relação das residências que serviram de objeto de

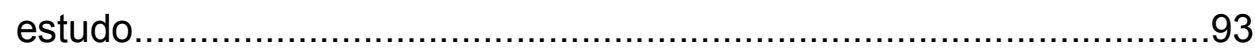

Tabela 4.2 - Determinação do índice para a medição da integração dos sistemas de serviços na edificação - MSIR - Edificação 6......................................98

Tabela 4.3 - Tabela de cargas da Edificação 6 - Pavimento Térreo........................102

Tabela 4.4 - Fatores de Demanda e Potência da Casa Edificação 6 - Pavimento

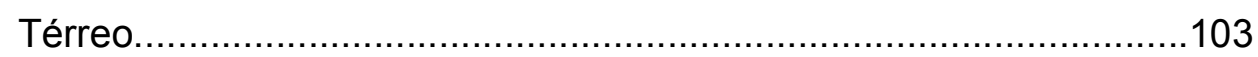

Tabela 4.5 - Tabela de Cargas da Edificação 6 - Pavimento Superior......................104

Tabela 4.6 - Fatores de Demanda e Potência da Edificação 6 - Pavimento

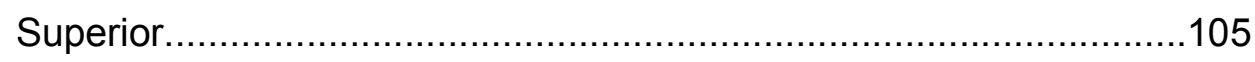

Tabela 4.7 - Dimensionamento da Entrada Consumidora...................................105

Tabela 4.8 - Fatores de Demanda e Potência da Edificação 6 - Dimensionamento

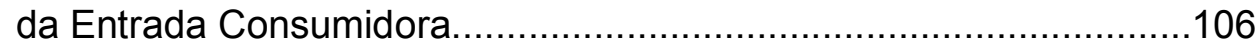

Tabela 4.9 - Determinação do índice para a medição da integração dos sistemas de serviços na edificação MSIR - Edificação 1......................................122

Tabela 4.10 - Determinação do índice para a medição da integração dos sistemas de serviços na edificação MSIR - Edificação 2

Tabela 4.11 - Determinação do índice para a medição da integração dos sistemas de serviços na edificação MSIR - Edificação 3

Tabela 4.12 - Determinação do índice para a medição da integração dos sistemas de serviços na edificação MSIR - Edificação 4.

Tabela 4.13 - Determinação do índice para a medição da integração dos sistemas de serviços na edificação MSIR - Edificação 5 
Tabela 4.14 - Determinação do índice para a medição da integração dos sistemas de

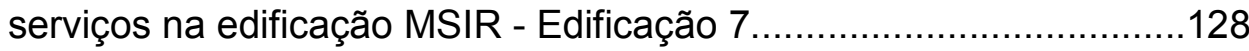

Tabela 4.15 - Determinação do índice para a medição da integração dos sistemas de serviços na edificação MSIR - Edificação 8....................................130

Tabela 4.16 - Tabela integrada para comparação das edificações residenciais inteligentes........................................................................ 129 


\section{SUMÁRIO}

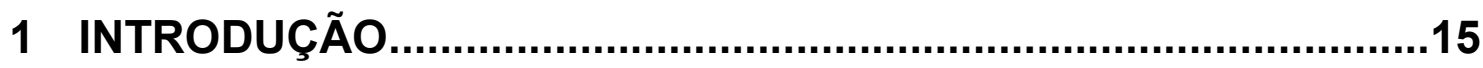

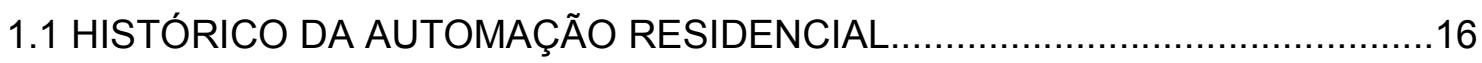

1.2 ESTÁGIO ATUAL DA AUTOMAÇÃO RESIDENCIAL.....................................18

1.3 JUSTIFICATIVAS PARA A ADOÇÃO DA AUTOMAÇÃO RESIDENCIAL............26

2 CARACTERÍSTICAS GERAIS DOS SISTEMAS DE AUTOMAÇÃO

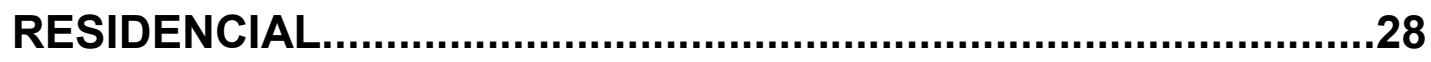

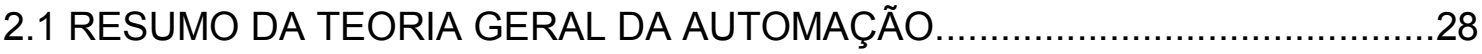

2.1.1 Classificação dos sistemas de automação pela natureza das variáveis controladas.

2.1.2 Classificação dos sistemas de automação pela arquitetura em malha aberta ou malha fechada - teoria de controle..........................................30

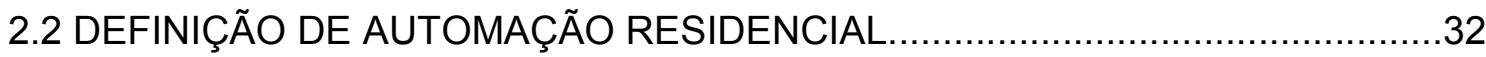

2.3 CLASSIFICAÇÃO DOS NÍVEIS DAS AUTOMAÇÕES INDUSTRIAL, PREDIAL E

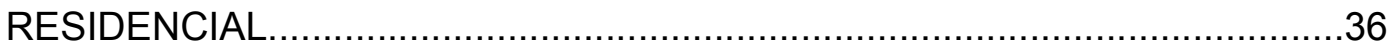

2.4 EXEMPLOS DE TECNOLOGIAS DESTINADAS A SISTEMAS DE AUTOMAÇÃO

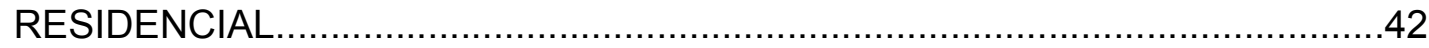

2.4.1 Tecnologia de sensores de presença atuadores, dimerizadores e interruptores minuterias...........................................................................42

2.4.2 Tecnologia para acionamento de cargas por meio de relés de impulso...47

2.4.3 Tecnologia com comunicação de dados por meio da rede elétrica I......49

2.4.3.1 Tecnologia de comunicação por meio da rede elétrica II..........................51

2.4.4 Tecnologia para automatização de persianas, cortinas e toldos...............52

2.4.5 Tecnologia de sistemas de controle de iluminação e outros

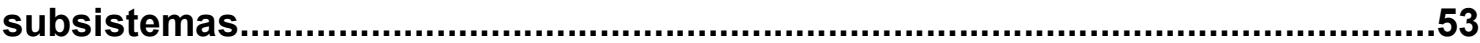

2.4.6 Tecnologia de controle central para automação residencial.......................54

2.4.7 Tecnologia centralizada para sistemas de automação residencial.............55

2.4.7.1 Tecnologia IHC (Intelligent Home Control)...........................................55

2.4.7.2 Tecnologia IBM - Home Net Center....................................................57

2.4.8 Tecnologias Descentralizadas para Sistemas de Automação

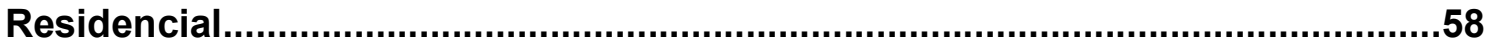




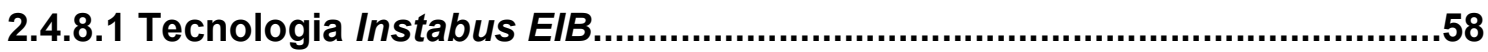

2.4.8.2 Tecnologia Lonworks..............................................................................63

2.4.8.3 Tecnologia modularizada para automação residencial e predial............64

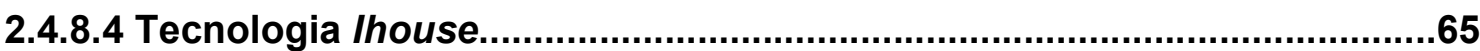

2.5 TENDÊNCIAS TECNOLÓGICAS DE SISTEMAS DE AUTOMAÇÃO

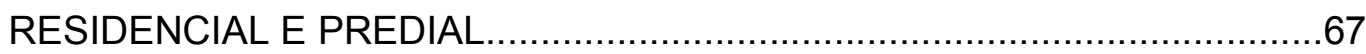

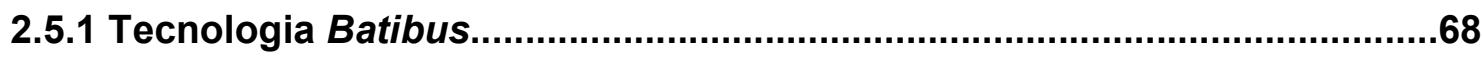

2.5.2 Tecnologia CEBus (Consumer Eletronics Bus).......................................68

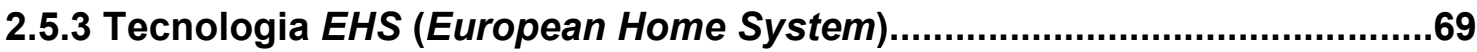

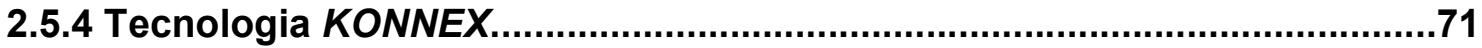

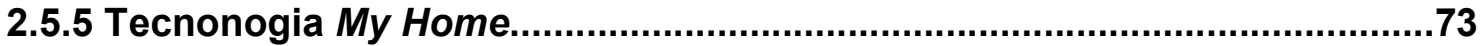

2.5.6 Quadro Comparativo entre as tecnologias apresentadas..........................75

3 FUNDAMENTAÇÃO TEÓRICA E APRESENTAÇÃO DA METODOLOGIA MAEAR - METODOLOGIA PARA AUXÍLIO DA ENGENHARIA EM AUTOMAÇÃO RESIDENCIAL........................80

3.1 INTRODUÇÃO

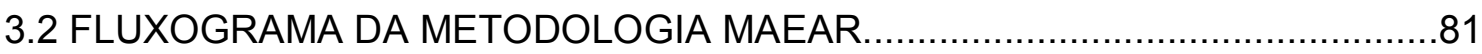

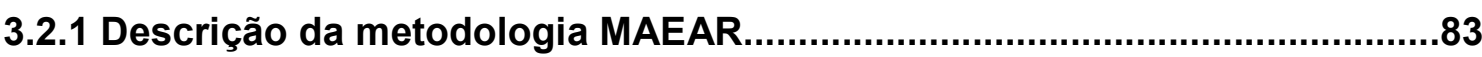

3.2.1.1 Avaliação métrica do nível de automação................................................84

4 APLICAÇÃO DA METODOLOGIA MAEAR - METODOLOGIA PARA AUXÍLIO DA ENGENHARIA EM AUTOMAÇÃO

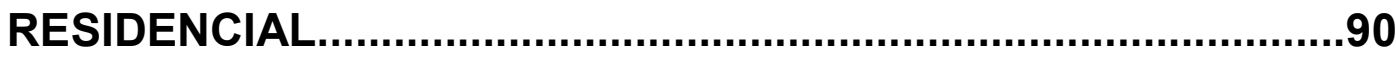

4.1 INTRODUÇÃO

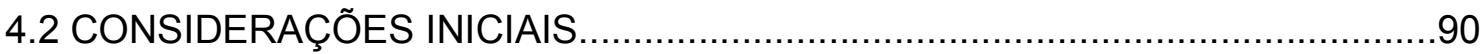

4.3 ESTUDOS REALIZADOS PARA VALIDAÇÃO DA MAEAR …..........................92

4.3.1 Considerações iniciais ao projeto por meio da MAEAR............................94

4.3.1.1 Início da aplicação da metodologia MAEAR.............................................95

4.3.1.2 Introdução ao desenvolvimento do projeto baseado na metodologia

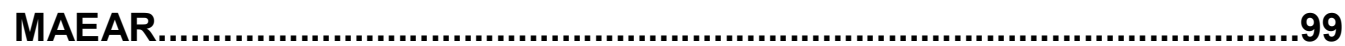

4.3.1.3 Desenvolvimento do Projeto - Características gerais...........................100

4.3.1.4 Avaliação métrica do nível de automação/integração proposto no

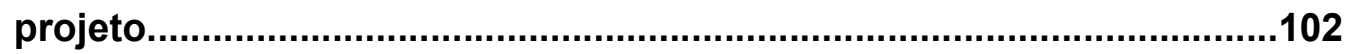

4.3.1.5 Apresentação da proposta de projeto ao usuário para avaliação........ 107 
4.3.1.6 Implementação do projeto e considerações..........................................107

4.3.1.7 Testes e start-up assistido do projeto de estudo de caso......................109

4.3.1.8 Entrega final do projeto de estudo de caso...........................................109

4.3.1.9 Considerações finais da implantação do projeto de estudo de caso...110

5 CONCLUSÃO.....................................................................112

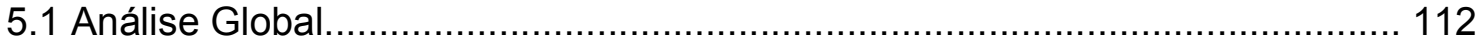

5.2 Sugestões para trabalhos futuros.................................................................. 112

Referências Bibliográficas........................................................114

APÊNDICE A - DESCRIÇÃO EXEMPLO DE UMA CASA INTELIGENTE...........119

APÊNDICE B - TABELAS DE DADOS DOS ESTUDOS DE CASO......................122 


\section{INTRODUÇÃO}

Os projetos das edificações residenciais no Brasil até o presente momento não são orientados, na sua maioria, para a melhoria de eficiência energética, da segurança, do conforto e principalmente para o pleno emprego das possibilidades que a Automação Residencial pode proporcionar. Tal fato se deve a muitos fatores e os principais são listados a seguir:

a) desinformação do consumidor em relação a preços, benefícios e configurações possiveis;

b) falta de ferramentas de engenharia que auxiliem no projeto e na análise técnica econômica ;

c) uma maior integração entre as grandes empresas produtoras de tecnologia da respectiva área e os profissionais, e;

d) uma maior integração entre os profissionais e consumidores envolvidos no processo de construção de uma edificação.

À medida que se pesquisam implantações de Automação Residencial no Brasil ou sob a denominação domótica, como também é chamada essa área do conhecimento, percebe-se a dificuldade de obter informação técnica integrada e organizada. Nota-se que ainda hoje a AR no Brasil é considerada preponderantemente um artigo de luxo. A MAEAR pretende contribuir para o processo de popularização da AR.

Este trabalho tem dois objetivos:

Auxiliar na ruptura do paradigma de que automação residencial é exclusivamente artigo de luxo, contribuindo para a popularização do conhecimento, e;

Apresentar o desenvolvimento de uma metodologia de análise técnica para servir como ferramenta de engenharia na definição e especificação de projetos de automação residencial.

Este trabalho está organizado em cinco capítulos.

O Capítulo 1 é composto por esta introdução e pela descrição do histórico da Automação Residencial, o estágio atual e as previsões de desenvolvimento mercadológico e tecnológico. Este capítulo apresenta também a "Teoria do Abismo" 
de Geoffrey Moore (1991), assim como, os conceitos de um índice de avaliação dos edifícios inteligentes, criados por uma associação da América do Norte, as quais justificam em parte do por que a automação residencial ainda não ter atingido um alto grau de popularização. Este capítulo também descreve as possibilidades e justificativas técnicas para implantação de sistemas de automação residencial e estabelece a correlação com o atual estado da arte da área em questão.

O Capítulo 2 apresenta a teoria geral da automação. Descreve uma visão global das características gerais dos sistemas atuais de automação residencial. Apresenta uma matriz de sistematização e classificação dos níveis de Automação Residencial. Aborda também aspectos de arquiteturas e de caracterização dos sistemas, redes de comunicações de dados e seus protocolos de comunicação.

O Capítulo 3 apresenta a fundamentação teórica que embasa a criação de uma metodologia para auxiliar a implantação da automação residencial. Este capítulo apresenta também a metodologia de análise técnica, intitulada: Metodologia para Auxílio da Engenharia em Automação Residencial - MAEAR.

O Capítulo 4 apresenta a aplicação da ferramenta de auxílio para o planejamento da implantação da automação residencial denominada MAEAR e relata o desenvolvimento de um projeto do sistema elétrico de uma residência, orientado pela própria metodologia.

Este capítulo apresenta também alguns estudos de caso e relatos de visitas técnicas em edificações residenciais com diferentes níveis de automação, proporcionando a comparação da avaliação métrica proposta na MAEAR.

O Capítulo 5 apresenta a análise global deste trabalho de pesquisa e propõe novos desenvolvimentos nesta área do conhecimento.

\subsection{HISTÓRICO DA AUTOMAÇÃO RESIDENCIAL}

Os primeiros produtos e sistemas de Automação Residencial remontam ao final da década de 70 nos Estados Unidos. A tecnologia pioneira deste seguimento foi o lançamento de pequenos "módulos", (denominados X10 devido ao protocolo de comunicação utilizado na transmissão dos dados), que se interligavam pela rede elétrica existente nas casas e podiam acionar luzes e eletrodomésticos à distância. 
Estes produtos, de fácil instalação, podiam e podem ser adquiridos até hoje em lojas de departamentos, em hipermercados, e atualmente também pela internet, sendo que são colocados para funcionar pelo próprio usuário, sem grandes complicações técnicas.

Porém, sua confiabilidade é limitada pela qualidade da energia elétrica e pela característica da instalação elétrica existente. As aplicações básicas são isoladas, sem nenhuma integração entre os diversos sistemas residenciais que o mesmo está instalado.

No final dos anos 80, os computadores pessoais passaram a ser uma realidade e a sua crescente capacidade de processamento e de velocidade, e também o seu barateamento, auxiliaram o emprego dos mesmos em aplicações de automação doméstica.

A popularização dos microcomputadores permitiu o desenvolvimento e o aumento de aplicações de softwares para acionar e monitorar equipamentos de uso residencial.

Começaram então a surgir as primeiras "casas inteligentes" que empregavam computadores para controlar vários sistemas.

Para citar um exemplo, a empresa americana Echelon, desenvolvedora de tecnologia de controle em rede para automação de sistemas, mantém uma demonstração disponível para livre consulta e interação em seu site: http://demo.echelon.com/layout.htm.

Trata-se da simulação de uma sala instalada na própria sede da empresa em San José, Califórnia, com alguns dispositivos, como luminárias, persiana e ar condicionado, podendo ser controlados e monitorados por meio da rede mundial de computadores (Internet).

No site também é possível acompanhar a potência elétrica demandada, a potência elétrica máxima, a potência elétrica consumida total e a potência elétrica em uso.

A figura 1.1 ilustra um breve histórico do desenvolvimento científico tecnológico da Automação Residencial 


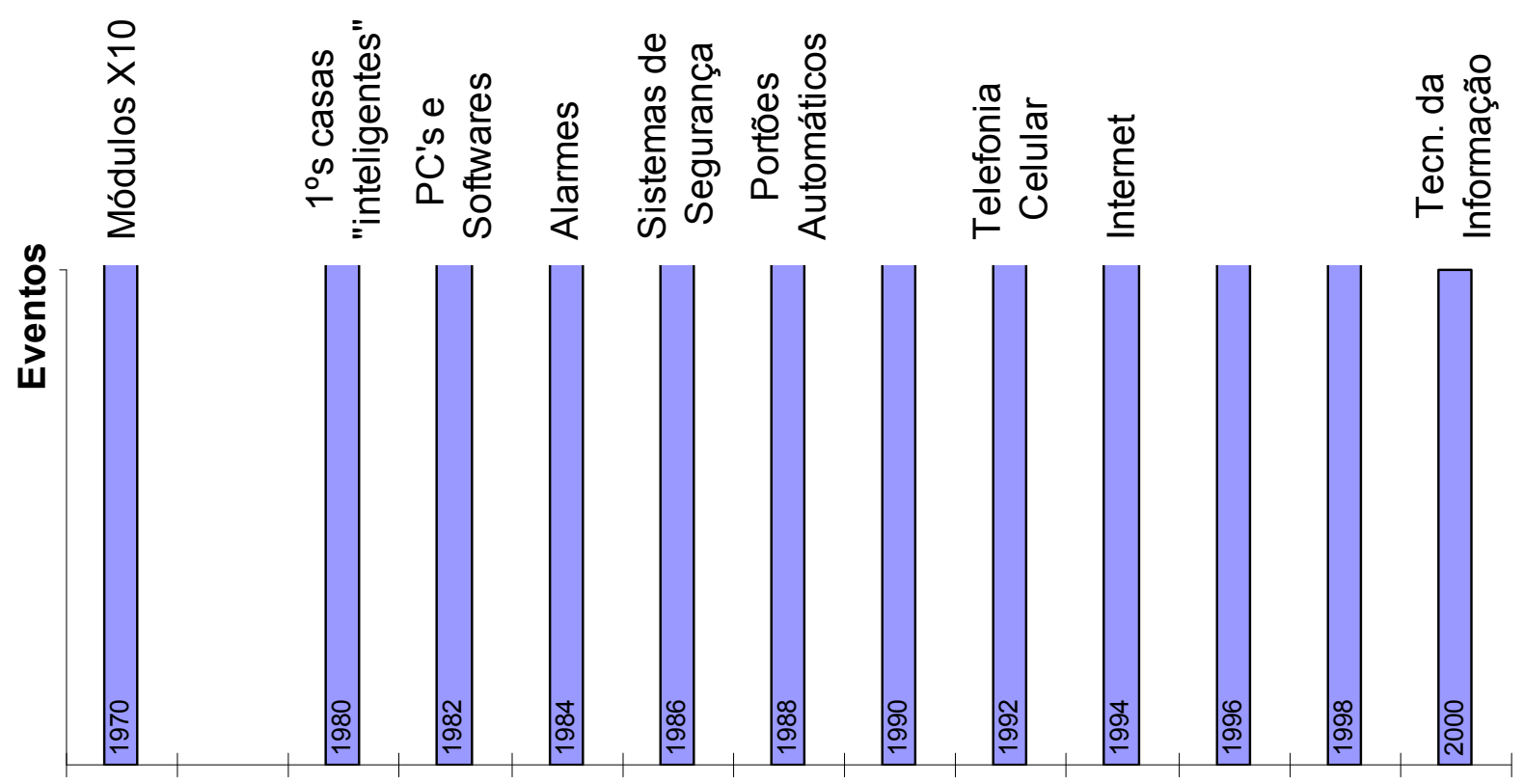

Anos

Figura 1.1 - Breve histórico da automação residencial - Fonte: Aureside (2003)

\subsection{ESTÁGIO ATUAL DA AUTOMAÇÃO RESIDENCIAL}

Apesar dos conceitos de Automação Residencial, para muitas pessoas, apresentarem-se como futuristas, o potencial de mercado é enorme. Nos Estados Unidos, são aproximadamente 5 milhões de residências automatizadas. Entre 1998 e 2002, segundo dados da AURESIDE - Associação Brasileira de Automação Residencial, as receitas anuais no mercado americano de Automação Residencial aproximadamente dobraram, resultando num aumento de US\$1.6 bilhão de dólares. O crescimento anual até o ano de 2002 ficou em torno de 19\% ao ano. De 2002 ao final de 2003, de acordo com pesquisas o mercado dobrou novamente, crescendo para US\$ 3.2 bilhões de dólares. E para 2008 está previsto alcançar US\$ 10.5 bilhões de dólares, o que se traduzirá em aumento de US\$ 7.3 bilhões, num período 
de 5 anos, ou seja, um crescimento anual de aproximadamente $27 \%$ para o novo período. Veja figura ilustrativa:

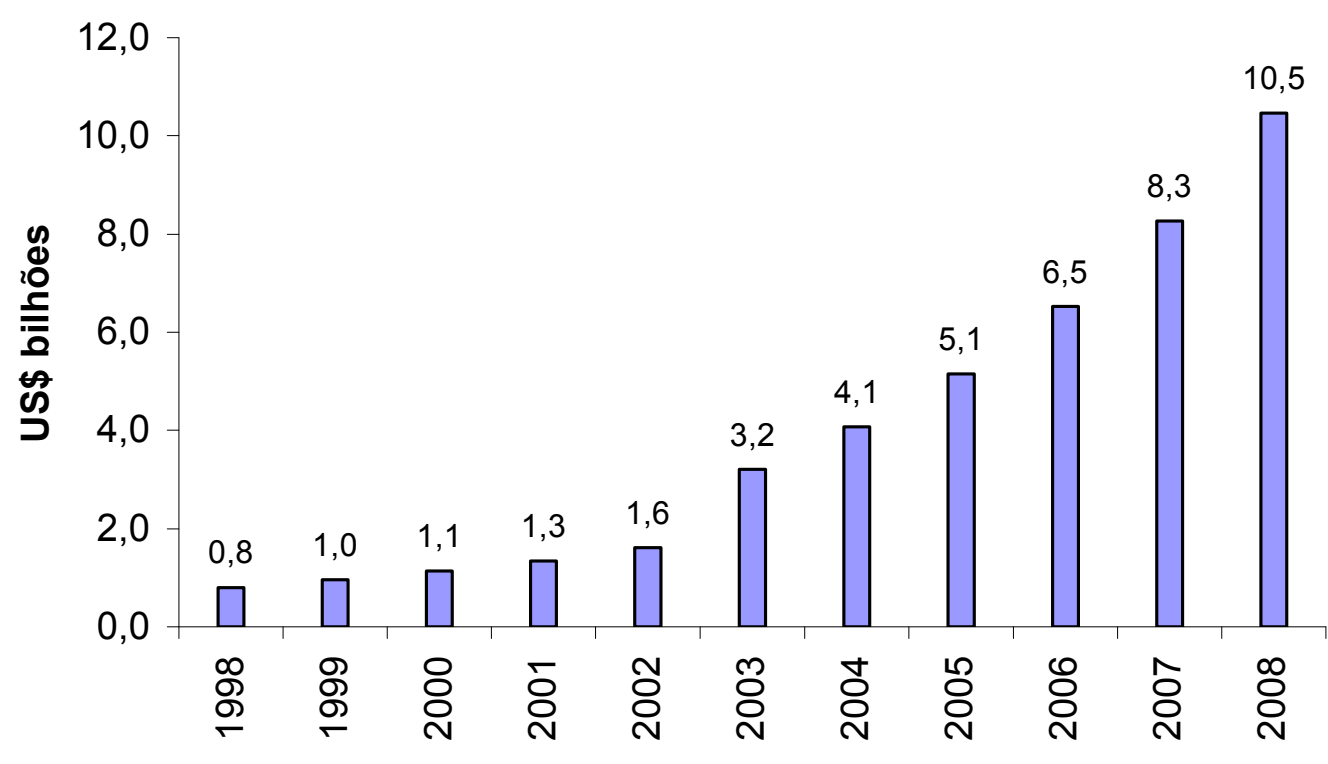

Anos

Figura 1.2 - Estimativa das Receitas Anuais do Mercado de Automação Residencial dos EUA - Fonte: Aureside (2006)

De acordo com a Parks Associates, uma das empresas líderes na área de pesquisa de tecnologias emergentes, a procura por soluções de comunicações e redes vai continuar crescendo fortemente nos próximos anos, alavancando vários tipos de negócios na área residencial, de pequenos escritórios e soluções móveis.

$\mathrm{Na}$ promissora área de soluções para entretenimento, constatou-se que os usuários estão buscando soluções modernas, além da TV e do rádio tradicional. Música e vídeos pela Internet estão ganhando espaço.

Perguntados sobre a importância das opções de entretenimento doméstico da lista abaixo, os chefes de família responderam na seguinte ordem:

1) Ouvir música - $59 \%$

2) Usar o PC - $53 \%$

3) Assistir TV - 51\%

4) Assistir filmes - 38\%

5) Ver fotos digitais - $31 \%$

6) Ver filmes domésticos - $16 \%$ 
Com os provedores de serviços despertando para o mercado doméstico, o número de casas conectadas partiram de 100.000 em 2002 devendo alcançar mais de 6 milhões até o final de 2007, de acordo com o In-Stat MDR (mercado norteamericano). A pesquisa também indica que a capacidade dos provedores de oferecer mais serviços aos equipamentos conectados à rede e à banda larga poderá multiplicar as oportunidades de negócios neste mercado.

As projeções da pesquisa podem ser vistas na figura 1.3.

\section{Service Provider Managed Home Networks}

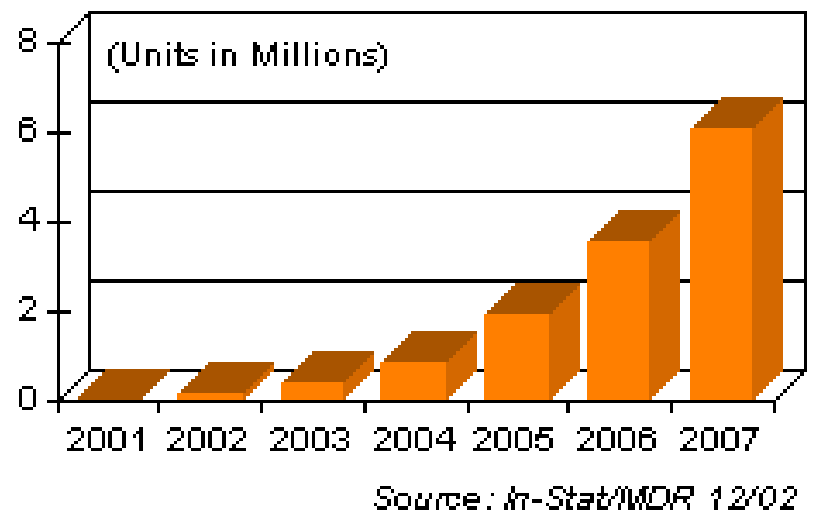

Figura 1.3 - Estimativa do Crescimento dos Provedores de Redes de Banda Larga nos EUA - Fonte: In-Stat/MDR (2002)

No entanto podem-se alinhar as projeções junto à da construção civil, inicialmente apenas para os imóveis de alto padrão, mas em seguida avançar em níveis de automação diferentes, alcançando as demais classes sociais. Nota-se um crescente número de reportagens na mídia, eventos, congressos e um aumento significativo de empresas especializadas nessa área do conhecimento. Atualmente existem diversas empresas no Brasil divulgando o desenvolvimento de projetos e de tecnologias por meio de seus sites especializados na Internet.

Nesta linha de raciocínio, espera-se que a indústria da construção civil, principalmente por meio de incorporadores e construtores, ofereça seus próximos lançamentos imobiliários com projetos de automação incorporados, assim como também os pequenos consumidores descubram e planejem suas residências aproveitando para analisar as possibilidades de implementar alguma das tecnologias existentes. Como proposta, pode-se ainda aproveitar para esclarecer e estimular a instalação de dispositivos de proteção e de segurança que atuam automaticamente 
em possiveis falhas ocorridas e que inclusive são exigidos por Normas, mas infelizmente na maioria dos projetos em residências populares não são instalados por falta de informação e orientação.

Mesmo com um número significativo de sites e empresas especializadas em AR surgindo a cada dia no Brasil, verifica-se ainda o paradigma de que sistemas de Automação Residencial são, para a maioria da população brasileira, artigos de luxo.

Analisando um pouco mais as razões das dificuldades para o pleno emprego das possibilidades que a automação residencial pode proporcionar, constata-se, além dos fatores já citados, que:

- as grandes companhias se especializam na manufatura dos produtos, mas sua inércia operacional dificulta que alguns desses produtos cheguem ao projeto final de um pequeno consumidor de automação residencial, onde normalmente as soluções devem ser customizadas às necessidades dos usuários;

- os pequenos integradores (profissionais) têm um contato mais próximo com o usuário e são capazes de especificar as soluções por eles desejadas; no entanto, para que isso ocorra, estes profissionais necessitam conhecer em detalhes os produtos e saibam como utilizar ao máximo suas características originais. Normalmente, torna-se complicado efetuar adaptações ou alterar as propriedades de um produto fabricado em série; e

- a automação residencial, por definição ainda não é um mercado de massa, devido aos estágios de desenvolvimento do mercado de produtos de alta tecnologia.

A seguir, é apresentada a classificação dos estágios de desenvolvimento do mercado de produtos de alta tecnologia, segundo Geoffrey Moore (1996).

Em 1991, ele popularizou uma tese, até hoje válida, delineando os estágios de desenvolvimento do mercado de produtos de alta tecnologia. Ao longo do tempo, segundo ele, o mercado destes produtos se compõe de consumidores com as seguintes características, em ordem cronológica:

1. os inovadores (entusiastas da tecnologia);

2. os pioneiros (visionários);

3. a maioria imediata (pragmáticos);

4. a maioria posterior (conservadores); e

5. os retardatários (céticos). 
Para cada grupo deve existir uma abordagem especifica de marketing. Os consumidores dos grupos 1 e 2, por exemplo, estão dispostos até a servir de cobaias para o desenvolvimento dos produtos, pois aceitam isto como o preço de serem vanguardistas. No entanto, muitas vezes representam um grupo pequeno em volume de demanda e não obtém dos fornecedores a atenção merecida.

Já os consumidores nos grupos 3 e 4 representam o mercado de larga escala, para os quais já não se admitem testes; os resultados devem ser os desejados, sem falhas. É nesta fase que os fornecedores conseguem maximizar o retorno do investimento.

Esta classificação, bastante oportuna e realista, no entanto, não é a mais valiosa contribuição do estudo de Geoffrey Moore (1996). Sua principal constatação é a existência de um "abismo" entre as fases 2 e 3, ou seja, uma descontinuidade entre a introdução do produto no mercado e a sua consolidação como um produto de larga escala.

É neste "abismo", diz ele, que a maioria das empresas falha por não dispor do instrumental de marketing ou de engenharia para lidar com a situação.

A figura 1.4 ilustra os estágios de desenvolvimento do mercado de produtos de alta tecnologia, segundo Geoffrey Moore (1996).

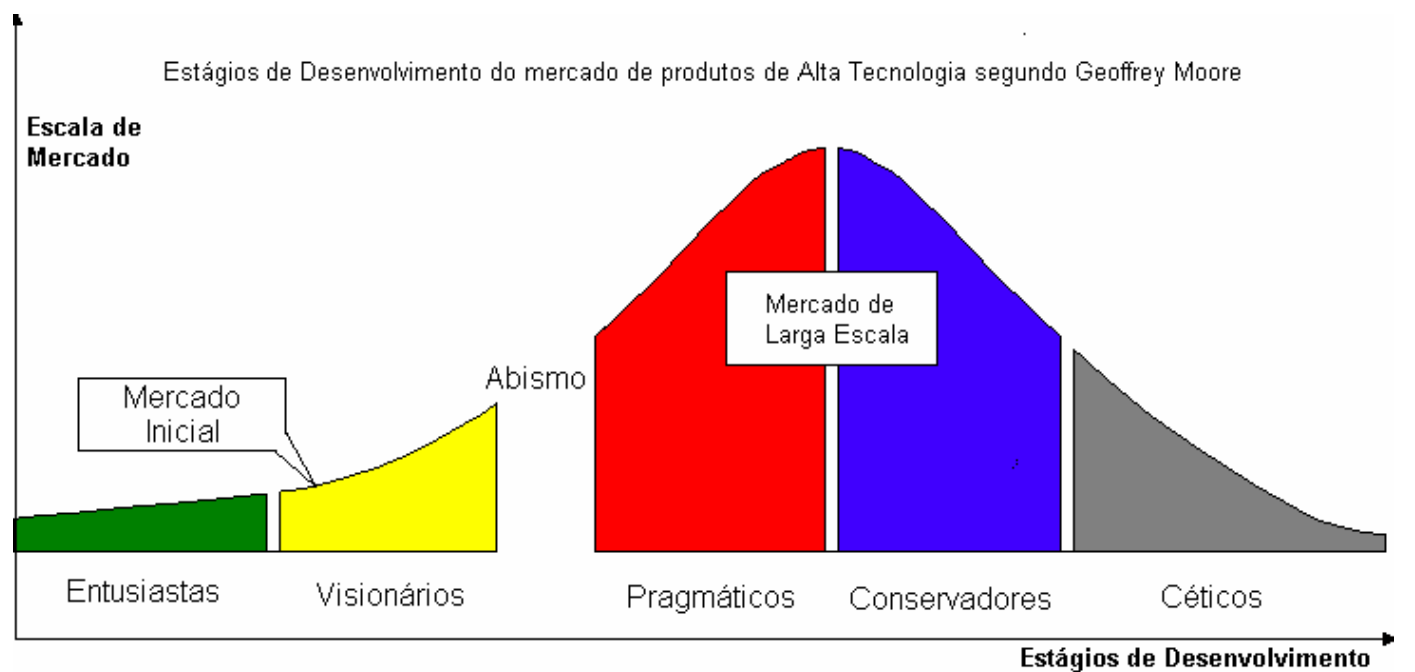

Figura 1.4 - Teoria do "Abismo" - Fonte: Geoffrey Moore (1996) 
A importância dessa discussão no caso do mercado brasileiro de automação residencial é exatamente o fato de que algumas das tecnologias podem estar atualmente "a beira do abismo", segundo dados da própria AURESIDE. Ou seja, existe uma necessidade de enfrentar essa transição de um mercado incipiente e baseado apenas no pioneirismo de alguns consumidores para o mercado de larga escala. O tamanho deste mercado e a sua taxa de crescimento serão definidos na razão direta da competência dos profissionais e de seu empenho ao enfrentar os desafios.

Segundo o próprio Geoffrey Moore (1996) uma proposta viável é a do marketing de nichos, ou seja, efetuar a transição do abismo atacando nichos específicos, consolidando as posições nesses nichos ao mesmo tempo em que diminuem os riscos para conquistar os nichos seguintes. Essa situação lembra a de uma jogada de boliche, quando se precisa derrubar um pino para, a seguir, derrubar os adjacentes. A evolução da telefonia celular pode fornecer um exemplo ideal desta tática.

Esses "nichos" devem ser escolhidos através de certos critérios. Podem ser puramente geográficos (concentrados nas áreas de maior densidade de novas construções), de modismos (atualmente comenta-se bastante os home offices), tecnológicos (por meio de inovações) ou, ainda, por meio de eventos que auxiliem a estimular o mercado de automação residencial. Certos produtos emergentes podem ser eleitos para concentrar as ações de mercado, como aconteceu com o lançamento dos DVD's (com um único produto, estimulou-se a reformular todo o conceito dos home theaters). Também pode se citar como outro exemplo o acesso ultra-rápido à Internet.

No mercado de automação residencial, pode-se dizer que esses primeiros nichos a serem conquistados dependem de um eficiente trabalho de reconhecimento dos benefícios oferecidos. Embora os primeiros consumidores se contentem com o status e a modernidade representados pela automação de seus lares, os pragmáticos e os conservadores só se deixarão conquistar se estiverem certos de obter conveniência, conforto, segurança e economia em um grau elevado. E é para estes consumidores que as empresas devem realmente se voltar, pois é nesta fase que os lucros são maximizados, podendo haver uma demanda maior, uma conseqüente redução de preços, e também auxiliar na popularização da AR. 
Para que se consiga isto, por raciocínio lógico, os consumidores de um mesmo nicho estão em busca de uma solução tecnológica comum. Se produtos e serviços forem introduzidos com sucesso nesse determinado nicho, poderão se beneficiar do valioso efeito da propaganda boca-a-boca.

Mas ainda assim, segundo o presidente da AURESIDE é preciso convencer os consumidores relutantes. Além da exposição de todos os benefícios da $A R$, devem ser combatidos os três aspectos que criam a resistência às novidades: o medo, a incerteza e a dúvida. Cada produto ou serviço apresentado deve conter intrinsecamente as características que anulem estes efeitos negativos. $E$, neste particular, é uma grande vantagem oferecer produtos de alta tecnologia, desde que adequadamente acompanhados por serviços de apoio. Portanto, não basta um produto doméstico ser sofisticado, ele deve ser de fácil operação e manutenção. Por isso, esse mercado proporciona tantas e tão estimulantes alternativas de serviços compartilhados, como projeto, programação, instalação e assistência técnica.

O nicho escolhido deve ter potencial suficiente para atender aos objetivos dos fabricantes e usuários, mas a estratégia de marketing deve ser adequadamente planejada para poder se ter o domínio sobre o assunto e aproveitar deste beneficio.

Um esforço equivalente desenvolvido para auxiliar os projetos de Edifícios Inteligentes na América do Norte, pode ser comparado. Trata-se de um consócio entre três empresas respeitáveis, são elas: Sustainable Environmental Solutions Inc., ECD Energy and Environment Canada e IBI Group, que desenvolveram uma associação e a mesma uma ferramenta de identificação e comparação dos níveis de integração e de automação dos projetos dos edifícios inteligentes. A Associação é denominada CABA - Continental Automated Building Association e o índice de avaliação dos edifícios é denominado BIQ - Building Intelligent Quotient.

Cabe salientar que a CABA não tem fins lucrativos, trata-se de uma associação da indústria que promove e estimula o desenvolvimento de tecnologias avançadas para a automatização dos edifícios na América do Norte. Outra informação adicional é a de que o processo de avaliação do edifício se faz on-line via Internet.

O índice, denominado BIQ - Building Intelligent Quotient, utiliza uma metodologia que pode auxiliar nos projetos e implantações dos edifícios inteligentes; pois: 
1. fornece uma avaliação inicial do perfil do edifício;

2. ajuda na articulação para atingir os objetivos de edifícios com alto desempenho operacional;

3. permite uma análise da lacuna e das possibilidades existentes entre a avaliação inicial do edifício elementar e do edifício inteligente com alta performance; e

4. apresenta quais os passos devem ser seguidos para atingir os objetivos do projeto escolhido.

A figura 1.5 ilustra o conceito do índice BIQ - Building Intelligent Quotient

Alto Desempenho de objetivos dos edifícios inteligentes

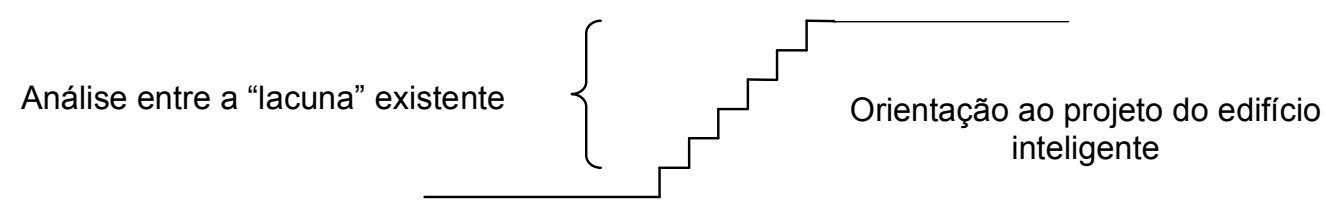

Avaliação inicial do perfil do edifício

Figura 1.5 - Apresentação do conceito BIQ - Building Intelligent Quotient Fonte: CABA (2005)

No Brasil não se tem conhecimento de metodologia específica para o desenvolvimento e implantação de projetos em AR, existem em geral métodos empíricos seguindo normalmente a seguinte ordem:

1. Coleta de informações (levantamento de necessidades) com o usuário;

2. Apresentação de possibilidades e de equipamentos;

3. Elaboração de projeto e;

4. Programação/cronograma de implantação.

É comum, segundo os integradores de sistemas de automação, se deparar durante a implantação da AR com diversas situações conflitantes, como por exemplo, para citar os mais simples, não estarem previstos ao projeto elétrico as 
caixas de passagem ou tubulações necessárias para a instalação de seus dispositivos.

Assim sendo, este trabalho apresenta no capítulo 3 a proposta de uma metodologia denominada MAEAR - Metodologia para Auxílio da Engenharia em Automação Residencial.

\subsection{JUSTIFICATIVAS PARA A ADOÇÃO DA AUTOMAÇÃO RESIDENCIAL}

O emprego de sistemas de automação nas residências pode tornar-se um fator positivo para o emprego mais racional da energia elétrica.

A automação residencial também oferece uma gama de serviços e de integração de sistemas, como:

- áudio, vídeo, som ambiente, TV por assinatura;

口 segurança (alarmes, monitoramento, CFTV - Circuito Fechado de TV);

- controle de iluminação;

๑ telefonia;

- redes de dados e informática;

\ ar condicionado e aquecimento;

\ persianas e cortinas automáticas;

- eletrodomésticos comandados à distância;

- utilidades, (irrigação, bombas, aspiração central, gás, energia alternativa, etc.);

- gerenciamento da energia elétrica, etc.

A automação residencial pode assumir as funções de supervisionar, comandar, controlar e otimizar os equipamentos e sistemas da edificação, que opera automaticamente, segundo parâmetros predefinidos, pelo usuário. A operação automática ou semi-automática da edificação possibilita um funcionamento confiável, com redução de atos falhos ou possíveis esquecimentos.

Os sistemas de automação residencial também podem oferecer serviços de apoio aos métodos recentes de acompanhamento energético. A automação será de grande utilidade se houver um gerenciamento da energia em comunicação com as técnicas de monitoração utilizadas pelas concessionárias, como o Sistema Argos exigida pela Aneel - Agência Nacional de Energia Elétrica. 
Existem ainda os medidores capazes de controlar demanda e consumo de energia elétrica por meio de tarifação diferenciada, que poderão, reunidos estes conceitos, exercer um papel fundamental para o aumento da eficiência energética. Cabe aqui mencionar um recente trabalho de mestrado efetuado no Departamento de Engenharia de Energia e Automação Elétricas da Escola Politécnica de São Paulo, intitulado "Desenvolvimento de medidor eletrônico de energia de custo competitivo associado a estudos sobre medições de energia elétrica" (Garcia D. A. de A. 2000).

A automação residencial, conforme afirmado anteriormente, oferece uma grande variedade de serviços, de acordo com o tipo de configuração sistêmica implementada. Entretanto, cada consumidor apresenta diferentes níveis de necessidades.

O que se verifica, portanto, é que uma das dificuldades de se implantar sistemas de automação residencial com sucesso técnico e comercial não está somente no custo ou no momento correto da decisão da implantação, mas também na análise individualizada da edificação e no perfil do consumidor.

Assim, é necessário que o profissional de automação residencial disponha de uma metodologia e de uma ferramenta de engenharia que o auxilie a especificar um sistema de automação residencial adequado, levando em conta diversos parâmetros, inclusive o perfil do consumidor.

Neste trabalho de pesquisa são apresentados os principais fatores que devem ser observados para o projeto e implementação de sistemas de Automação Residencial. 


\section{CARACTERÍSTICAS GERAIS DOS SISTEMAS DE AUTOMAÇÃO RESIDENCIAL}

\subsection{RESUMO DA TEORIA GERAL DA AUTOMAÇÃO}

A engenharia da automação pode lidar com processos de diversas naturezas. A classificação desses processos pode ser efetuada de várias maneiras: pela natureza das variáveis controladas segundo Cassandras (1992), pela arquitetura em malha aberta ou fechada (Teoria de Controle), pelo nível de automação (HAA), e outras.

\subsubsection{Classificação dos sistemas de automação pela natureza das variáveis controladas}

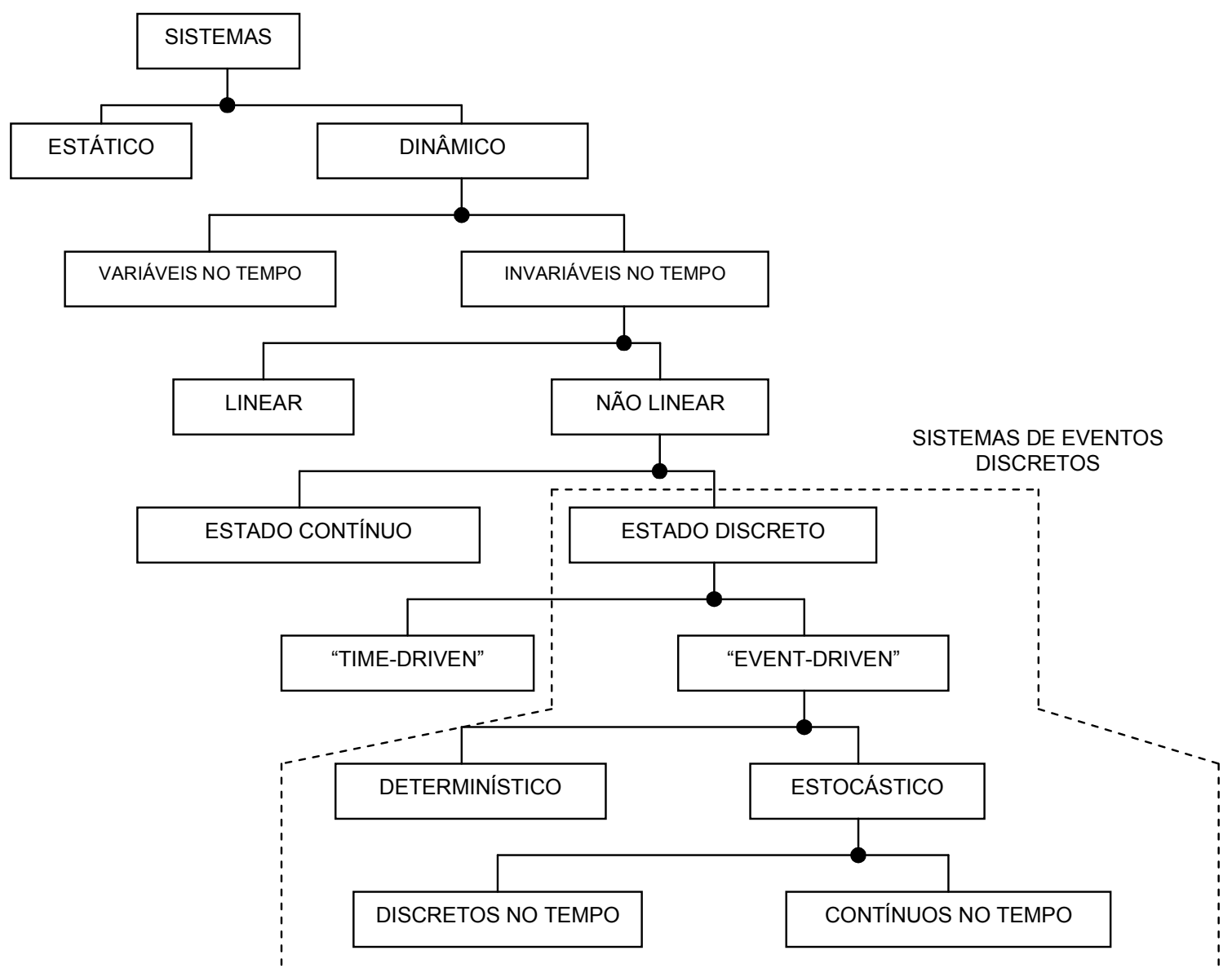

Figura 2.1 - Classificação dos sistemas físicos de automação - Fonte: Cassandras (1992) 
- Sistemas estáticos e dinâmicos - em um sistema estático, a saída independe dos valores anteriores das entradas. Em um sistema dinâmico é o contrário, ou seja, a saída depende dos valores anteriores das entradas, assim como também dos valores atuais das variáveis de entrada.

- Sistemas variáveis e invariáveis no tempo - o comportamento de um sistema invariável não muda com o passar do tempo. Esta propriedade, também chamada estacionária, significa que, ao se aplicar um sinal a uma entrada específica, o sistema sempre apresenta a mesma resposta. Assim, o sistema variável tem o conceito inverso. Com o passar do tempo, pode haver respostas diferentes em função das alterações das características intrínsecas do sistema.

- Sistemas lineares e não lineares - são sistemas cujas funções que representam o reconhecimento entre as variáveis de entrada e as variáveis de saída são lineares, ou seja, possuem as propriedades das funções lineares.

Exemplo:

$x(s)=g\left(a_{1} \cdot u_{1}+a_{2} \cdot u_{2}\right)=x(s)=u_{1} \cdot g_{1} \cdot\left(a_{1}\right)+u_{2} \cdot g_{2} \cdot\left(a_{2}\right)$,

onde:

$x(s)$ é o resultado da função $g, g_{1}$ e $g_{2}$;

$a_{1}$ e $a_{2}$ são variáveis de entrada; e

$\mathrm{u}_{1}$ e $\mathrm{u}_{2}$ são números reais constantes.

- Sistemas de estados contínuos e discretos - em um sistema contínuo, o estado das variáveis pode assumir genericamente qualquer valor real ou complexo. No sistema estado discreto, os estados das variáveis são elementos fixos.

- Sistemas time-driven e event-driven - no sistema time-driven, o estado muda continuamente no decorrer do tempo. No event-driven, somente muda o estado quando existir uma ocorrência gerada de forma assíncrona por meio de um evento que force a transição do mesmo. Entre a ocorrência e o evento, o estado fica inalterado.

- Sistemas determinístico e estocástico - um sistema torna-se estocástico quando uma ou mais variáveis de saídas variam randomicamente. Neste caso, o estado do sistema torna-se um processo, e o estudo probabilístico se faz necessário para descrever o comportamento do sistema. Já o sistema determinístico, como o próprio nome diz, tem como característica as variáveis predeterminadas. 
- Sistemas discreto e contínuo no tempo - um sistema contínuo no tempo é aquele cuja todas as variáveis de entradas, saídas e estados são definidas prevendo todas as possibilidades de valores. Em um sistema discreto no tempo, uma ou mais variáveis são definidas pontualmente. É normalmente utilizado, por exemplo, em processos de amostragem para o controle da qualidade.

Como mostrado na figura 2.1 para efeito de identificação de sistemas, foi destacado o sistema de eventos discretos que desenvolve automação em função das possíveis naturezas das variáveis a serem controladas.

Percebe-se, no entanto, a complexidade envolvida e a necessidade de reunir os conceitos sobre a automação, a fim de analisar, e em seguida planejar, avaliando a implementação de acordo com a classificação adequada aos tipos de sistemas.

\subsubsection{Classificação dos sistemas de automação pela arquitetura em malha aberta ou malha fechada - teoria de controle}

- Sistemas de controle em malha aberta - segundo Ogata (2003), são aqueles em que a saída não tem nenhum efeito automático sobre a ação de controle. O controle em malha aberta pode ser usado, na prática, somente se a relação entre a entrada e a saída for conhecida e se não houver distúrbios internos e externos. A figura 2.2 ilustra um sistema em malha aberta.

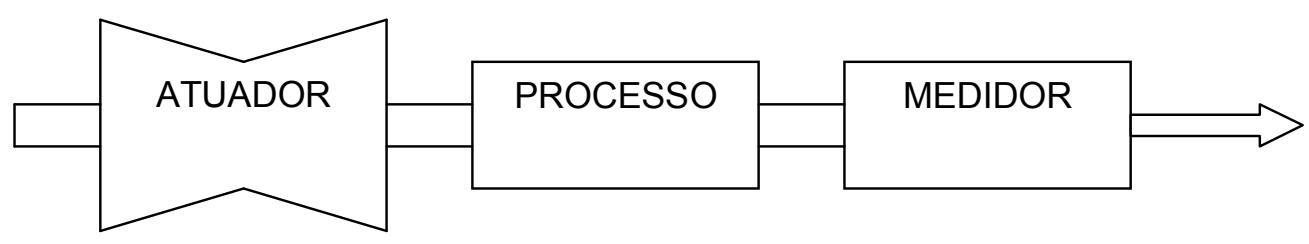

Figura 2.2 - Sistema de controle em malha aberta - Fonte: Ogata (2003)

- Sistemas com controle manual - segundo Castrucci (2001), são aqueles que implicam em ter um operador presente no processo criador de uma variável física. De acordo com alguma regra de seu conhecimento, ele opera um aparelho qualquer (válvula, alavanca, chave, elemento de controle), que, por sua vez, 
produz alterações naquela variável. A figura 2.3 ilustra um sistema com controle manual.

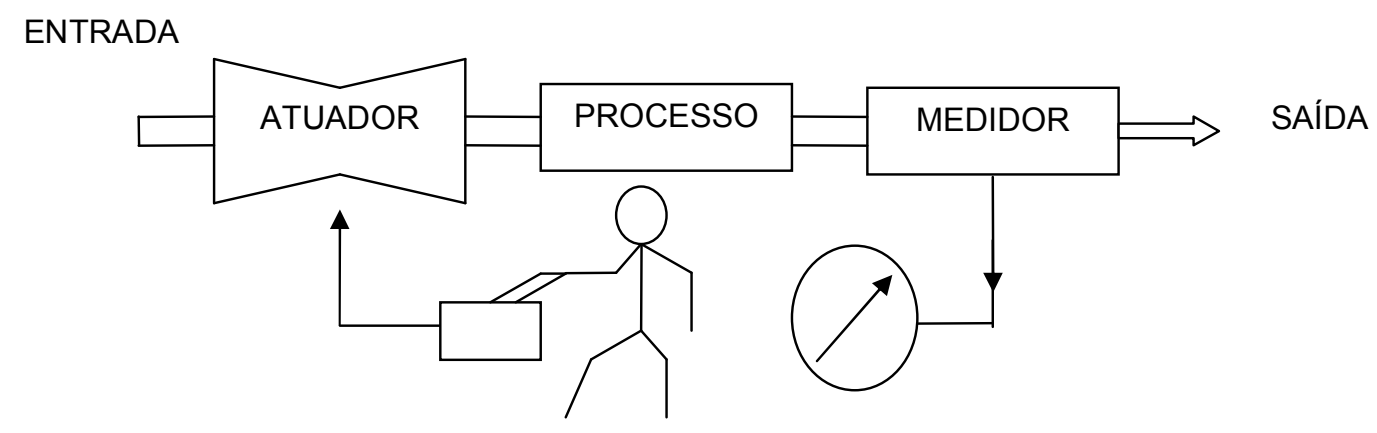

Figura 2.3 - Sistema com controle manual - Fonte: Ogata (2003)

- Sistemas de controle automático a programa - segundo Castrucci (2001), são aqueles que envolvem a existência de um programa de ações, que se cumpre com base no decurso do tempo ou a partir de modificações eventuais em variáveis externas ao sistema. No primeiro caso, tem-se um programa temporal e, no segundo, um programa lógico. A figura 2.4 ilustra um sistema de controle automático a programa.

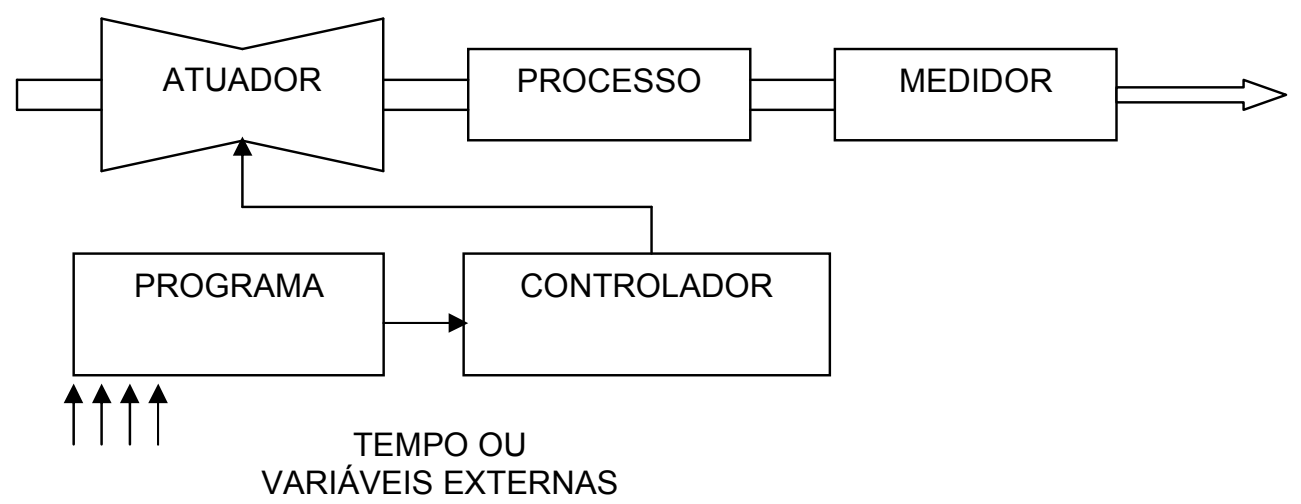

Figura 2.4 - Sistema com controle automático a programa - Fonte: Ogata (2003)

- Sistemas de controle em malha fechada - também denominado sistemas de controle realimentados, segundo Ogata (2003), são aqueles em que a saída tem efeito automático sobre a ação de controle. O sinal de erro atuante, que é a 
diferença entre o sinal de entrada e o sinal realimentado (que pode ser o próprio sinal de saída e suas derivadas), é introduzido no controlador, de modo a reduzir o erro e trazer a saída do sistema a um valor desejado. A figura 2.5 representa um sistema em malha fechada.

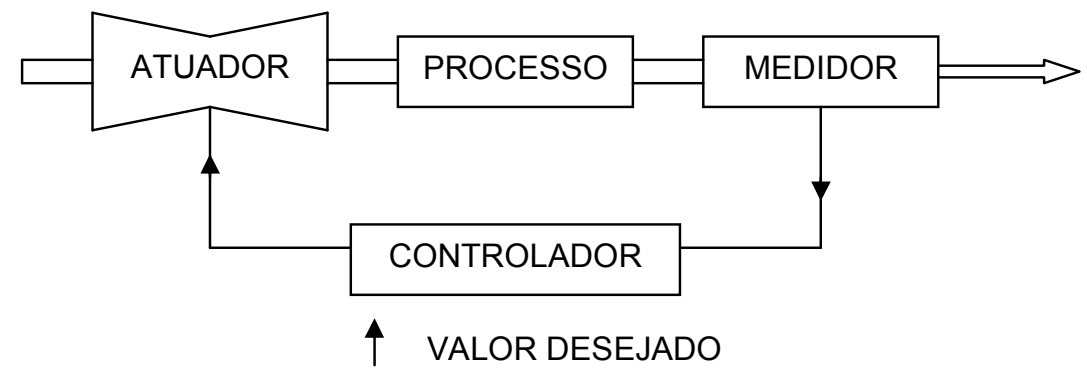

Figura 2.5 - Sistema com controle em malha fechada - Fonte: Ogata (2003)

A explanação mostrada por meio das figuras anteriores, trazendo os conceitos relacionados à teoria de controle, tem como efeito identificar a abrangência dos sistemas de automação de forma genérica.

Mas também aqui se percebe a complexidade envolvida e a importância de reunir tais conceitos sobre a automação, para analisar e, em seguida, planejar, enquadrando a implementação de acordo com a classificação adequada aos tipos de sistemas a serem adotados em uma residência.

É apresentada, na seqüência, uma forma de sistematizar e classificar essas informações. Porém, existe a necessidade de definir antes o que é automação residencial.

\subsection{DEFINIÇÃO DE AUTOMAÇÃO RESIDENCIAL}

Existem diversas definições vigentes para automação residencial, também conhecida, em inglês, como home control, intelligent home ou smart home, entre outras. Algumas das definições aceitas são: 
- "conjunto de equipamentos, sistemas e subsistemas que mantêm certas habilidades de interação entre si, permitindo o estabelecimento de funções independentes. Isto possibilita que proprietários de residências possam controlar funções proporcionadas por equipamentos ou sistemas de uso individual ou coletivo", segundo representante de fabricante de produtos para automação residencial.

- "viver numa grande cidade implica trabalhar para se conseguir ter uma residência segura; dispor, se possível, de entretenimento sem sair de casa; e, conforme uma tendência atual, provavelmente também nela trabalhar pelo menos algumas horas por semana. Para tal, condôminos residenciais estão passando a incluir em seus projetos a infra-estrutura básica para automação", segundo a Aureside - Associação Brasileira de Automação Residencial; e

- "processo ou sistema utilizando diversos métodos ou equipamentos, que provêem facilidade para melhorar o estilo de vida das pessoas, fazendo os lares mais confortáveis, seguros e eficientes", segundo a Associação Americana HAA - Home Automation Association.

A Instituição Americana Intelligent Building Institution localizada em Washington, definia na década de 80 o termo "intelligent building", edifício inteligente, ou casa inteligente, como:

๑ "um edifício inteligente é aquele o qual integra vários sistemas para efetivamente gerenciar recursos de modo coordenado visando maximizar desempenho técnico, investimento e operação com custo econômico, e também deve ser flexível".

Na década de 90, em um Congresso Internacional em Tel Aviv, Israel, um grupo de trabalho de pesquisa da área em estudo, denominado CIB Working Group W98, definiu edifício inteligente, ou o termo em inglês "intelligent building", como:

- "um edifício inteligente é uma arquitetura que fornece resposta de forma dinâmica a cada ocupante com produtividade, com efetivo custo e condições ambientalmente aprovadas por uma interação contínua entre quatro elementos básicos: lugar (tipo da edificação, estrutura, facilidades), processos (automação, controle, sistemas), pessoas (serviços, usuários) e gerenciamento (manutenção, desempenho), e a inter-relação entre eles".

Reunir os conceitos de tais definições e opiniões profissionais na tentativa de expressar poeticamente tecnologia torna-se difícil. Existem outras definições, mas 
todas enfatizam a integração dos processos, com respostas adequadas aos usuários e aos espaços, e gerenciamento dos negócios (automação predial), e a customização dos ambientes (automação residencial), de forma flexível.

Mas o que significa o termo inteligente? Uma opinião é aquela em considerar a inteligência como algo inato, uma habilidade cognitiva implícita a todos os processos do raciocínio convencional. J. Piaget define não como um atributo, mas como um complexo hierárquico da habilidade de processar informações, implícito na adaptação e equilíbrio entre o indivíduo e seu ambiente.

Existem outras opiniões a respeito, mas Piaget tem definido algo que pode ser estendido para entender como pessoas trabalham ou moram em edificações e interagem com seus micro climas, na construção do edifício e no ambiente externo. Sem discutir profundamente o argumento sobre a validade da inteligência artificial, existe atualmente um sistema, denominado em inglês knowledge-based systems, utilizado para realizar tarefas que requerem perícia, mas não demandam introspecção ou originalidade, próprias do ser humano.

Uma edificação inteligente demanda inteligência aplicada sobre conceitos como desenvolver estágios de construção e operação dos projetos sob o acompanhamento dos próprios clientes, consultores projetistas e contratantes, com facilidades de gerenciamento.

Um iglu (habitação esquimó em forma de cúpula, construída em blocos de neve), é uma edificação inteligente? Para o esquimó sempre foi, pois a forma e a estrutura moderam o impacto climático.

O layout interno e o uso trazem vantagem com relação ao gradiente de temperatura, mas não poderia responder bem em condições extremamente maiores de temperaturas ou outras condições variáveis. O edifício Helicon, construído em Londres, tenta suprir as necessidades na utilização de escritórios, oferecendo respostas de conforto e controle de energia para os ocupantes e administradores do prédio.

O átrio do edifício Kajima Corporation em Tóquio, tenta fornecer um ambiente refrescante, de tal forma que respeite a necessidade do ciclo mental do ser humano, contribuindo para concentração e relaxamento, a fim de se trabalhar eficazmente.

Então uma edificação inteligente pode ser simples ou tecnologicamente sofisticada dependendo das circunstâncias.

Contudo pode-se definir que, preferencialmente uma casa inteligente seja: 
- "um espaço residencial ecológico e evoluído em termos de arquitetura e construção, acompanhado de soluções integradas à tecnologia da informação, permitindo aos seus usuários segurança, conforto e economia e, ao planeta, eficiência energética."

A figura 2.6 organiza e ilustra as possibilidades de serviços a serem executados, definidos pela AURESIDE - Associação Brasileira de Automação Residencial.

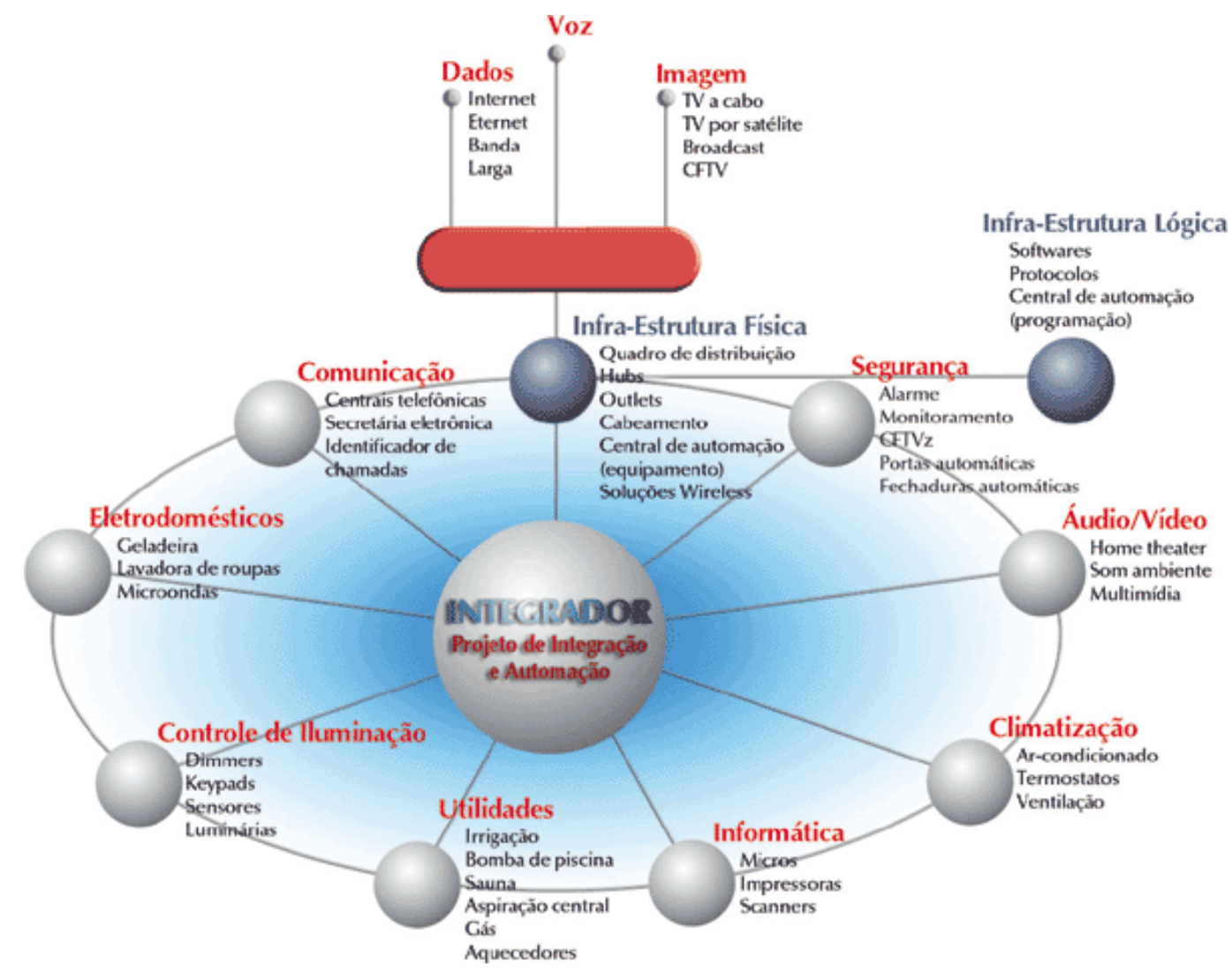

Figura 2.6 - Abrangência da Automação Residencial - Fonte: Aureside (2002)

Dentro das diversas possibilidades existentes de automatizar uma residência, é importante que o projetista avalie as vantagens de cada sistema em função das necessidades do usuário. Mesmo que o proprietário queira instalar apenas um subsistema, como segurança, deve ser uma preocupação do projetista deixar alguma interface pronta para prováveis integrações futuras. Assim, o proprietário do imóvel poderá agregar novas tecnologias à sua residência. 


\subsection{CLASSIFICAÇÃO DOS NIVEIS DAS AUTOMAÇÕES INDUSTRIAL, PREDIAL E RESIDENCIAL}

Neste item serão apresentados os macros conceitos para a classificação dos diversos níveis que as automações industrial, predial ou residencial podem ter.

Segundo Moraes; Castrucci (2001) a automação industrial pode ser classificada em cinco níveis conforme é mostrado na figura 2.7:

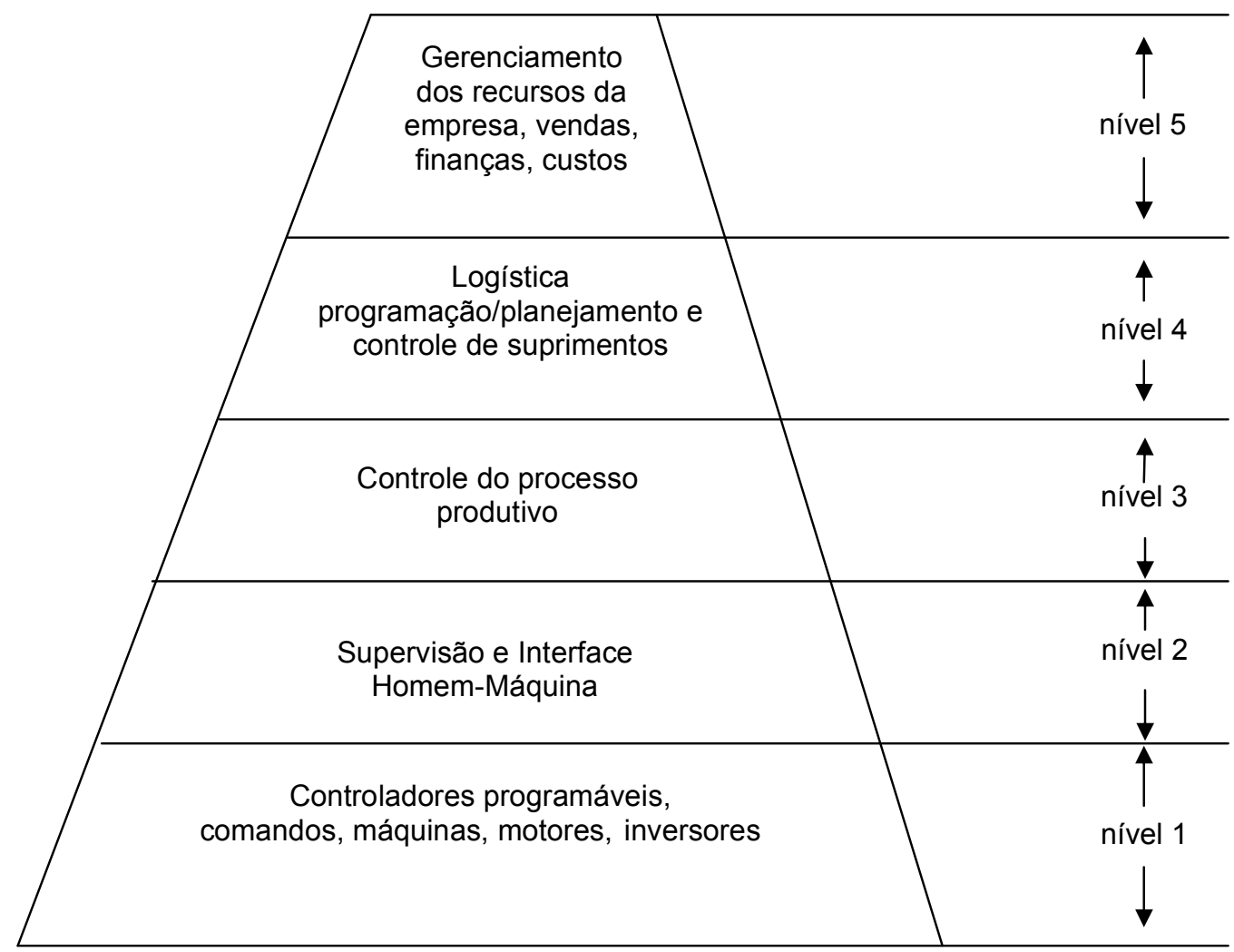

Figura 2.7 - Pirâmide da Automação Industrial - Fonte: Moraes, Castrucci (2001)

Nessa figura cada nível está associado a uma determinada classificação de operação de equipamentos:

- nível 1 - é o nível das máquinas, dispositivos e componentes (chão de fabrica), onde a automação é realizada pelo controlador programável. Para exemplificar podem-se mencionar máquinas de embalagem, linha de montagem ou manufatura;

- nível 2 - sua característica é ter algum tipo de supervisão associada ao processo. É o nível onde se encontram os concentradores de informações sobre 
o nível 1 e as Interfaces Homem-Máquina (IHM). Para exemplificar pode-se mencionar a sala de supervisão de um laminador de tiras a fio;

- nível 3 - permite o controle do processo produtivo da planta. Normalmente, é constituído por banco de dados com informações dos índices da qualidade da produção, relatórios e estatísticas de processo, índice de produtividade, algoritmos de otimização da operação produtiva. Para exemplificar, podem-se mencionar a avaliação e controle da qualidade em processo químico ou alimentício;

- nível 4 - é o nível responsável pela programação e pelo planejamento da produção, realizando o controle e a logística dos suprimentos. Para exemplificar, pode-se mencionar o controle de suprimentos e estoques em função da sazonalidade e da distribuição geográfica; e

- nível 5 - é o responsável pela administração dos recursos da empresa, em que se encontram os softwares para gestão de vendas e gestão financeira. É também onde se realizam a decisão e o gerenciamento de todo o sistema.

Para a automação predial, a classificação dos níveis de automação pode ser enquadrada na pirâmide da automação industrial (figura 2.7) nos casos de edifícios inteligentes corporativos, especialmente aqueles em que o incorporador do imóvel vende serviços ou os próprios espaços. Um exemplo é o edifício localizado na avenida Nações Unidas, na cidade de São Paulo, SP, de uma grande editora brasileira.

Alguns dados operacionais médios do edifício, fornecidos pela própria editora, são:

- 3800 partidas de elevadores por dia;

- 12000 pessoas circulam diariamente;

- consumo total de energia elétrica equivalente a uma cidade com 55000 habitantes; e

- sistema de controle de acesso em todas as dependências do edifício.

Todo sistema implementado visa auxiliar no gerenciamento, produtividade, manutenção e segurança de modo otimizado.

Assim, devido à sua complexidade e interesses comerciais envolvidos, a classificação dos níveis de automação industrial, descritos anteriormente, também podem ser aplicáveis em shoppings centers, hotéis, hospitais, centros comerciais, parques temáticos, e outros. 
Já para condomínios residenciais ou residências, especificamente, os níveis de automação industrial, normalmente não são aplicáveis.

Enquanto a Automação Industrial é classificada por diversos autores em cinco níveis, conforme já apresentado, a HAA Home Automation Association classifica automação residencial em três níveis, como mostra a figura 2.8.

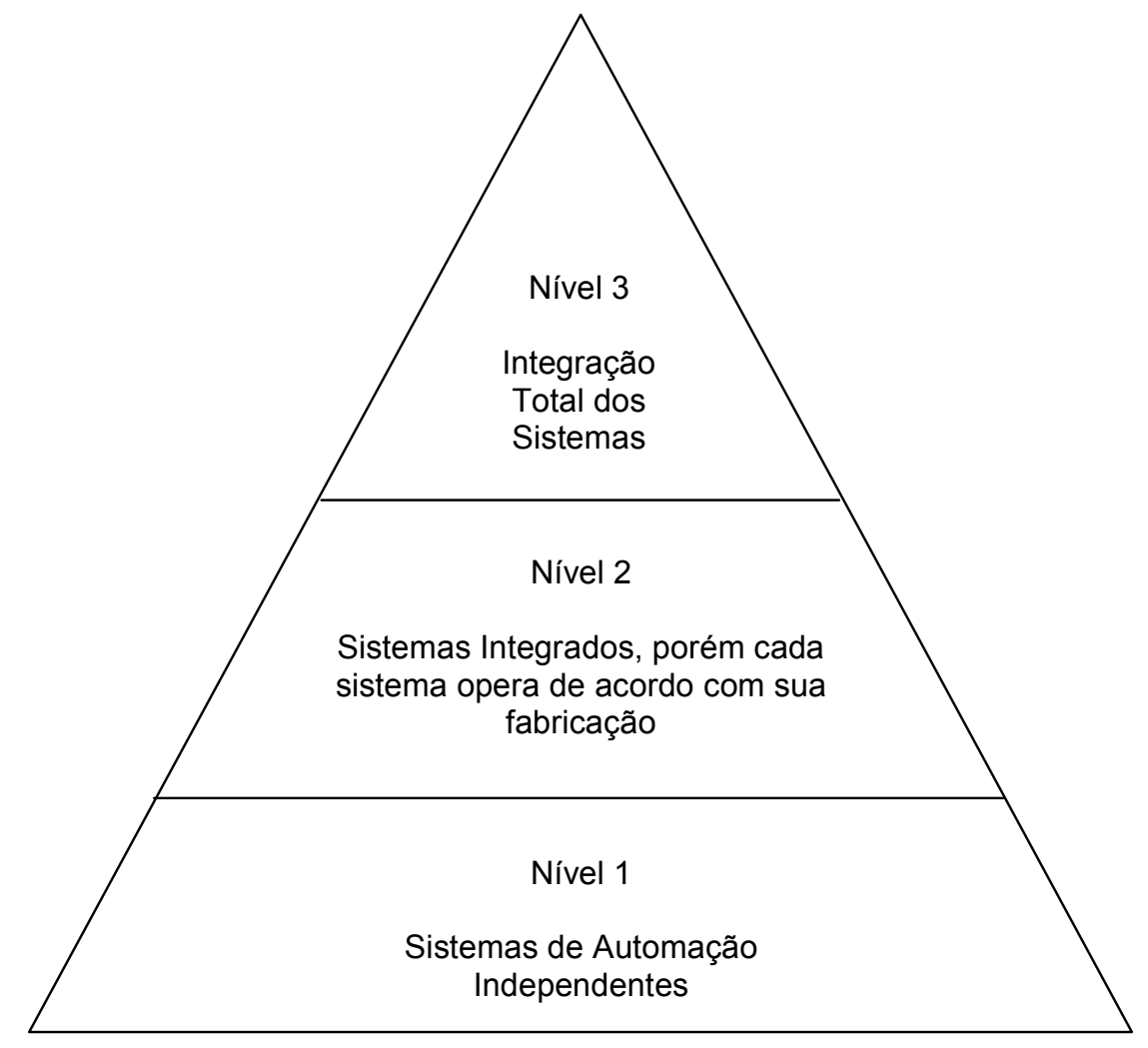

Figura 2.8 - Níveis de automação residencial segundo a HAA - Home Automation Association Fonte: Aureside (2002)

A partir da figura 2.8, é possível fazer uma breve descrição de cada nível:

- nível 1, sistema de automação independente - é o nível que se aplicam equipamentos individuais ou subsistemas que provêem funções independentes e não se relacionam diretamente com outros equipamentos ou subsistemas. Para exemplificar pode-se mencionar a utilização de um sensor de presença para o controle automático da iluminação de um ambiente;

- nível 2, sistemas integrados - este é o nível de aplicação quando existem múltiplos sistemas de automação integrados entre si, utilizando-se um único controle. Entretanto, cada sistema ou equipamento opera de acordo com sua 
fabricação. Um exemplo é a criação automática de uma ambientação luminosa e de uma preparação de equipamentos de áudio e vídeo, (dimerização da iluminação, fechamento de cortinas, acionamentos de equipamentos de áudio e vídeo e outros). Ao se acionar um único comando, de modo convencional ou a partir de uma central por meio de controle remoto, todo o ambiente de determinada sala é automaticamente preparado para assistir a um filme; porém os equipamentos interagem entre si, somente por meio de interfaces e adaptações entre os dispositivos/equipamentos;

- nível 3, sistemas totalmente integrados, casa "inteligente" - há uma completa interação entre todos os sistemas, com possibilidade de supervisão. Para exemplificar, pode-se mencionar uma automação residencial utilizando sistemas abertos de comunicação entre os dispositivos e equipamentos, para o controle de modo descentralizado, por meio de pontos, (nós) inteligentes; também podem ser supervisionados todos os sistemas de automação integrados via computador ou via controlador centralizado.

Independentemente do nível de aplicação de cada sistema de automação residencial, cabe salientar que os projetos devem ser customizados para atender as necessidades específicas de cada usuário.

Preferencialmente, no momento do projeto, o arquiteto, o técnico ou o engenheiro, enfim, o profissional integrador de sistemas, em conjunto com o proprietário, descreve as funções e define as melhores aplicações dentro das possibilidades técnicas e econômicas que permitam a implantação adequada ao uso dos produtos, individualmente ou como sistema.

Outro fato importante a ressaltar: determinar a classificação dos níveis de cada uma das diversas possibilidades mostradas na figura 2.6 (abrangência da automação residencial) depende da definição do sistema de automação que será escolhido, pois sempre existirá uma vasta gama de tecnologias para cada aplicação, que podem estar englobadas em qualquer um dos níveis mencionados anteriormente.

Portanto, com a apresentação da teoria geral da automação, da definição de automação residencial e das possibilidades de suas classificações, este trabalho propõe, por meio das tabelas 2.1 e 2.2, uma forma de sistematização tecnológica e conceitual de alguns dos principais produtos existentes no mercado atual, divididos 
em grandes áreas, que pode, de acordo com a necessidade, ser adaptada a quaisquer outras tecnologias. As informações nelas contidas são resultados de estudos realizados na oportunidade, e podem, portanto, serem atualizadas a qualquer momento.

Tabela 2.1 - Classificação da automação residencial I

\begin{tabular}{|c|c|c|c|c|c|c|c|c|c|c|c|c|c|c|c|c|c|c|c|c|c|}
\hline \multicolumn{22}{|c|}{ Tabela I - Sistematização da automação residencial } \\
\hline \multirow[b]{3}{*}{ Tecnologias } & & \multicolumn{12}{|c|}{ Classificação dos sistemas de automação pela natureza das variáveis } & \multicolumn{4}{|c|}{$\begin{array}{c}\text { Classificação dos sistemas de automação pela } \\
\text { arquitetura - Teoria de Controle }\end{array}$} & \multirow{2}{*}{\multicolumn{2}{|c|}{\begin{tabular}{|c|} 
Comunicação \\
Protocolo \\
\end{tabular}}} & \multirow{2}{*}{\multicolumn{2}{|c|}{\begin{tabular}{|l} 
Classifi- \\
cação
\end{tabular}}} \\
\hline & & \multirow[b]{2}{*}{$\begin{array}{c}\text { Está- } \\
\text { tico }\end{array}$} & \multirow[b]{2}{*}{$\begin{array}{l}\text { Dinâ- } \\
\text { mico }\end{array}$} & \multirow[b]{2}{*}{$\begin{array}{c}\text { Variável no } \\
\text { tempo }\end{array}$} & \multirow[b]{2}{*}{$\begin{array}{l}\text { Invariável } \\
\text { no tempo }\end{array}$} & \multirow[b]{2}{*}{ Linear } & \multirow[b]{2}{*}{$\begin{array}{l}\text { Não } \\
\text { Linear }\end{array}$} & \multirow[b]{2}{*}{$\begin{array}{c}\text { Estado } \\
\text { Contínuo }\end{array}$} & \multirow[b]{2}{*}{$\begin{array}{l}\text { Estado } \\
\text { Discreto }\end{array}$} & \multirow[b]{2}{*}{$\begin{array}{c}\text { Time } \\
\text { Driven }\end{array}$} & \multirow[b]{2}{*}{\begin{tabular}{|c|} 
Event \\
Driven
\end{tabular}} & \multirow[b]{2}{*}{$\begin{array}{c}\text { Determi- } \\
\text { nistico }\end{array}$} & \multirow[b]{2}{*}{$\begin{array}{c}\text { Estocás- } \\
\text { tico }\end{array}$} & \multirow[b]{2}{*}{$\begin{array}{c}\text { Malha } \\
\text { Aberta }\end{array}$} & \multirow[b]{2}{*}{$\begin{array}{l}\text { Controle } \\
\text { Manual }\end{array}$} & \multirow[b]{2}{*}{$\begin{array}{c}\text { Automação a } \\
\text { Programa }\end{array}$} & \multirow[b]{2}{*}{$\begin{array}{l}\text { Malha } \\
\text { Fech. }\end{array}$} & & & & \\
\hline & & & & & & & & & & & & & & & & & & \begin{tabular}{|c|}
$\begin{array}{c}\text { Aber- } \\
\text { to }\end{array}$ \\
\end{tabular} & \begin{tabular}{|c|}
$\begin{array}{c}\text { Proprie- } \\
\text { tário }\end{array}$ \\
\end{tabular} & \multicolumn{2}{|c|}{1223} \\
\hline & Tipo & & & & & & & & & & & & & & & & & & & & \\
\hline \multicolumn{22}{|l|}{ Sensores } \\
\hline \multirow{3}{*}{$\begin{array}{l}\text { Sensor de } \\
\text { Presença }\end{array}$} & PIR & $x$ & & & & & & & & & & & & & & $x$ & & & & $\mathrm{x}$ & \\
\hline & $\begin{array}{l}\text { Ultrasô- } \\
\text { nico }\end{array}$ & $\mathrm{x}$ & & & & & & & & & & & & & & $\mathrm{x}$ & & & & $\mathrm{x}$ & \\
\hline & Dual & & $x$ & & $x$ & & $x$ & $x$ & & & $x$ & $x$ & & & & $x$ & & & & $\mathrm{x}$ & \\
\hline Fotocélula & LDR & & $x$ & & $\mathrm{x}$ & & $\mathrm{x}$ & $\mathrm{x}$ & & & $\mathrm{x}$ & $\mathrm{x}$ & & & & $\mathrm{x}$ & & & & $\mathrm{x}$ & \\
\hline \multirow{2}{*}{\multicolumn{22}{|c|}{ Atuadores }} \\
\hline & & & & & & & & & & & & & & & & & & & & & \\
\hline Interruptores & $\begin{array}{c}\text { Conven- } \\
\text { cional }\end{array}$ & & $x$ & & $\mathrm{x}$ & $\mathrm{x}$ & & & & & & & & & $x$ & $x$ & & & & $\mathrm{x}$ & \\
\hline Minuteria & $\begin{array}{l}\text { "inteli- } \\
\text { gente" }\end{array}$ & & $\mathrm{x}$ & $\mathrm{x}$ & & & $x$ & & $\mathrm{x}$ & $x$ & & & & & $\mathrm{x}$ & $\mathrm{x}$ & & & & $\mathrm{x}$ & \\
\hline Dimerização & Analó-gica & $\mathrm{x}$ & & & & & & & & & & & & & $\mathrm{x}$ & & & & & $\mathrm{x}$ & \\
\hline & Digital & & $x$ & $x$ & & & & & & & & & & & $x$ & $\mathrm{x}$ & & & & $\mathrm{x}$ & \\
\hline $\begin{array}{c}\text { Automacão de } \\
\text { Cortinas }\end{array}$ & Somfy & & $\mathrm{x}$ & & $\mathrm{x}$ & $\mathrm{x}$ & & & $\mathrm{x}$ & & $x$ & $\mathrm{x}$ & & & $\mathrm{x}$ & $x$ & & & & $\mathrm{x}$ & $\mathrm{x}$ \\
\hline $\begin{array}{l}\text { Relés de } \\
\text { Impulso }\end{array}$ & Finder & $\mathrm{x}$ & $x$ & & $x$ & $x$ & & & $x$ & & $\mathrm{x}$ & $x$ & & & $x$ & & & & & $\mathrm{x}$ & $x$ \\
\hline $\begin{array}{l}\text { Sistemas de } \\
\text { lluminação }\end{array}$ & & & & & & & & & & & & & & & & & & & & & \\
\hline & Lutron & & $x$ & & $x$ & & $x$ & $x$ & & & $x$ & $x$ & & & $x$ & $x$ & & & & $\mathrm{x}$ & $\mathrm{x}$ \\
\hline Controle de & $\begin{array}{l}\text { Home- } \\
\text { works }\end{array}$ & $\mathrm{x}$ & & & $x$ & $\mathrm{x}$ & & & $\mathrm{x}$ & & $\mathrm{x}$ & $\mathrm{x}$ & & $x$ & $\mathrm{x}$ & & & & & $\mathrm{x}$ & \\
\hline lluminaçao & $\begin{array}{l}\text { Home } \\
\text { serve }\end{array}$ & $x$ & & & $x$ & $x$ & & & $\mathrm{x}$ & & $x$ & $\mathrm{x}$ & & $x$ & $\mathrm{x}$ & & & & & $\mathrm{x}$ & \\
\hline & Radio $R A$ & $\mathrm{x}$ & & & $x$ & $\mathrm{x}$ & & & $\mathrm{x}$ & & $x$ & $x$ & & $x$ & $\mathrm{x}$ & & & & & $\mathrm{x}$ & \\
\hline
\end{tabular}

Nas tabelas 2.1 e 2.2 verificam-se a existência de várias demarcações com relação às classificações de um mesmo sistema. Por exemplo, quando em um determinado tipo de sistema representado na tabela 2.1 ou na tabela 2.2 se encontrar assinalados tanto malha aberta como malha fechada é porque o sistema permite duas possibilidades operacionais. 
Tabela 2.2 - Classificação da automação residencial II

\begin{tabular}{|c|c|c|c|c|c|c|c|c|c|c|c|c|c|c|c|c|c|c|c|c|c|c|}
\hline \multicolumn{23}{|c|}{ Tabela II - Sistematização da automação residencial } \\
\hline & & \multicolumn{12}{|c|}{ Classificação dos sistemas de automação pela natureza das variáveis } & \multicolumn{4}{|c|}{$\begin{array}{l}\text { Classificação dos sistemas de automação pela } \\
\text { arquitetura - Teoria de controle }\end{array}$} & \multirow{2}{*}{\multicolumn{2}{|c|}{\begin{tabular}{|c|} 
Comunicação \\
Protocolo \\
\end{tabular}}} & \multirow{2}{*}{\multicolumn{3}{|c|}{$\begin{array}{c}\begin{array}{c}\text { Classifi- } \\
\text { cação }\end{array} \\
\text { Niveis AR } \\
\end{array}$}} \\
\hline \multirow[b]{2}{*}{ Tecnologias } & & \multirow[b]{2}{*}{$\begin{array}{c}\text { Está- } \\
\text { tico }\end{array}$} & \multirow[b]{2}{*}{$\begin{array}{l}\text { Dinâ- } \\
\text { mico }\end{array}$} & \multirow[b]{2}{*}{$\begin{array}{c}\text { Variável no } \\
\text { tempo }\end{array}$} & \multirow[b]{2}{*}{$\begin{array}{l}\text { Invariável } \\
\text { no tempo }\end{array}$} & \multirow[b]{2}{*}{ Linear } & \multirow[b]{2}{*}{$\begin{array}{l}\text { Não } \\
\text { Linear }\end{array}$} & \multirow[b]{2}{*}{$\begin{array}{c}\text { Estado } \\
\text { Continuo }\end{array}$} & \multirow[b]{2}{*}{$\begin{array}{c}\text { Estado } \\
\text { Discreto }\end{array}$} & \multirow[b]{2}{*}{$\begin{array}{c}\text { Time } \\
\text { Driven }\end{array}$} & \multirow[b]{2}{*}{$\begin{array}{l}\text { Event } \\
\text { Driven }\end{array}$} & \multirow[b]{2}{*}{$\begin{array}{c}\text { Determi- } \\
\text { nístico }\end{array}$} & \multirow[b]{2}{*}{$\begin{array}{c}\text { Estocás- } \\
\text { tico }\end{array}$} & \multirow[b]{2}{*}{$\begin{array}{l}\text { Malha } \\
\text { Aberta }\end{array}$} & \multirow[b]{2}{*}{$\begin{array}{c}\text { Controle } \\
\text { Manual }\end{array}$} & \multirow[b]{2}{*}{$\begin{array}{c}\text { Automação a } \\
\text { Program }\end{array}$} & \multirow[b]{2}{*}{$\begin{array}{l}\text { Malha } \\
\text { Fech. }\end{array}$} & & & & & \\
\hline & & & & & & & & & & & & & & & & & & $\begin{array}{c}\begin{array}{c}\text { Aber- } \\
\text { to }\end{array} \\
\end{array}$ & $\begin{array}{c}\begin{array}{c}\text { Proprie- } \\
\text { tário }\end{array} \\
\end{array}$ & 1 & 2 & 3 \\
\hline $\begin{array}{l}\text { Equip. de } \\
\text { Redes Elétr. }\end{array}$ & Tipo & & & & & & & & & & & & & & & & & & & & & \\
\hline \multirow[t]{2}{*}{$\begin{array}{l}\text { PLC - Power } \\
\text { Line Carrier }\end{array}$} & $\begin{array}{c}\text { X10 Teleco- } \\
\text { mando }\end{array}$ & $\mathrm{x}$ & & & $x$ & & $\mathrm{x}$ & & $\mathrm{x}$ & & $\mathrm{x}$ & $\mathrm{x}$ & & $\mathrm{x}$ & $\mathrm{x}$ & & & $\mathrm{x}$ & & $\mathrm{x}$ & & \\
\hline & X10 CFTV & & $\mathrm{x}$ & & $x$ & & $\mathrm{x}$ & $\mathrm{x}$ & & & $\mathrm{x}$ & $\mathrm{x}$ & & & & $\mathrm{x}$ & & $x$ & & & $\mathrm{x}$ & \\
\hline & & & & & & & & & & & & & & & & & & & & & & \\
\hline \multicolumn{23}{|l|}{ Supervisório } \\
\hline $\begin{array}{l}\text { Central de } \\
\text { Controle de }\end{array}$ & Panja AMx & & $\mathrm{x}$ & & $x$ & & $\mathrm{x}$ & $\mathrm{x}$ & & & $x$ & $\mathrm{x}$ & & $x$ & $x$ & $x$ & & & & & $\mathrm{x}$ & \\
\hline Automação & Creston & & $x$ & & $x$ & & $x$ & $\mathrm{x}$ & & & $x$ & $x$ & & $x$ & $x$ & $x$ & & & & & \begin{tabular}{|l|l}
$x$ \\
\end{tabular} & \\
\hline & & & & & & & & & & & & & & & & & & & & & & \\
\hline Controla-dores & & & & & & & & & & & & & & & & & & & & & & \\
\hline Integração de & IHC & & $x$ & & $x$ & & $x$ & & $x$ & $x$ & $x$ & $x$ & $x$ & $x$ & $x$ & $x$ & $x$ & & $x$ & & $\mathrm{x}$ & $x$ \\
\hline Sistemas & HNC IBM & & $x$ & & $x$ & & $x$ & & $x$ & & $x$ & $x$ & & & & $x$ & & & $x$ & & \begin{tabular}{l|l}
$x$ & \\
\end{tabular} & $x$ \\
\hline & & & & & & & & & & & & & & & & & & & & & & \\
\hline & $E I B$ & & $x$ & & $x$ & & $x$ & $x$ & $x$ & $x$ & $x$ & $x$ & $x$ & $x$ & $x$ & $x$ & $x$ & $x$ & & & & $x$ \\
\hline Tecnologia & Lonworks & & $x$ & & $x$ & & $x$ & $x$ & $x$ & $x$ & $x$ & $x$ & $x$ & $x$ & $x$ & $x$ & $x$ & & $x$ & & & $x$ \\
\hline Descentrali- & IHC Bus & & $x$ & & $x$ & & $x$ & & $x$ & $x$ & $x$ & $x$ & $x$ & $x$ & $x$ & $x$ & $x$ & & $x$ & & & $x$ \\
\hline zada & Heading & & $x$ & & $x$ & & $x$ & & $x$ & $x$ & $x$ & $x$ & $x$ & $x$ & $x$ & $x$ & $x$ & & $x$ & & & $x$ \\
\hline & Ihouse & & $x$ & & $x$ & & $x$ & & $x$ & $x$ & $x$ & $x$ & $x$ & $x$ & $x$ & $x$ & $x$ & $x$ & & & & $x$ \\
\hline & & & & & & & & & & & & & & & & & & & & & & \\
\hline & Batibus & & $x$ & & $x$ & & $x$ & $x$ & $x$ & $x$ & $x$ & $x$ & $x$ & $x$ & $x$ & $x$ & $x$ & $x$ & & & $\mathrm{x}$ & $x$ \\
\hline Tendências & EHS & & $x$ & & $x$ & & $x$ & $x$ & $x$ & $x$ & $x$ & $x$ & $x$ & $x$ & $x$ & $x$ & $x$ & $x$ & & & \begin{tabular}{l|l}
$x$ & \\
\end{tabular} & $x$ \\
\hline Tecnológicas & Cebus & & $x$ & & $x$ & & $x$ & $x$ & $x$ & $x$ & $x$ & $x$ & $x$ & $x$ & $x$ & $x$ & $x$ & $x$ & & & \begin{tabular}{l|l}
$x$ \\
\end{tabular} & $x$ \\
\hline & HBS & & $x$ & & $x$ & & $x$ & $x$ & $x$ & $x$ & $x$ & $x$ & $x$ & $x$ & $x$ & $x$ & $x$ & $x$ & & & \begin{tabular}{l|l}
$x$ \\
\end{tabular} & $x$ \\
\hline & Konnex & & $x$ & & $x$ & & $x$ & $x$ & $x$ & $x$ & $x$ & $x$ & $x$ & $x$ & $x$ & $x$ & $x$ & $x$ & & & \begin{tabular}{l|l}
$x$ & \\
\end{tabular} & $x$ \\
\hline & My Home & & $x$ & & $x$ & & $x$ & $x$ & $x$ & $x$ & $x$ & $x$ & $x$ & $x$ & $x$ & $x$ & $x$ & $x$ & & & \begin{tabular}{|l|l}
$x$ & \\
\end{tabular} & $x$ \\
\hline
\end{tabular}

As tabelas 2.1 e 2.2 apresentam as principais tecnologias disponíveis e empregadas atualmente no mercado de AR. Entretanto, vários artigos indicam que em um período de aproximadamente cinco anos diversos fabricantes de produtos e de sistemas de AR estarão oferecendo arquiteturas sistemáticas baseada em "wireless" ou outras, pois se trata de uma área de conhecimento em pleno desenvolvimento.

A metodologia MAEAR poderá também ser aplicada como ferramenta de auxílio de engenharia para sistemas de AR baseada em qualquer tecnologia. $\mathrm{Na}$ seqüência é apresentada uma breve descrição dos princípios de funcionamento das tecnologias citadas nas tabelas de sistematização/classificação. 


\subsection{EXEMPLOS DE TECNOLOGIAS DESTINADAS A SISTEMAS DE AUTOMAÇÃO RESIDENCIAL}

Os itens a seguir apresentam a descrição de alguns sistemas e topologias dos fabricantes de controle e automação residencial disponíveis atualmente, assim como as tendências tecnológicas do setor e a relação com seus respectivos níveis de classificação segundo a HAA - Home Automation Association.

\subsubsection{Tecnologia de sensores de presença atuadores, dimerizadores e interruptores minuterias}

Desenvolvido atualmente por diversos fabricantes os sensores de presença atuadores, dimerizadores e as minuterias controlam a iluminação do ambiente de forma independente de outros sistemas de automação residencial. Os sensores de presença atuadores foram desenvolvidos pensando na otimização de energia e na comodidade para o usuário. Ao detectar a presença de uma pessoa na área controlada, os sensores de presença atuadores comandam um circuito comutador que por sua vez está conectado à luminária. Porém, os dispositivos sensores de presença não são necessariamente somente conectados a sistemas de iluminação. Os mesmos podem enviar sinais de deteç̧ão em outros processos de comando, como, sistemas de segurança, acionamento de portas, climatização e outros.

As principais tecnologias existentes são:

- Raios infravermelhos passivos;

- Ultra-sônica;

- Dual.

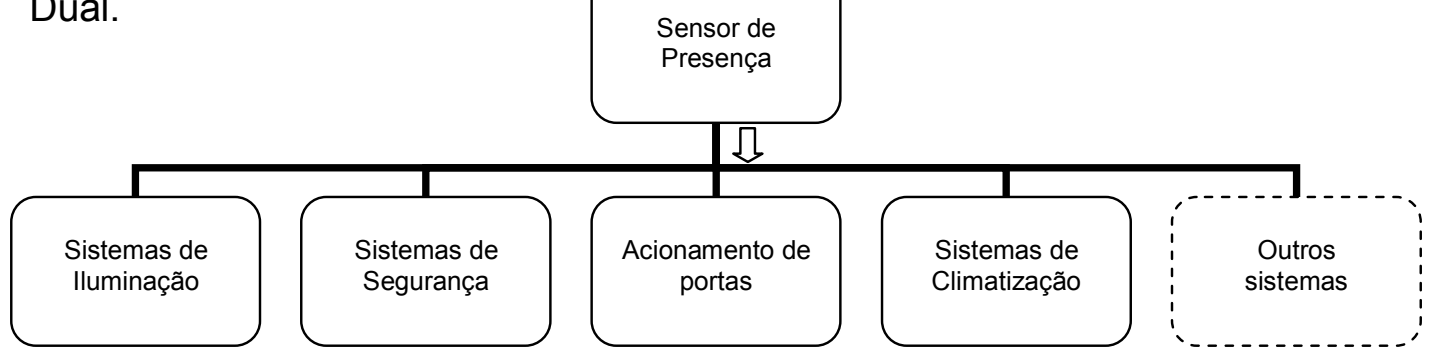

Figura 2.9 - Possibilidades de cargas para sensores de presença 
Os sensores com tecnologia por raios infravermelhos passivos (PIR), reagem somente a determinadas fontes de energia, como o corpo humano. Eles detectam presença através da diferença entre o calor emitido pelo corpo humano e o espaço ao redor.

Os sensores PIR utilizam uma lente Fresnel que distribui os raios infravermelhos em diferentes zonas, obtendo assim uma melhor área de cobertura a controlar. Quando acontece uma mudança de temperatura em alguma dessas zonas, detecta-se presença, e a carga é acionada.

A fim de aumentar a confiabilidade do funcionamento, normalmente esta tecnologia utiliza, também, um filtro de luz que elimina a possibilidade de falsas detecções causadas pela luz natural (raios solares), assim como, circuitos especiais para maior imunidade a ondas de rádio freqüência.

A tecnologia PIR permite definir com precisão a área de cobertura desejada. A figura 2.10 ilustra alguns modelos de sensores de presença em diferentes modos de instalação, como teto, parede ou de embutir, respectivamente.
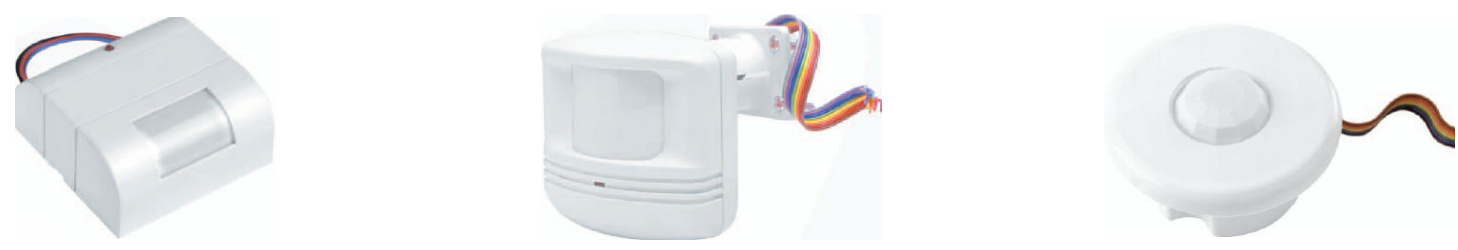

Figura 2.10 - Sensores de presença com tecnologia por raios infravermelhos - Fonte: Catálogo Bticino (2004)

A tecnologia ultra-sônica utiliza o princípio Doppler, ou seja, são sensores de movimento volumétricos. Esses sensores emitem ondas de ultra-som na área a controlar, essas ondas rebatem nos objetos presentes, e retornam ao receptor do sensor de presença.

O movimento de uma pessoa na área faz com que as ondas ultra-sônicas retornem com uma freqüência diferente da recebida com objetos em repouso, o que é interpretado como detecção de presença. 
Os sensores ultra-sônicos funcionam com um transmissor e um ou dois receptores. Eles transmitem as ondas em alta freqüência, gerada por um oscilador de cristal de quartzo. Esta freqüência é tão alta que não pode ser percebida pelos seres humanos.

A cobertura ultra-sônica não necessita "visão direta" da área de cobertura, podendo estar sensível através de portas e divisórias. Contudo se faz necessário instalá-lo em uma localização adequada, a fim de evitar possíveis detecções fora da zona desejada.

As áreas com carpetes e materiais antiacústicos absorvem a onda ultrasônica e podem reduzir a cobertura. A eficiência do sensor também pode ser alterada por fluxo excessivo de ar (provocado por ar-condicionado, ventilador, calefação ou outros).

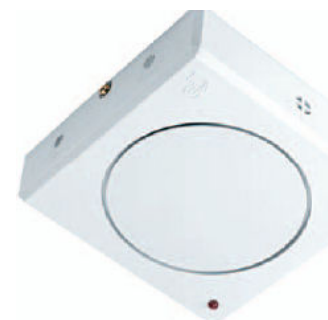

Figura 2.11 - Sensor de presença com tecnologia por raios ultra-sônicos - Fonte: Catálogo Bticino (2004)

A tecnologia dual combina as tecnologias PIR (raios infravermelhos passivos) e ultra-sônica, proporcionando assim o controle da iluminação nas áreas onde os sensores de apenas uma tecnologia poderiam apresentar falhas na detecção.

A combinação de raios infravermelhos com ultra-sônicos permite que o sensor aproveite as melhores características de cada tecnologia, oferecendo assim uma maior sensibilidade e adaptabilidade de funcionamento em função do ambiente e características de aplicação.

Esta tecnologia apresenta diferentes configurações de operação. A configuração padrão aciona a iluminação quando as duas tecnologias detectam presença simultaneamente, mantém acesa a luz desde que uma das tecnologias continue detectando presença, e a apaga quando a área é desocupada. Segundo as características da área a ser controlada, é possível alterar essa configuração.

Um exemplo de aplicação de um sensor de presença com tecnologia dual pode ser de uma sala de computador: o fluxo de ar (gerado pelo ar-condicionado) 
poderia provocar uma falsa detecção por um sensor ultra-sônico, assim como o baixo índice de atividade/movimento na área (digitação) poderia provocar o desligamento indesejado da iluminação por um sensor PIR. Este tipo de problema pode ser resolvido com a tecnologia dual, já que, para o acendimento das luzes, na configuração padrão, é necessária detecção de presença das duas tecnologias (podendo-se entender como "confirmação" de presença na área), e, para manter as luzes acesas, é necessário que apenas uma das duas tecnologias detecte o movimento, por menor que este seja.

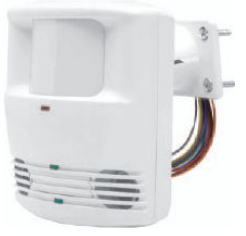

Figura 2.12 - Sensor de presença com tecnologia dual - Fonte: Catálogo Bticino (2004)

Cabe citar ainda um dispositivo que se utiliza da tecnologia sensível à variação da luz, como o (LDR) Lighting Dependent Resistor, para em conjunto com outros componentes controlar a função liga e desliga da iluminação de acordo com o amanhecer e o anoitecer, é comum este dispositivo também ser denominado fotocélula.

A fotocélula é encarregada de medir a quantidade de luz natural do ambiente e controlar as cargas automaticamente desligando-as quando houver luz natural suficiente e ligando-as quando for insuficiente. O sensor também possui uma chave para anulação, que atua no caso da necessidade de iluminação constante.

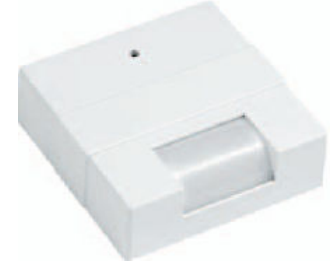

Figura 2.13 - Sensores com fotocélula - Fonte: Catálogo Bticino (2004)

Assim como na tecnologia dual a combinação destas tecnologias (raios infravermelhos com ultra-sônicos e fotocélulas) permite que o sensor aproveite as características destas tecnologias. Pode oferecer uma maior sensibilidade e flexibilidade de funcionamento. Pode-se citar como exemplo, o acionamento da 
carga (lâmpadas) somente quando detectar presença e houver a falta de luz natural no ambiente. A figura 2.14 apresenta alguns modelos de sensores de presença com fotocélula para instalação em teto, parede, ou teto/parede, respectivamente.
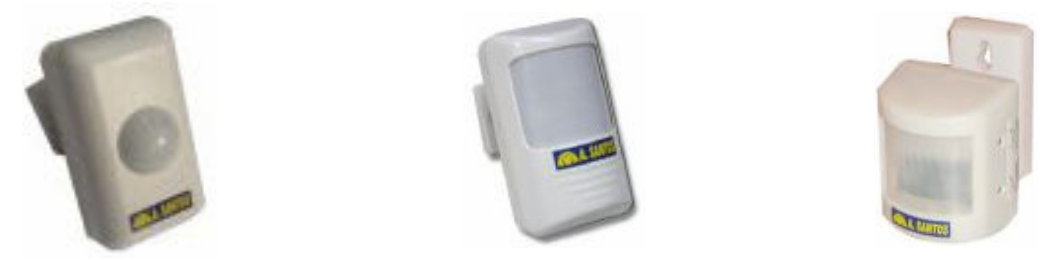

Figura 2.14 - Sensores de presença com fotocélula e - Fonte: Catálogo A. Santos (2004)

Existe também, além da dimerização convencional (controlador de intensidade luminosa por meio da eletrônica), da minuteria (mantém a carga acionada por um tempo pré-estabelecido após comando), a dimerização digital programável ou interruptor denominado inteligente, com funções integradas, como:

- a função com um período pré-ajustado; a luz diminui a intensidade gradualmente;

- a função temporizador; após o tempo pré-estabelecido, desliga automaticamente;

- a função simulador de presença; mantém a lâmpada ligada por um tempo, desligada por outro, alternando-se sucessivamente nesses intervalos; e

- a função dimerização; que controla a intensidade luminosa com modelos tanto para lâmpadas incandescentes como para fluorescentes.
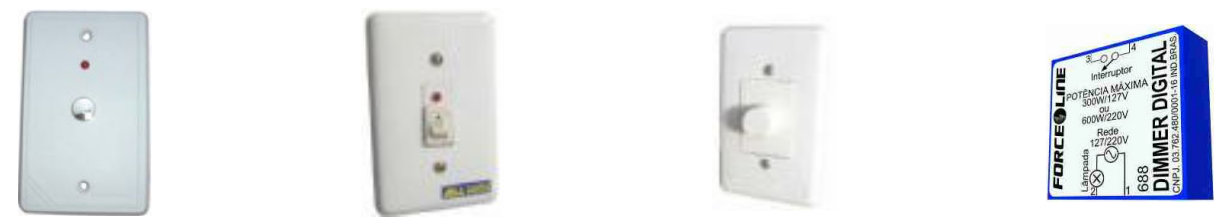

Figura 2.15 - Minuterias e dimmer's - Fonte: Catálogo A. Santos (2004)

Como se pode verificar existem características diversificadas entre as tecnologias apresentadas, ou seja, diferentes aplicações. Contudo, como em qualquer situação similar, deve-se verificar qual a que mais atenderá as necessidades em função das características do ambiente e das circunstâncias.

Estas tecnologias de controle de iluminação podem ser consideradas nível 1 de automação residencial, pois se aplicam em sistemas individuais ou subsistemas 
que provêem funções independentes que não se relacionam diretamente com outros equipamentos ou subsistemas.

É comum não serem previstos em projetos residenciais populares a instalação das tecnologias citadas principalmente por falta de informação aos usuários finais. Normalmente, criam-se alguns paradigmas como: custo, crença que haverá dificuldade na instalação/manutenção, ou até por acreditar-se em uma dificuldade de encontrar tais dispositivos para aquisição.

Entretanto, tais tecnologias atualmente estão disponíveis no mercado nos mais diversos modelos e marcas e com instalação que exige apenas a interpretação de instruções que acompanham os dispositivos.

\subsubsection{Tecnologia para acionamento de cargas por meio de relés de impulso}

Os relés são componentes eletromecânicos capazes de chavear circuitos de potências elevadas a partir de pequenas correntes ou tensões, tornando-se um componente fundamental nos equipamentos elétricos.

Um relé eletromagnético se compõe de um eletroímã (ou bobina), uma base montada e os contatos.

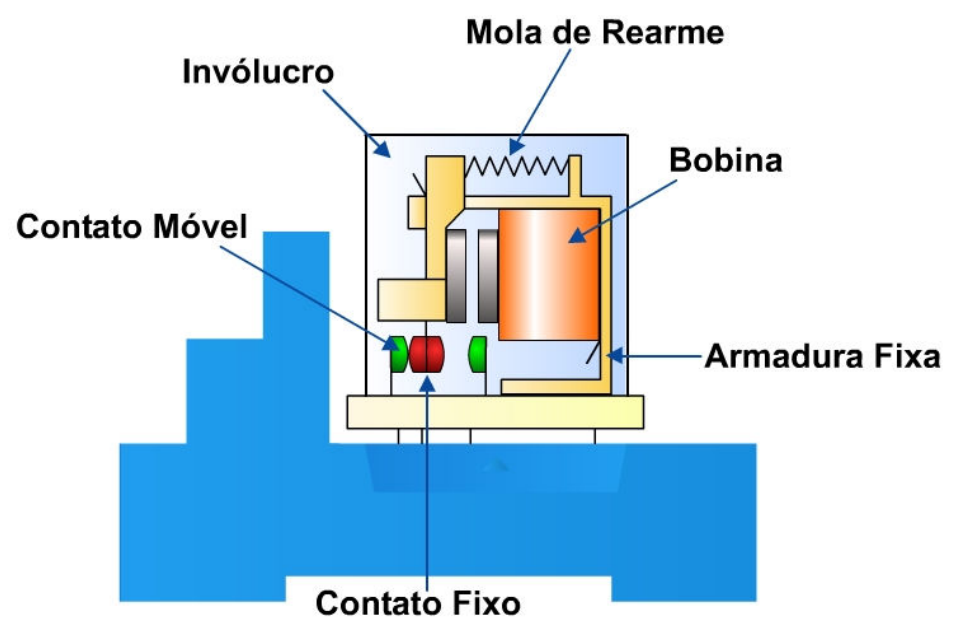

Figura 2.16 - Relé Eletromagnético - Fonte: Palestra Finder (2004) 
Algumas características do relé eletromagnético:

- $\quad$ um relé pode controlar sinais DC por meio de sinais $A C$ ou vice-versa;

- $\quad$ a tensão de controle da bobina é menor que a dos contatos;

- $\quad$ sinais de saída são completamente isolados e independentes dos sinais de entrada;

- pode haver o acionamento de um circuito ao mesmo tempo com um único sinal.

Dos relés tradicionais eletromagnéticos que devem ser acionados por sinais liga/desliga, foram desenvolvidos relés que são acionados por pulsos denominados relés de impulso. A figura 2.17 ilustra o projeto do primeiro relé de impulso desenvolvido.

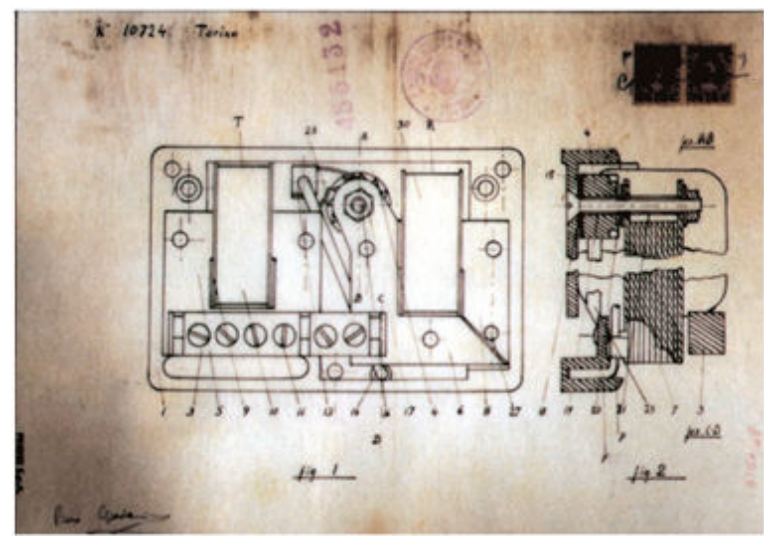

Figura 2.17 - Projeto do $1^{\circ}$ relé de impulso - 1950 - Piero Giordanino -

Patenteado pela empresa Finder - Fonte: Palestra Finder (2004)

Com a programação através de came, o relé pode efetuar diferentes seqüências de acionamento compostos por até dois contatos. Portanto, podem-se controlar diversos circuitos ao mesmo tempo utilizando um conjunto de botões pulsadores, controlando a quantidade de pulsos. A figura 2.18 apresenta um modelo de relé de impulso e suas possibilidades.

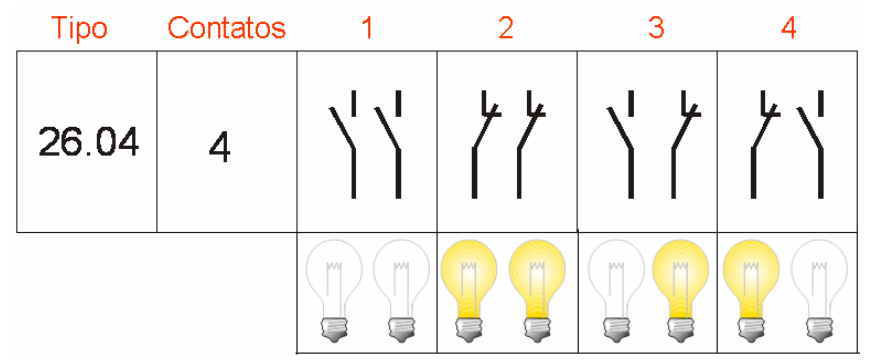

Figura 2.18 - Exemplo de seqüência de relé de impulso - Fonte: Manual Finder (2006) 
Além de relés de impulso pode ser planejada a utilização de relés programáveis, relés com a função de minuteria, relés associados a sensores crepusculares (fotocélulas) ou a controles de dimerização, relés com a função SELV (Segurança Extra em Baixa Tensão), entre outros. A figura 2.19 mostra alguns tipos de relés de impulso.
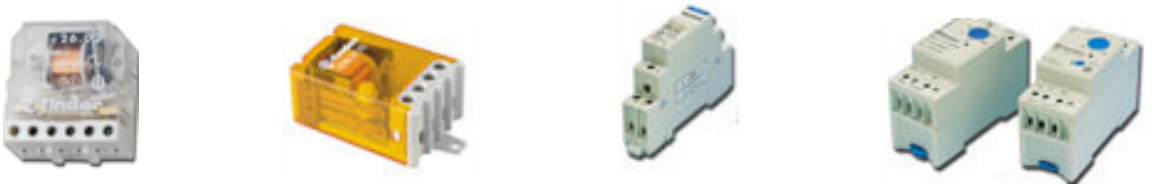

Figura 2.19 - Modelos de relés de impulso - Fonte: Manual Finder (2006)

Assim como os sensores, e de acordo com a definição dos níveis de AR, segundo a HAA, esta tecnologia de controle de iluminação pode ser considerada nível 1 de automação residencial, pois se aplicam em sistemas individuais ou subsistemas que provêem funções independentes que não se relacionam diretamente com outros equipamentos ou subsistemas. Mas, se desenvolvido as devidas interfaces, torna-se possível alcançar o nível 2 de AR.

Também é comum não serem previstos em projetos a instalação das tecnologias citadas por falta de informação aos usuários finais e até mesmo a uma parte de alguns projetistas e executores, e também normalmente por alguns paradigmas: como custo, crença que haverá dificuldade na instalação/manutenção, ou até por acreditar-se em uma dificuldade de encontrar tais dispositivos para aquisição.

De fato, os relés de impulso e dispositivos correlatos não são amplamente encontrados em quaisquer lojas de materiais elétricos. Entretanto, o principal fabricante com representação em suas filiais, mantém e disponibiliza seus produtos por meio de rede de distribuidores específicos. Os dispositivos são de fácil instalação, tendo como condição ideal, o planejamento prévio da instalação.

\subsubsection{Tecnologia com comunicação de dados por meio da rede elétrica I}

A tecnologia X10 PLC (Power Line Carrier) existe há mais de vinte anos e foi criada inicialmente para integrar baixo custo e controle de equipamentos. 
Originalmente unidirecional, hoje em dia é possível encontrar equipamentos bidirecionais. Os módulos transmissores do X10 são adaptadores que conectados à tomada de energia elétrica enviam sinais aos módulos receptores para controlar equipamentos simples: interruptores, controles remoto, sensores de presença, entre outros.

A modulação utilizada é por amplitude - AM (Amplitude Modulation). Para diferenciar os sinais, a portadora utiliza a passagem por zero volt da onda senoidal $(60 \mathrm{~Hz}$ ou $50 \mathrm{~Hz})$ da linha elétrica de corrente alternada (CA), tanto no ciclo positivo quanto no negativo.

A transmissão na passagem por zero justifica-se por ser este o instante de menor ruído e interferência de outros equipamentos ligados à rede. $\mathrm{O}$ um binário é representado por um pulso de 3 a $5 \mathrm{~V}$, com duração de aproximadamente $1 \mathrm{~ms}$, no primeiro ponto do cruzamento pelo zero e pela ausência desse pulso no segundo zero.

O zero binário é um inverso: ausência no primeiro pulso e presença no segundo. Dessa forma, cada bit precisa de um ciclo completo de $60 \mathrm{~Hz}$ para ser transmitido, limitando a taxa em 60 bits por segundo.

Um comando completo do X10 consiste de dois pacotes com um intervalo de 3 ciclos entre eles, e cada pacote leva 11 ciclos para ser transmitido. No total são necessários 47 ciclos para se transmitir um comando, o equivalente a 0,8s. Essa limitação de velocidade acabou restringindo a tecnologia ao controle de aplicações simples como iluminação e segurança.

O protocolo de comunicação X10 em si, não é proprietário, no sentido de que qualquer fabricante pode produzir dispositivos X10 e oferecê-los ao consumidor, porém não se comunica com outro tipo de protocolo de comunicação. A figura 2.20 ilustra alguns módulos X10: transmissor, controle remoto, acionamento de cargas e acionamento de lâmpadas tipo soquete, respectivamente.
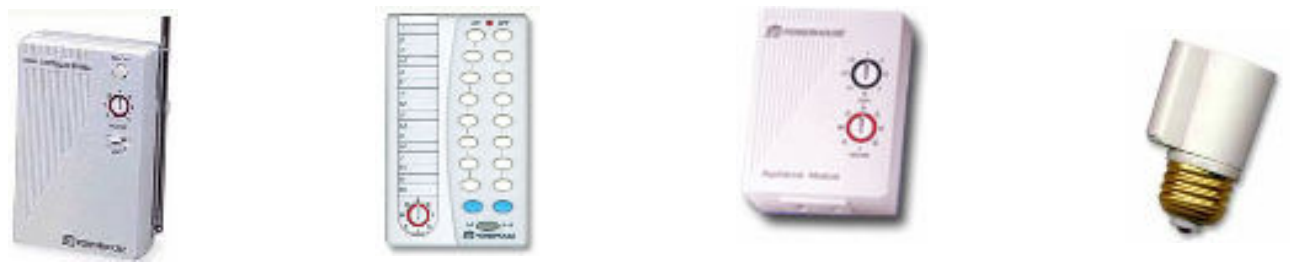

Figura 2.20 - Módulos de controle X10 - Fonte: Catálogo X10 (2006) 
Contudo, além dos exemplos citados até aqui existe também atualmente uma vasta gama de possibilidades de dispositivos que se comunicam por meio do protocolo X10, como por exemplo, na área de segurança (câmeras e correlatos) utilizando o mesmo princípio de funcionamento. Esta tecnologia pode ser considerada nível 1 de automação residencial ou quando o sistema permitir supervisão e programação por meio de interfaces utilizando o computador, nível 2.

\subsubsection{Tecnologia de comunicação por meio da rede elétrica II}

A tecnologia PLC denominada (Powerline Communication) assemelha-se a tecnologia X10, porém sob outros propósitos e abrangências. Assim como o X10 a topologia da rede será a mesma utilizada para distribuição de energia elétrica, tornando cada tomada um ponto potencial para transmissão de dados, transformando desta maneira a rede elétrica de prédios e residências em uma verdadeira rede de comunicação local.

A diferença do X10 é que o padrão da tecnologia PLC aqui apresentada propõe utilizar a própria rede elétrica para conectar computadores em rede, ou dispositivos de telemetria, ou a própria internet, e não somente dispositivos sensores ou atuadores. A figura 2.21 ilustra a proposta da tecnologia PLC (Powerline Communication).

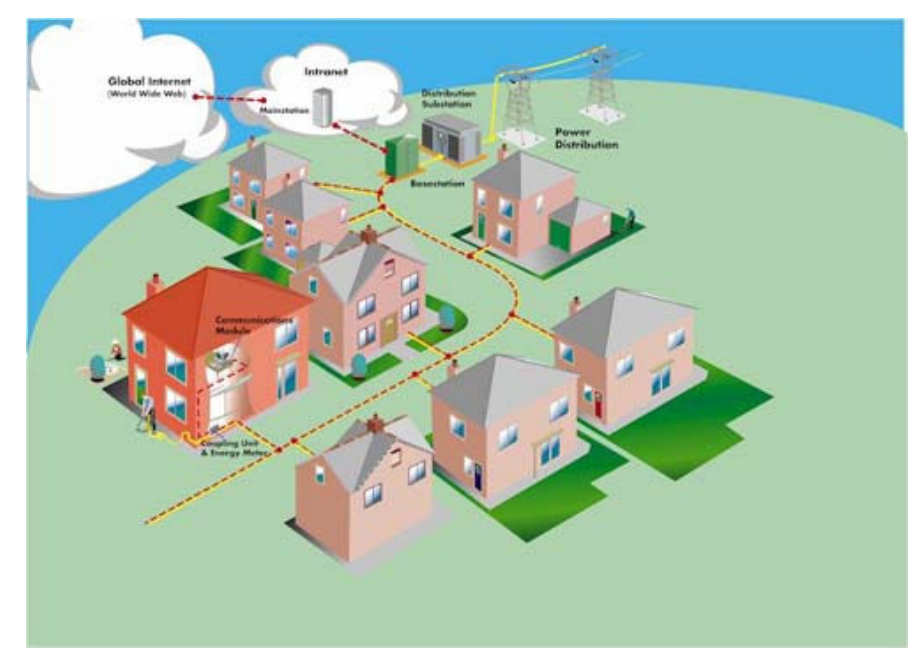

Figura 2.21 - Rede Internet pela rede elétrica - Fonte: Vargas (2004) 
Existem projetos utlizando a tecnologia PLC no exterior e no Brasil, entretanto este trabalho de pesquisa não tem como foco analisá-los mais detalhadamente. Um trabalho de pesquisa, Vargas (2004) que apresenta um estudo apropriado foi desenvolvido por pesquisadores da Universidade Federal do Rio Grande do Sul, denominado Comunicação de dados através da rede elétrica.

Conclui-se que a tecnologia PLC (Powerline Communication) ou (Power Line Carrier) são ambas uma comunicação por rede elétrica, que tem cada qual o seu propósito. As mesmas podem permitir aplicações por uma simples tomada elétrica, ou seja, transformam cabos de cobre das redes convencionais de distribuição de energia elétrica em potencial meio de transmissão de dados, voz, e imagens.

Assim, pode-se enquadrar essa tecnologia a nível 2 da AR, podendo alcançar o nível 3, pois futuramente os próprios computadores pessoais podem se tornar os dispositivos de controle da residência.

A diferença, comparados à outras tecnologias, é de que os dados e comandos, de maneira integrada, poderão utilizar da própria rede elétrica.

\subsubsection{Tecnologia para automatização de persianas, cortinas e toldos}

Existem diversos fabricantes desta tecnologia. É um sistema de motorização de cortinas, persianas e toldos que tem como características de aplicação a utilizaç7ão de pequenos motores (110/220VCA ou 24VCC). Os motores são comandados por impulsos em controle remoto ou botões pulsadores e acionados por relés eletromagnéticos ou dispositivos eletrônicos, e podem ser interligados às principais tecnologias de automação residencial disponíveis.

As últimas inovações são sistemas de motorização de cortinas utilizando baterias, e outras com sensor solar, permitindo a instalação de modo individual mesmo sem a prévia instalação elétrica, normalmente necessária no modo convencional.

O nível de automação residencial para esta tecnologia dependendo da aplicação pode ser nível 1, sistema independente, ou nível 2, pois permite a integração de comando por meio interfaces com outros dispositivos ou sistemas de controle. 


\subsubsection{Tecnologia de sistemas de controle de iluminação e outros subsistemas}

Existem diversos fabricantes de sistemas de controle de iluminação. Incluem itens variados desde simples controles instalados em parede que ajustam a luminosidade em uma sala, como os dimerizadores citados anteriormente, até sistemas mais sofisticados para o controle de toda residência, escritório ou grandes instalações.

Trata-se de sistemas de controle de iluminação com programação da ambientação luminosa com interface amigável. Existem por exemplo, dispositivos que controlam a iluminação e criam uma ambientação luminosa em até oito pontos, podendo totalizar até 48 zonas de iluminação, considerando a potência permissível de cada ponto.

Os mesmos permitem incluir o controle de outros equipamentos como parte desta ambientação, como telas de projeção e cortinas automatizadas. Comportam ainda 16 possibilidades de ambientação em sua memória.

A figura 2.22 mostra um modelo de um sistema de controle de iluminação.

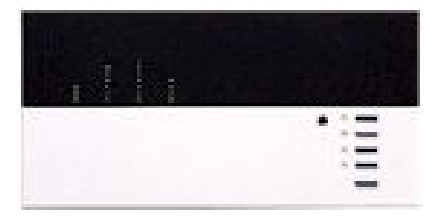

Figura 2.22 - Modelo de central de controle iluminação - Fonte: Manual Lutron (2001)

Existem também outros dispositivos que apesar de terem os mesmos objetivos mencionados nos outros modelos, contam com painéis de dimerização e atendem aplicações de maior porte, possibilitando a integração com sistemas de automação predial. Estes modelos podem chegar a atender de 128 a 512 zonas de iluminação.

Como exemplo de inovação em um evento denominado Habitar 2003 realizado em São Paulo, duas empresas em parceria programaram e implementaram, em um modelo de casa inteligente, um sistema de controle de iluminação por meio do comando de voz. 
Existem ainda sistemas de controle de iluminação voltados especificamente para residências, e permitem três possibilidades de utilização:

- totalmente cabeado (Homeworks);

- totalmente por radiofreqüência/wireless (Homeserve); ou

- ambos conforme as necessidades da infra-estrutura.

Os sistemas permitem controlar a iluminação de um ou mais pontos, podendo criar inclusive caminhos de luz com apenas um toque em um botão. Conta também com a função memória/temporizador diferenciada, ou seja, pode repetir exatamente a mesma iluminação utilizada na última semana ou no último mês na casa inteira, simulando a presença dos moradores.

E pode possibilitar também o acionamento a distância por telefone. Dentro ainda da tecnologia para controle da iluminação existe a possibilidade de se utilizar outro sistema de comunicação por radiofreqüência/wireless (radioRA), e que permite integração com outros dispositivos atuadores.

Por exemplo, é possível integrar o sistema de controle da iluminação ao sistema automático do portão da garagem. As tecnologias utilizadas para sistemas de controle de iluminação enquadra-se nos níveis de automação residencial 1 e 2 , pois podem ser aplicados em sistemas individuais ou subsistemas que provêem funções independentes que não se relacionam diretamente com outros equipamentos ou subsistemas (nível 1), ou quando existem múltiplos sistemas de automação integrados entre si utilizando-se um único controle, mas que entretanto cada sistema ou equipamento opera de acordo com sua fabricação (nível 2).

\subsubsection{Tecnologia de controle central para automação residencial}

Existem diferentes fabricantes de centrais de controle para automação residencial e predial. Uma central controla subsistemas como iluminação, áudio, vídeo, cortinas ou outros equipamentos elétricos por meio de um painel de comando. Pode-se considerar, portanto, uma central de controle como um elemento integrador de tecnologias.

Sua principal característica de aplicação é, por meio de um painel de mesa, parede, ou portátil com tecnologia touchscreen, e normalmente utilizando rádio 
freqüência, configurar e controlar os acionamentos das cargas com toques no próprio painel.

É um equipamento específico para realizar a integração de subsistemas enquadrando-se em nível 2 na classificação de níveis da automação residencial. Assim, podem existir múltiplos sistemas de automação integrados entre si utilizandose um único controle que é a própria central. Entretanto, cada sistema ou equipamento opera de acordo com sua fabricação. A figura 2.23 ilustra um modelo de central de controle.

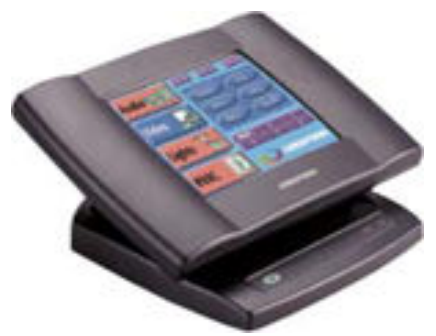

Figura 2.23 - Modelo de central de controle - Fonte: Manual Creston (2001)

\subsubsection{Tecnologia centralizada para sistemas de automação residencial}

Existem atualmente algumas tecnologias de modo centralizado para automação residencial com sistema proprietário de comunicação entre os dispositivos. Na seqüência são apresentadas algumas aplicadas no mercado nacional.

\subsubsection{Tecnologia IHC (Intelligent Home ControI)}

Existem diversas tecnologias possíveis para integração de sistemas de automação residencial de modo centralizado. Uma das que se destacam é a desenvolvida por uma empresa dinamarquesa, a LK, do grupo Scheneider que tem uma linha de produtos denominados IHC (Intelligent Home Control). 
A tecnologia IHC é uma central de automação que permite os controles de aquecimento, ar condicionado, iluminação, climatização, eletrodomésticos, irrigação, cortinas e outros subsistemas.

Trata-se de um sistema de módulos de entradas e saídas, sensores e sistema supervisório opcional e adaptável a equipamentos convencionais, como o controle de toda a iluminação, utilizando interface a relés. Assemelha-se ao CLP (Controlador Lógico Programável) utilizado industrialmente, porém adaptado à residência com acionamentos em tensão reduzida (24VDC) e possibilidade de acrescentar módulos para dimerização. Apresenta-se em três tipos de arquitetura: Centralizada, Descentralizada e BUS Link.

A arquitetura disponível no Brasil é o modo centralizado. Seu princípio básico de funcionamento é aquele em que após ter sido realizado as leituras das entradas e enviado ao processador central, onde em sua memória encontra-se o programa do usuário, atualiza as informações, e executa os acionamentos das saídas conforme desejado, fechando assim um ciclo de máquina (microprocessador). A figura 2.24 auxilia na compreensão do conceito utilizado por um sistema de automação residencial centralizado.

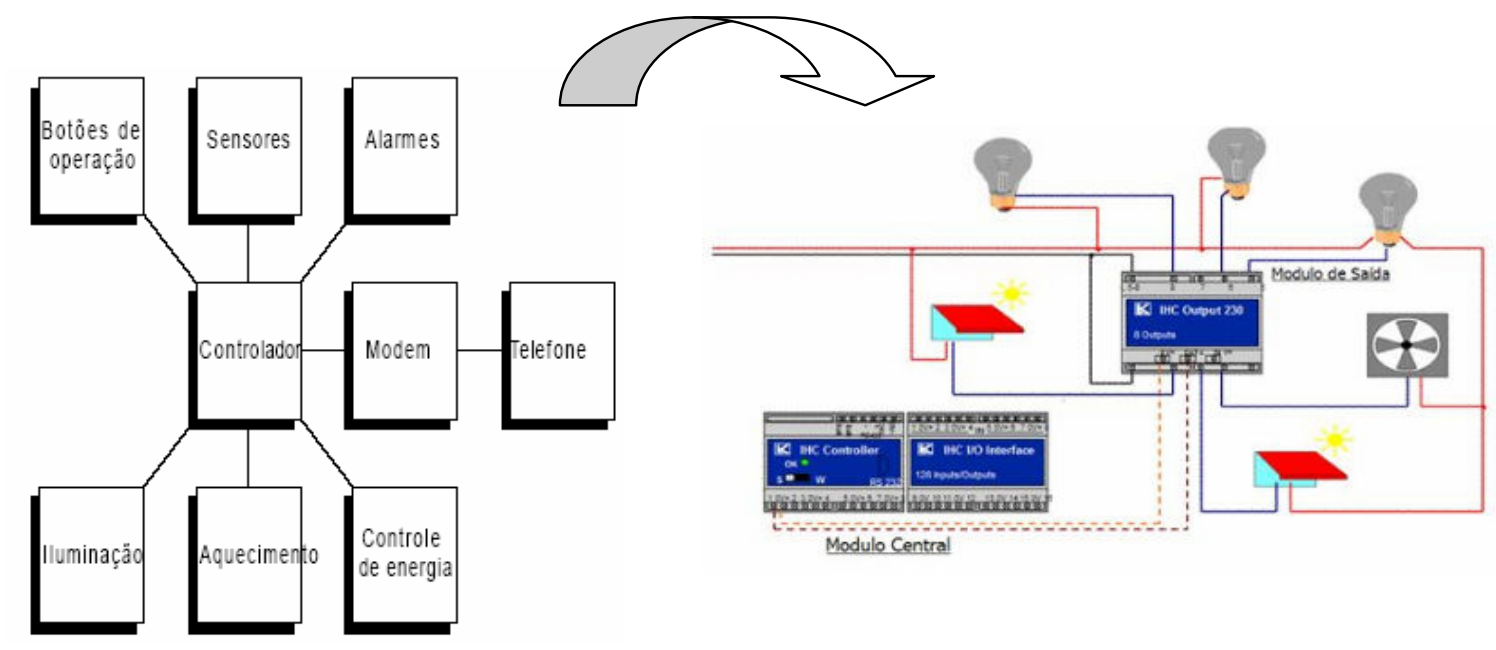

Figura 2.24 - Conceito do sistema de automação centralizado IHC - Fonte: Manual IHC (1998)

O nível de automação residencial para tecnologia IHC pode ser considerado 2 ou 3 dependendo do sistema a implementar. Existe a possibilidade da utilização de 
tecnologia, centralizada que permite múltiplos sistemas integrados entre si, mas que, entretanto cada sistema ou equipamento opera de acordo com sua fabricação (nível 2). Contudo, se houver a instalação das devidas interfaces nos dispositivos de entrada e saída, a tecnologia IHC possibilita a integração total (nível 3).

\subsubsection{Tecnologia IBM - Home Net Center}

Entre outras possibilidades de implementar uma residência inteligente essa é uma tecnologia desenvolvida pela IBM, a mesma permite que o controle do sistema de iluminação e aparelhos ligados à rede elétrica seja feito por controle remoto ou via Internet.

A solução da IBM Global Services para a automação residencial é um sistema denominado Home Net Center. O sistema provê uma solução com integração total de todos os sistemas recebidos no mesmo, que aproveita das vantagens da Internet para monitoração ou controle, por meio de um dispositivo, (hardware), chamado de "Webdyn".

O "Webdyn" tem uma arquitetura aberta, combinada com as aplicações do servidor e gateways de comunicação. Este dispositivo permite ao usuário também controlar eletrodomésticos via rede Ethernet por meio da Internet, e que para tal, utiliza o auxílio também de outras tecnologias como CAD AC Modem ou X10 Modem.

No Home Net Center está previsto a otimização, integrando, por exemplo, os seguintes sistemas:

- distribuição de Internet com alta velocidade;

- computador no escritório e controle de eletrodomésticos;

- conexões para TV, telefone e fax;

- acesso e gerenciamento dos sistemas de controle dos ambientes (HVAC, iluminação), ou do sistema integrado de segurança.

Assim como a tecnologia IHC pode-se considerar que o nível de Automação Residencial do sistema Home Net Center está entre 2 ou 3, pois existe a possibilidade da utilização de tecnologia, centralizada que permite múltiplos sistemas integrados entre si, mas que entretanto cada sistema ou equipamento opera de 
acordo com sua fabricação (nível 2), ou do ponto de vista da integração total (nível 3).

Por meio do compartilhamento das informações entre sistemas utilizando o dispositivo Webdyn, como energia e segurança entre outros, otimizando assim o gerenciamento da residência.

\subsubsection{Tecnologias Descentralizadas para Sistemas de Automação Residencial}

Existem atualmente algumas tecnologias de modo descentralizado para automação residencial com sistema aberto de comunicação entre os dispositivos. $\mathrm{Na}$ seqüência são apresentadas algumas disponíveis no mercado nacional.

\subsubsection{Tecnologia Instabus EIB}

O EIB (European Installation Bus) é um protocolo de comunicação desenvolvido por um conjunto de empresas líderes do mercado Europeu de materiais elétricos e teve como o objetivo criar um padrão europeu que permitisse a comunicação entre todos os dispositivos de uma instalação, seja residência ou edifício.

Este conjunto de atualmente de 114 empresas é mais especificamente uma associação intitulada EIBA - Association European Installation Bus, que se iniciou em 1990, com apenas 15 membros.

A mesma tem sede em Bruxelas e seus membros cobrem cerca de $90 \%$ do negócio dos materiais elétricos na Europa, segundo dados da própria EIBA.

Utilizando o conjunto dispositivo e o BUS de comunicação cria-se um sistema de gerenciamento de equipamentos elétricos que permite o controle de funções como iluminação, persianas, climatização, irrigação, sensores e aparelhos domésticos em geral. 
As características de transmissão do protocolo de comunicação denominado também como instabus EIB permitem ao sistema BUS distribuído e programável, utilizar transmissão de dados seriados para seu controle, monitoramento e realização de tarefas.

Este link de transmissão seriado é compartilhado, por meio do BUS, permitindo que os dispositivos conectados troquem informações uns com os outros. A comunicação de dados deve ocorrer de acordo com as regras definidas no protocolo EIB.

A informação dada é adicionada a um padrão de transmissão standard, chamado telegrama, a qual o sensor (emissor) distribui para um ou mais participantes (receptor).

Após a transmissão ter sucesso o receptor confirma que recebeu o telegrama. No caso de não reconhecimento a transmissão é repetida até três vezes. Então, se ainda não for possível confirmar o recebimento, o processo de envio é abortado e o problema gravado na memória do dispositivo que enviou o telegrama.

A transmissão com o instabus EIB não é eletricamente isolada, ou seja, apesar de se utilizar um cabo semelhante ao telefônico, especificado como YCYM $2 \times 2 \times 0,8$, e sendo constituído por dois pares de fios, somente o par (vermelho e preto) serve a transmissão de sinal, porém simultaneamente serve também como fonte de alimentação.

O outro par (amarelo e branco) serve para aplicações adicionais. A tensão de alimentação utilizada é (24VDC) entre os dispositivos, e é transmitida ao longo da mesma linha de BUS.

Os telegramas são modulados para essa tensão de forma lógica, como um pulso. Os dados transmitidos são equivalentes à lógica zero e os dados não transmitidos, lógica 1.

Um dado individual de telegrama é transmitido fora de sincronização. A transmissão como um todo, entretanto, é sincronizada através da adição de bits de start e stop bit.

O acesso para o BUS, como meio físico de comunicação compartilhada para transmissão sem sincronização, requer regulações completas. $\mathrm{O}$ instabus EIB usa o protocolo CSMA/CA (Carrier Sense Multiple Access with Colilision Avoidance), semelhante à Ethernet, que utiliza o CSMA-CD (Carrier sense multiple access/collision detect), mas evitando colisões. Esse protocolo garante um acesso 
aleatório ao BUS livre de colisões sem ter que reduzir a taxa de transmissão ao mesmo tempo.

Todos os participantes do BUS monitoram os telegramas transmitidos, mas apenas aqueles direcionados irão responder. Quando do envio, um participante do BUS tem que monitorar o mesmo, esperando que tudo o que for enviado seja completado (Carrier Sense - "Senso de Mensageiro"). Se não há telegramas no BUS, na teoria, qualquer participante pode começar um processo de envio (Multiple Access).

No caso de dois participantes iniciarem o envio simultaneamente, o participante com maior prioridade deve continuar sua transmissão sem atraso (Collision Avoidance - Evitar Colisão), enquanto o outro se retira para tentar novamente depois.

Se ambos os telegramas tiverem prioridade equivalente, o que tiver endereço físico mais baixo será enviado. A figura 2.25 ilustra genericamente um BUS de um sistema de automação residencial descentralizado.

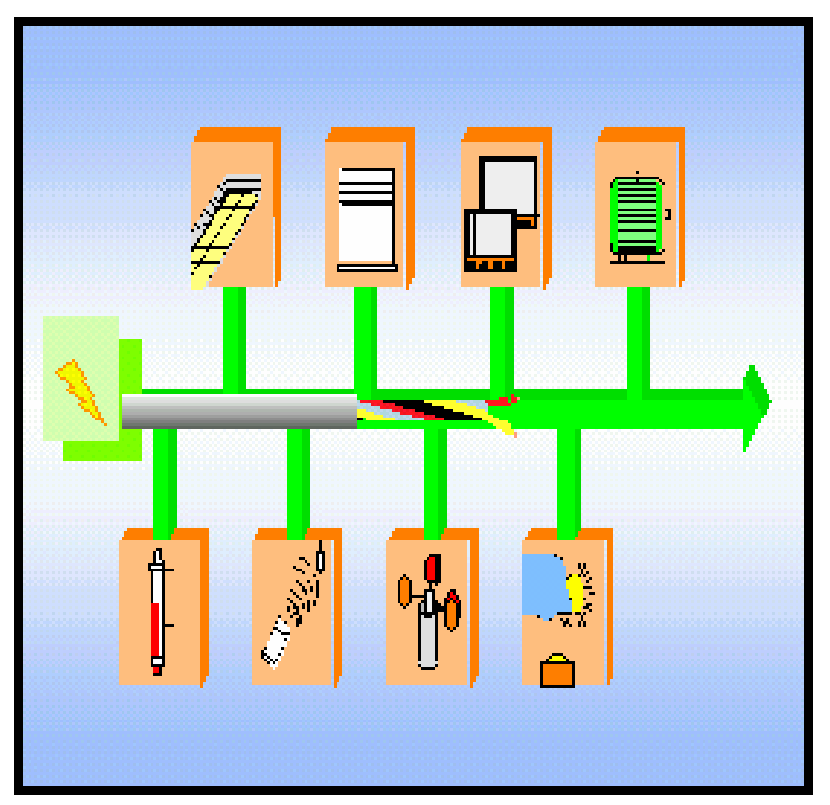

Figura 2.25 - Conceito da rede de comunicação BUS - instabus EIB - Fonte: Catálogo Siemens (2001) 
Toda ordem de comando para ser enviada, necessita inicialmente de um endereçamento, que é enviado para toda linha do barramento. Assim, como uma correspondência tem um endereço particular que identifica quem a receberá, cada equipamento do barramento também possui um endereço único que o identifica entre os demais.

Quando o sistema protocolo EIB está em serviço normal, a lógica usual é a comunicação por telegrama. Ao recebê-lo, o equipamento do barramento o aceita se o telegrama contiver o grupo de endereço do equipamento (transmissão com sucesso). Mas pode também rejeitá-lo, e este ser entendido por outro dispositivo devidamente endereçado.

O elemento básico do sistema instabus EIB é a linha. Até 64 dispositivos podem ser usados em uma linha única através de um "acoplador de linha". Através da adição de "acopladores de linha" às chamadas "linhas principais", até 15 linhas podem ser combinadas a uma área.

Pela adição de "acopladores de áreas", mais de 15 áreas podem ser combinadas a um sistema único. Além disso, este acoplador mantém todas as interfaces (gateways) para mais sistemas EIB ou outros (SICLAMATX, ISDN etc.).

Mesmo quando se considera a possibilidade de utilização de mais de 15.000 pontos no BUS que podem ser utilizados num único sistema, a confiabilidade do sistema de BUS não é perdida.

O extravio dos telegramas é evitado, pois os telegramas somente passam por um acoplador se há um dispositivo BUS com um grupo de endereços em que esteja de acordo com o enviado. Para essa finalidade, os acopladores são providos de um filtro apropriado.

O endereço físico deriva do layout topológico do sistema: cada dispositivo BUS pode ser unicamente identificado por sua área, linha e número de esquema. Grupos de endereços são divididos em grupos e subgrupos com o objetivo de alocar aplicações específicas.

Durante a configuração os grupos de endereços devem ser divididos em até 14 grupos principais, por exemplo:

- controle de iluminação;

- controle de persianas; ou

- aquecimento, ventilação e controle de ar condicionado, etc. 
Cada grupo principal pode consistir de até de 2048 subgrupos, de acordo com os requerimentos dos projetos. A alocação dos grupos de endereços não interfere nos endereços físicos determinados. Então, qualquer esquema BUS é capaz de se comunicar com qualquer outro esquema BUS.

A figura 2.26 ilustra de forma genérica as expansões de um sistema instabus.

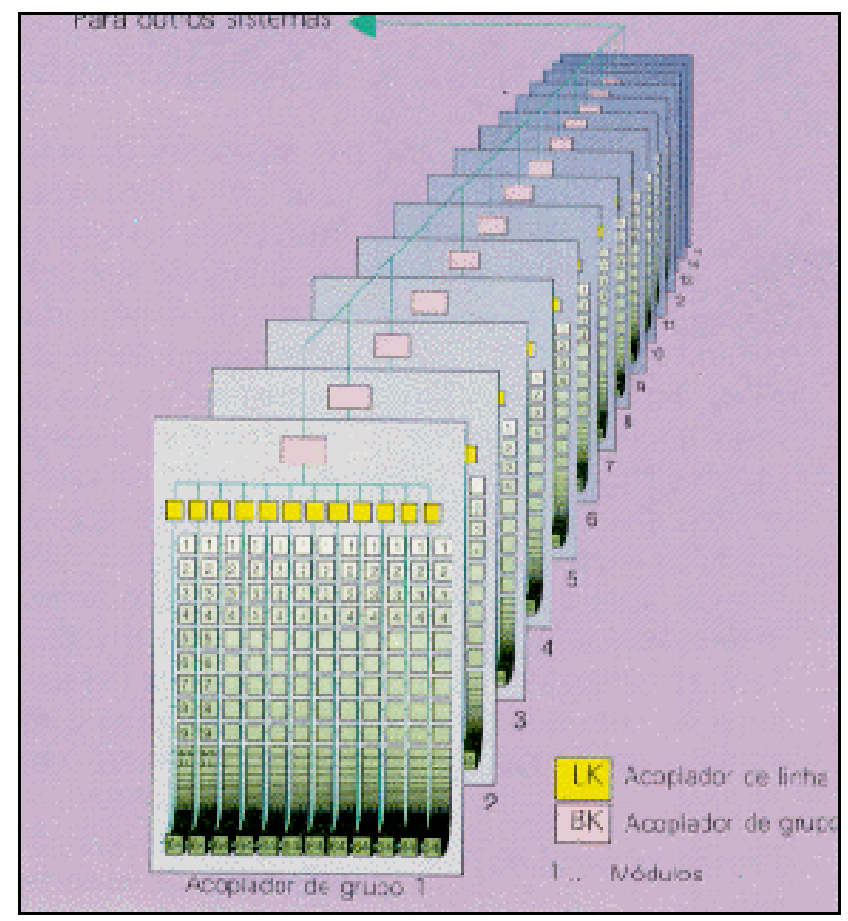

Figura 2.26 - Conceito da expansão da rede de comunicação BUS - instabus EIB Fonte: Siemens (2001)

Os dispositivos BUS então podem abranger:

口 Número de áreas: até 15;

口 Numero de linhas por área: até 15;

- Número de participantes por linha: até 64.

Totalizando uma possibilidade de atingir até aproximadamente 15000 pontos de controle.

A velocidade de transmissão dos telegramas é de 9600 bits/seg., ou $104 \mu \mathrm{s}$. Contudo, a classificação do nível de automação residencial da tecnologia instabus EIB pode ser considerado como nível 3, pois possibilita a integração total dos sistemas a serem automatizados. 


\subsubsection{Tecnologia Lonworks}

LonWorks é uma tecnologia da empresa Echelon que tem como objetivo oferecer uma infra-estrutura para a operação de rede local denominada LON (Local Operating Network). Está baseada no protocolo de comunicação proprietário LonTalk (ANSI 709.1), e está embarcado no chip Neuron, também proprietário.

Este sistema pode ser usado através de par trançado, cabo coaxial, RF, infravermelho, fibra ótica e rede elétrica. O sistema PLC apresenta comunicação peer-to-peer, adotando o protocolo CSMA como estratégia de acesso ao meio, funcionando a uma taxa de $10 \mathrm{Kbps}$. A tecnologia spread spectrum é utilizada para modulação das mensagens.

O alto custo da tecnologia é influenciada pelo chip Neuron, que possui três processadores de 8 bits, com até 10 Kbytes de RAM e até 10 Kbytes de ROM. Por essa razão e pela existência de soluções mais baratas para a automação residencial, a implementação massiva da tecnologia se deu em ambientes comercias e indústrias, afastando-se de usuários domésticos.

É uma topologia de rede criada pela Echelon em 1992. Criada com o intuito de solucionar os problemas de controle tem tido mais êxito nas implantações em edifícios administrativos, hotéis e indústrias. Devido ao custo, os dispositivos Lonworks não têm sido implementados em residências, sobretudo porque existem outras tecnologias com funcionalidades similares e custos menores.

Ainda em relação ao Neuron Chip pode-se então salientar:

- tem um identificador único, o Neuron ID, que permite direcionar qualquer nó de forma inequívoca dentro de uma rede de controle Lonworks. Este identificador, com 48 bits, é gravado na memória EEPROM durante a fabricação do circuito;

- tem um modelo de comunicação independente do meio físico sobre qual pode ser por par telefônico, rede elétrica, fibra-óptica, rádio freqüência, infravermelho, e cabo coaxial, entre outros. O transmissor-receptor é o encarregado de adaptar os sinais do Neuron Chip aos níveis de necessita cada meio;

- o firmware que implementa o protocolo Lontalk proporciona serviço de transporte e routing (rota) de extremo a extremo da rede. Está incluído um sistema operacional que executa e planeja a aplicação distribuída e que maneja as estruturas de dados que são comunicados entre os nós. 
Estes circuitos comunicam entre si enviando telegramas que contêm a direção do destinatário, informação para o routing, dados de controle assim como os dados de aplicação do utilizador e um checklist como código detector de erros. Todas as comunicações de dados são iniciadas num Neuron Chip. Um telegrama pode ter até 229 octetos de informação para aplicação distribuída.

Assim, como o instabus EIB, o nível de automação residencial considerado para o Lonworks é o 3 , pois possibilita a integração total dos sistemas a serem automatizados.

\subsubsection{Tecnologia modularizada para automação residencial e predial}

Desenvolvida pela Heading Produtos e Serviços a tecnologia Heading detêm vários tipos de sensores de presença e dimmers com diversas possibilidades assim como a tecnologia citada no item 2.4.1 e conta também com um sistema de automação predial que pode também ser aplicado em residências. Mesmo com alguns módulos e interfaces em desenvolvimento, detêm atualmente tecnologia com conceitos a serem também considerados.

A funcionalidade da linha denominada Install é baseada nas redes de comunicação de dados intituladas Local-net ${ }^{\circledR}$ e $H$-net ${ }^{\circledR}$, (protocolos proprietários), mas com conceito de funcionamento similar a tecnologia EIB Instabus (sistema aberto).

A rede Local-net $^{\circledR}$ é destinada à interligação de até 48 módulos periféricos e um computador de gerenciamento. Já a rede $H$-net ${ }^{\circledR}$ tem por função a interligação dos módulos concentradores numa topologia "estrela", e é utilizada para ampliar o sistema, permitindo a concepção de instalações maiores e hierarquizadas, como também, conectar um computador de gerenciamento ou de programação.

Diversos módulos compõem a linha Install:

- os módulos de controle que são módulos inteligentes e geralmente montados nos quadro de distribuição. Por meio de software contido neles, a instalação adquire sua funcionalidade. Entre os módulos de controle existem os controladores programáveis, os concentradores e os de interface com o PC; 
- os módulos periféricos são módulos destinados a aquisição de dados, sinalização e comando;

- os módulos dedicados, são módulos que contem hardware e software específicos para determinada aplicação como, por exemplo, o módulo de controle de bombas.

O software de controle da linha Install está presente nos módulos de controle, nos módulos concentradores e nos computadores de gerenciamento da instalação. A tecnologia Heading permite classificá-la em nível 1 e nível 3 de automação residencial.

$\mathrm{Na}$ linha de sensores de presença e dimmers podem ser aplicados em sistemas individuais ou subsistemas que provêem funções independentes que não se relacionam diretamente com outros equipamentos ou subsistemas (nível 1).

$\mathrm{Na}$ linha Install possibilita a integração total dos sistemas a serem automatizados (nível 3).

\subsubsection{Tecnologia IHouse}

A tecnologia IHouse é desenvolvida para automatizar residências e prédios de alto padrão. Existem alguns prédios residenciais em funcionamento e outros em fase de implantação. Todos os prédios foram contratos finalizados em fase de projeto e realizados com grandes incorporadoras da indústria da construção civil.

Trata-se de uma tecnologia com dispositivos distribuídos entre os sensores e atuadores interligados por uma rede física, previamente projetada e instalada. Os pontos "inteligentes" são também previamente configurados para realizar as funções desejadas e se comunicam por meio do software para automação CAN (Controller Area Network), a mesma tecnologia utilizada em aeronaves e veículos automotivos de última geração.

É uma tecnologia desenvolvida para integrar todos os equipamentos que se desejar. Cada módulo recebe uma denominação e uma aplicação, porém todos ficam conectados e informando status sobre o seu funcionamento a uma central com redundância, que por sua vez fica interligado a linha telefônica em banda larga (Ethernet) para quando for solicitado, conectar-se à internet, podendo manter 
informado tanto os moradores via telefone celular, como também, a própria assistência técnica IHouse, pois se houver alguma falha em qualquer parte do sistema, o software de monitoração envia a informação para a central de atendimento, onde provocará um contato de um responsável com o proprietário para agendamento de visita técnica a fim de verificar e reparar o equipamento danificado.

Os sistemas de controle da residência possibilitam o acionamento de diversos dispositivos e equipamentos, entre eles, podem-se citar alguns apenas para ilustração.

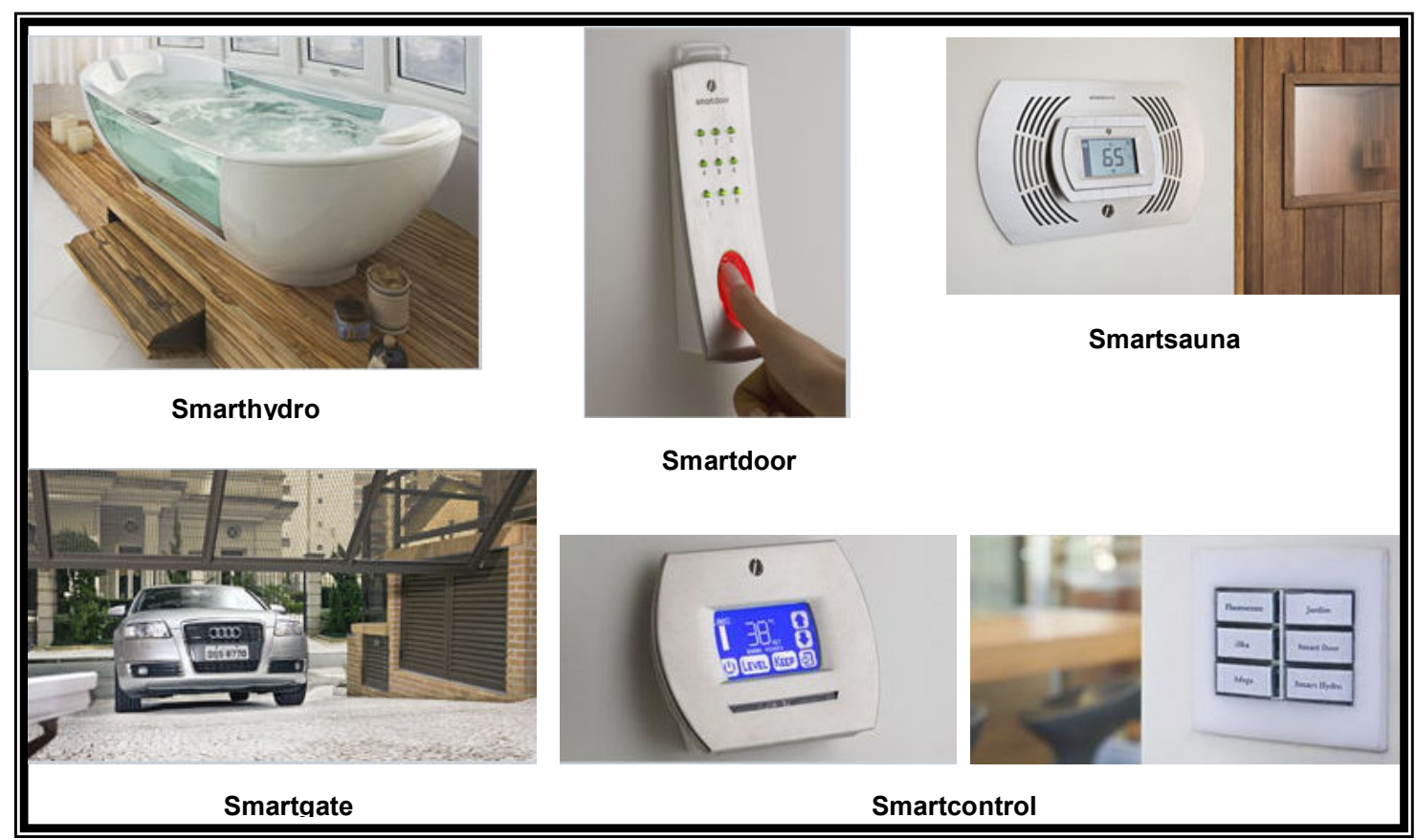

Figura 2.27 - Módulos de sensores e atuadores IHouse - Fonte: http://www.i-house.com.br/ <Acesso em 22/07/2007>

Portanto, mesmo sem a descrição específica de cada sistema ilustrado, podese verificar em função da possibilidade da integração total entre tais sistemas e dispositivos, de que o nível de automação residencial dessa tecnologia, é o nível 3.

Como mencionado anteriormente existem outras tecnologias de automação residencial atualmente no Brasil, porém foram apresentadas algumas que se destacaram durante o trabalho de pesquisa.

Cabe enfatizar novamente que a situação ideal é reunir os conceitos da automação residencial com a preocupação ao meio ambiente em termos de arquitetura e construções com soluções integradas baseadas na tecnologia da 
informação, contribuindo para uma melhoria na satisfação das pessoas em suas moradias e buscando a racionalização energética.

Um consenso geral entre os integradores de sistemas de AR é de que a condição ideal para facilitar a instalação de qualquer que seja a tecnologia adotada, é planejar a infra-estrutura necessária (tubulação e correlatos), e determinar na fase preliminar do projeto, o nível de automação/integração desejado.

Se for o caso, incluir também previamente o tipo de topologia de rede e as especificações e configurações adequadas dos dispositivos a serem utilizados.

Estabelecidos os níveis de classificação e os conceitos da automação residencial verifica-se então qual(is) a(s) tecnologia(s) escolhida(s), dado às diversas possibilidades mencionadas.

É importante enfatizar que os profissionais envolvidos com projetos prediais e residenciais, devem realizar sempre um estudo analisando as condições de inserir no planejamento um determinado nível de automação, mesmo que a decisão seja inicialmente somente a instalação da infra-estrutura para implementação futura.

A fim de ampliar ainda mais a área do conhecimento em estudo, na seqüência são apresentadas as atuais tendências tecnológicas do setor e o exemplo de uma casa inteligente.

\subsection{TENDÊNCIAS TECNOLÓGICAS DE SISTEMAS DE AUTOMAÇÃO RESIDENCIAL E PREDIAL}

Apesar de pouco disponível no Brasil, convém citar a utilização das tecnologias apresentadas na seqüência, pois além de reconhecidas mundialmente, se justificam por deterem de um protocolo aberto de comunicação, ou seja, outros fabricantes podem desenvolver produtos com o mesmo protocolo, acompanhando a principal tendência do setor e da automação em geral.

Dando prosseguimento a apresentação de tecnologias poderá ser realizada outras análises identificando comparativamente quais são as possibilidades atuais e futuras, podendo inclusive também constatar como estão sendo classificados os níveis de automação residencial para tais tendências. 


\subsubsection{Tecnologia Batibus}

Desenvolvido por outra associação de empresas européia a Batibus Club International e certificado como padrão (standard) europeu pelo Cenelec (Comitê Europeu de Normalização Eletrotécnica), o Batibus é um protocolo de comunicação entre dispositivos para automação residencial e predial totalmente aberto, isto é, pode ser implementado por qualquer empresa interessada em introduzi-lo em sua escala de produção.

Tem uma velocidade binária única de 4800 bps a qual é mais que suficiente para a maioria das aplicações de controle distribuído. Utiliza cabo blindado do tipo telefônico e admite as topologias em BUS, estrela, anel ou árvore. A única recomendação a respeitar é não atribuir direções físicas idênticas a dois dispositivos na mesma instalação.

O nível de acesso utilizado, assim como o EIB é a técnica CSMA-CA (Carrier Sense Multiple Access with Collision Avoidance). Isto é, se dois dispositivos enviam um dado ao mesmo tempo ao BUS, ambos detectam a possibilidade de colisão, então só aquele que tiver mais prioridade continua a transmitir retomando-o no instante seguinte.

A filosofia é a de que todos os dispositivos Batibus "escutam" tudo o que circula no BUS, todos processam a informação recebida, mas apenas aqueles que tiverem sido programados irão filtrar o telegrama, e o enviarão à aplicação existente para cada dispositivo. A direção física é atribuída tal como no protocolo X10 através de micro-interruptores ou mini-teclados. A tecnologia Batibus enquadra-se no nível 3 da classificação da Automação Residencial, pois possibilita a integração total dos sistemas a serem automatizados.

\subsubsection{Tecnologia CEBus (Consumer Eletronics Bus)}

O CEBus (Consumer Eletronics Bus), foi desenvolvido com o apoio da EIA (Eletronic Industries Alliance), por um grupo de engenheiros de empresas que 
representam redes de automação residencial nos Estados Unidos e que, atualmente, compõe o CEBus Industry Council (CIL).

CEBus é um conjunto de especificações baseadas em uma arquitetura aberta orientada para produtos caseiros e eletrodomésticos, que fazem uso de linhas de energia elétrica, par trançado, fibra óptica, infra-vermelho ou radiofreqüência.

As especificações definem o que os produtos baseados em CEBus devem fazer. Como os dispositivos inteligentes na rede transmitem e recebem informações, pode-se citar como características de aplicação:

- Interligar os produtos domésticos em rede;

- Fiação da rede elétrica pode ser utilizada para trocarem dados;

- Meio de monitorar utilidades;

- Interagir com o usuário controlando equipamentos, possibilitando a redução do consumo de energia elétrica, entre outros tipos de controle.

Atualmente cada dispositivo inserido na rede utiliza um circuito integrado (Chip) fabricado pela Intellon Corporation, contendo hardware de comunicação, linguagem e protocolo.

Ao CEBus somam-se outros protocolos, como TCP-IP para Internet, HAVi (Home Áudio/Vídeo Interoperability), IEEE 1394 (Home-based network), Upnp (Universal Plug\&Play), JINI, que é baseado em Java Virtual Machine, e também o OSGi (Open Services Gateway Initiative).

Assim como as tecnologias Batibus, o CEbus enquadra-se no nível 3 da classificação da Automação Residencial, pois possibilita a integração total dos sistemas a serem automatizados.

É preciso considerar que os equipamentos necessitam estar preparados, cada qual com tais tecnologias, e a interoperabilidade entre elas, torna-se um desafio a ser enfrentado.

\subsubsection{Tecnologia EHS (European Home System)}

Desenvolvido pela associação de indústrias européias de microprocessadores, a EHSA (European Home System Association), com o devido suporte da Comissão Européia, criaram uma tecnologia econômica que permitisse a 
implantação da automação residencial. O resultado foi a especificação do EHS no ano de 1992. O modelo OSI (Open Standard Interconnection) foi a topologia escolhida.

Desde o seu início envolveu-se nesta tecnologia a maior parte dos fabricantes de eletrodomésticos, de áudio e de vídeo, empresas distribuidoras de eletricidade, água, gás, operadoras de telecomunicações, enfim fabricantes de equipamentos elétricos e eletrônicos.

O conceito base foi criar um protocolo aberto que permitisse atender as necessidades de conectividade dos produtos de todos os fabricantes, utilidades e fornecedores de serviços.

Portanto o objetivo principal do EHS é o de atender a automação residencial, para aqueles proprietários que não podem se permitir o uso de sistemas mais sofisticados devido aos custos envolvidos.

O EHS vem atender, com funções e objetivos, o mercado que tem o CEbus nos Estados Unidos da América e o HBS no Japão, outros sistemas de automação residencial.

A EHSA (European Home System Association) impulsionou o desenvolvimento de um circuito integrado (St7537HS1) que permitisse transmitir dados por um canal série de modo assíncrono através da rede de baixa tensão das residências (correntes portadoras).

Esta tecnologia, baseada na modulação FSK (Frequency Shift Keying), suporta velocidade de 2400 bps e que também podem utilizar como suporte do sinal cabos de pares do tipo telefônicos.

Atualmente, tem-se utilizado ou desenvolvido os seguintes meios físicos:

- PL-2400: Rede elétrica a 2400 bps;

- TP0: Cabo de 2 pares a 4800 bps (idêntico ao meio físico do Batibus);

- TP1: Cabo de 2 pares/coaxial a 9600 bps;

- TP2: Cabo a 2 pares a $64 \mathrm{Kbps}$;

- IR-1200: Infravermelho a 1200 bps;

- RF-1100: Rádiofreqüência a 1100 bps.

O protocolo é totalmente aberto, isto é, qualquer fabricante associado da EHSA pode desenvolver seus produtos e equipamentos que implementem o EHS. 
Assumindo uma filosofia Plug\&Play, pretende-se:

- compatibilidade total entre produtos e equipamentos EHS;

- configuração automática dos dispositivos (Plug\&Play) e fácil ampliação das instalações;

- compartilhar o mesmo meio físico entre diferentes aplicações sem interferência entre os mesmos;

Assim como as tecnologias Batibus, CEbus e HBS a tecnologia EHS enquadra-se no nível 3 da classificação da automação residencial, pois possibilita a integração total dos sistemas a serem automatizados.

Também é preciso considerar para a tecnologia EHS que os equipamentos necessitam estar preparados cada qual com tais tecnologias e a interoperabilidade entre elas torna-se um desafio a ser enfrentado.

\subsubsection{Tecnologia KONNEX}

E se pensando na interoperabilidade entre diferentes tecnologias, três das associações européias mencionadas anteriormente, (EIBA, $B C l, E H S A)$ promoveram a iniciativa da criação de um único padrão europeu para a automação residencial e predial.

Esta convergência de tecnologia denominada KONNEX visa também de que seja capaz competir em qualidade, prestações de serviço e preços, com outros sistemas como o Lonworks ou o CEbus.

Atualmente a associação KONNEX detém as especificações do novo padrão o qual será compatível com os produtos EIB instalados. O padrão está aprovado na norma européia EN 50090 - EN 13321-1 e universalmente na ISO/IEC 14543.

Pode-se afirmar que o novo padrão (standard) terá o melhor do $E I B$, do $E H S$ e do Batibus e que aumentará consideravelmente a oferta de produtos para o mercado residencial.

A versão standard contempla três modos de funcionamento e que também poderiam ser comparados à classificação da automação residencial:

- S-mode (System mode): a configuração do modo sistema usa a mesma filosofia que o EIB atual, isto é, os diversos dispositivos ou modos da nova instalação, 
são instalados e configurados por profissionais especialistas com a ajuda de um software (ETS® 3 Professional) especialmente concebido para este propósito;

- E-mode (Easy mode): na configuração do modo simples os dispositivos são préprogramados em fábrica para realizar determinadas funções. Mesmo assim devem ser configurados alguns detalhes no local da instalação mediante o uso de um controlador ou micro-interruptores alojados nos dispositivos (semelhante ao X10). Também pode ser utilizado software com versão simplificada (ETS 3 Starter) para realização do planejamento e configuração do sistema;

- A-mode: (Automatic mode): na configuração do modo automático, com uma filosofia Plug\&Play, nem o instalador nem o usuário final necessitam configurar o dispositivo. Este modo será especialmente indicado para ser utilizado em eletrodomésticos e equipamentos de entretenimento. Planeja-se em próxima versão do software ETS ao menos ler os endereços escolhidos e realizar se necessário alguma configuração.

Referente ao meio físico o novo padrão (standard) poderá funcionar sobre:

- Par de condutores (TP0): aproveitando a norma Batibus equivalente;

- Par de condutores (TP1): aproveitando a norma EIB equivalente;

- Por meio da rede elétrica (PL100): aproveitando a norma EIB equivalente;

- Por meio da rede elétrica (PL132): aproveitando a norma EHS equivalente;

- Ethernet: aproveitando a norma "KNXnet/IP" equivalente;

- Radiofreqüência: este meio de comunicação, foi desenvolvido diretamente dentro da estrutura do padrão KNX.

Comparativamente pode-se verificar que a tecnologia KONNEX, devido a abrangência de seus objetivos, é classificada segundo os preceitos da HAA (Home Automation Association), como nível 1, 2 ou 3, sendo possível escolher qual a melhor ou mais adequada aplicação.

Sendo assim pode-se verificar que os conceitos desta última tecnologia (sintetizando três modos de operação), causam diante da necessidade de se atacar nichos do mercado de automação residencial a fim de combater o "abismo", mencionado no capítulo 1 deste trabalho de pesquisa, uma solução tecnologicamente inteligente e apropriada que poderá contribuir para a popularização da área do conhecimento e conseqüente aquecimento do mercado de automação residencial. 
Quanto mais fácil e flexível for a maneira de executar a instalação, e mais abrangente sua utilização, maior é a tendência de surgir novas implementações de tecnologias para automação residencial.

\subsubsection{Tecnonogia My Home}

Outra tecnologia que pode ser citada como tendência, pois está em seu início de implantação no Brasil, é um sistema de integração de comandos denominado My Home da empresa Bticino, que permite ao usuário controlar, a iluminação, a climatização e o sistema de comunicação ou segurança das residências, escritórios e consultórios.

My Home é um sistema modular que pode funcionar com um, dois, ou mais dispositivos instalados até a integração total dos comandos. O sistema permite a programação da ambientação luminosa, adaptando a iluminação ao desejado. Também pode controlar persianas, movimentar tela de home theater e pode integrar as funções de videofone, telefone, som ambiente e automação.

Por meio dos conectores de rede, pode-se acessar computador, TV e telefone em qualquer ambiente da casa, utilizando o mesmo meio físico (bus de comunicação).

O sistema de alarme permite notificar qualquer tentativa de invasão, além de indicar vazamento de gás, inundações e falta de energia. Alguns comandos do sistema podem ser acessados via celular ou internet.

Os interruptores de comando do My Home são instalados nas placas das linhas Living e Light, da BTicino. O sistema pode ser ajustado a qualquer projeto arquitetônico, novo ou em reforma.

A tecnologia denominada SCS (Simplified Cabling System) utiliza uma topologia de rede em árvore e o princípio de funcionamento similar à tecnologia $E I B$ apresentada. As duas tecnologias por meio de interface podem comunicar-se.

A tecnologia SCS, tem como característica e princípio de funcionamento pontos "inteligentes" distribuídos por toda a instalação que se comunicam por meio de uma rede física própria de comunicação e que também serve de alimentação aos dispositivos. 
A figura 2.28 ilustra um exemplo de utilização da tecnologia SCS.

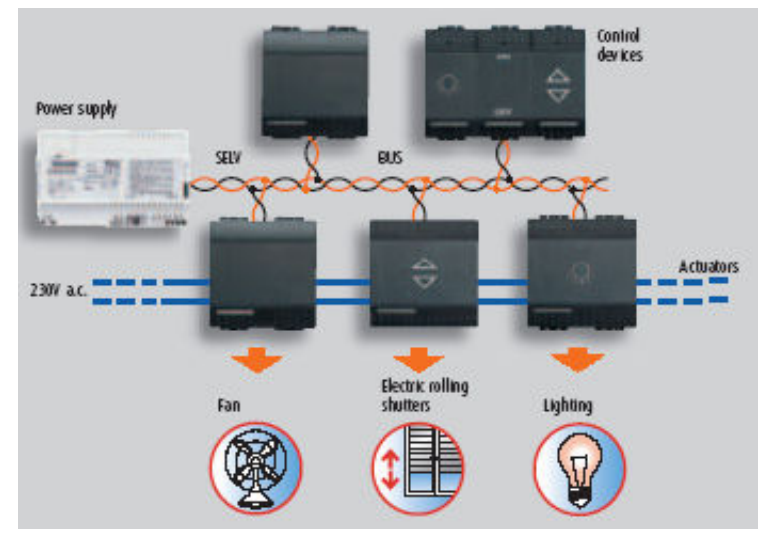

Fig. 2.28 - Topologia de rede distribuída SCS - Fonte : Catálogo BTcino (2005)

As principais diferenças entre a tecnologia SCS e a EIB são:

- a tecnologia EIB permite realizar a integração total entre os dispositivos de acionamento incluindo áudio, vídeo e telefonia, porém utilizando interfaces e os meios físicos de cada sistema, independentemente;

- a tecnologia SCS permite utilizar o mesmo meio físico para realizar a integração total entre os dispositivos incluindo áudio, vídeo e telefonia;

- enquanto para realizar a programação na tecnologia EIB é necessário a utilização de software específico, a SCS realiza a programação por meio da conexão dos denominados configuradores. Característica similar a tecnologia KONNEX, no modo de funcionamento E-mode (Easy mode).

A figura 2.29 demonstra um exemplo da instalação de um dispositivo sendo configurado.

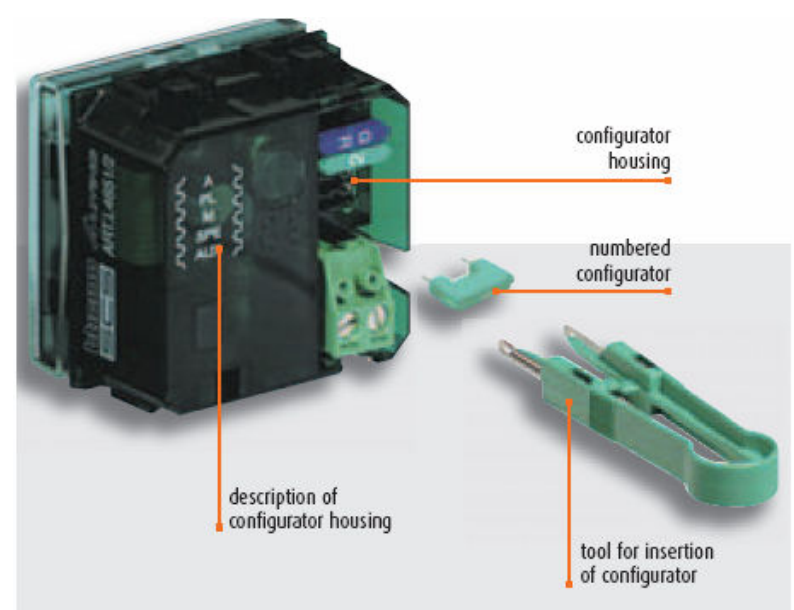

Fig. 2.29 - Exemplo de configuração de dispositivo SCS - Fonte: Catálogo BTcino (2005) 
Uma vez configurado o sistema a comunicação se realiza por meio físico e utilizando o protocolo SCS. A figura 2.28 ilustra o sensor enviando a informação pela rede de comunicação (BUS) até que o atuador devidamente configurado identifica a informação e realiza o acionamento desejado.

A figura 2.30 ilustra o processo de comunicação entre os dispositivos.

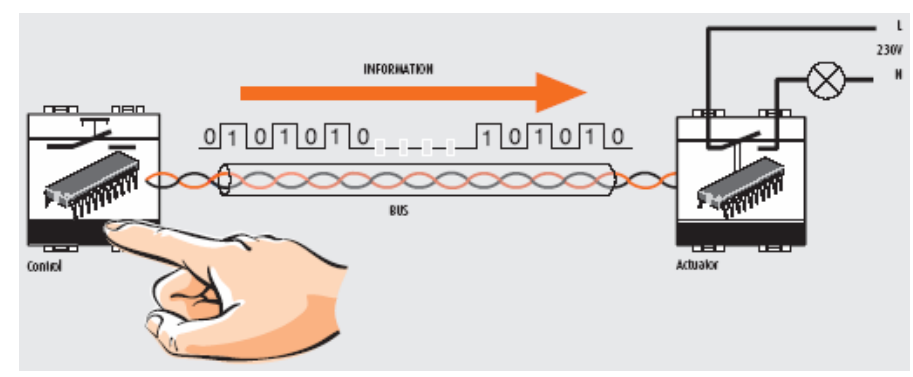

Fig. 2.30 - Princípio de comunicação entre dispositivos SCS - Fonte: Catálogo BTcino (2005)

Diferentemente das últimas tecnologias apresentadas como tendências e com o protocolo aberto de comunicação, este sistema tem o protocolo SCS de comunicação proprietário, ou seja, somente a Bticino pode utilizar, porém, por meio de interface comunica-se com o protocolo EIB.

Contudo, tanto o sistema Instabus EIB quanto o sistema My Home, permitem a conexão e conseqüentemente monitoração e controle de toda a residência de qualquer parte do mundo por meio da internet, pois seus fabricantes oferecem softwares para tal finalidade.

Portanto, o nível de automação residencial para o sistema My Home, é o nível 3, assim como o instabus EIB, pois permite a integração total entre os equipamentos e dispositivos.

\subsubsection{Quadro Comparativo entre as tecnologias apresentadas}

Após análise do estudo realizado com relação às tecnologias disponíveis no país, podem-se reunir os conceitos por meio de um quadro comparativo entre as tecnologias mais difundidas no país. 
Pode-se, então definir entre as tecnologias estudadas;

- as tecnologias mais utilizadas no país;

- a especialidade necessária para a execução da instalação;

- o nível dos padrões de residências unifamiliares em que se podem encontrar tais tecnologias; e

- seus níveis de automação conforme a classificação apresentada, segundo a HAA. (Home Automation Association).

A referência para a definição dos padrões das residências, foi extraída do Sinduscon-SP - Sindicato da Indústria da Construção Civil do Estado de São Paulo. O sindicato, seguindo orientação normalizada, apresenta os padrões como: baixo, normal e alto. E também calcula o Custo Unitário Básico da construção por padrão CUB (em R $\left.\$ / m^{2}\right)$.

E para cada padrão; por mão de obra, material, administrativo e global.

A norma NBR-12721/2006, tem vários padrões diferentes de construção residencial que são identificados por siglas. Ex.: H8-2N - H significa Habitação, 8 é o número de pavimentos, 2 é o número de dormitórios e $\mathrm{N}$ é o acabamento que nesse caso é Normal.

O CUB utilizado somente como referência do ponto de vista da construção de uma residência convencional foi o R1 - Residência Unifamiliar e com acabamento normal, sem automação residencial. O sindicato considera a instalação elétrica tradicional.

Deve-se enfatizar que o CUB global foi escolhido, como descrito acima, somente como referência para contribuir na definição dos padrões das residências e gerar uma breve ordem de grandeza com relação ao custo de uma construção convencional, ou seja, sem automação residencial.

Vale esclarecer que a norma (NBR-12721), assim como o CUB e outras informações correlacionadas, é utilizada há vários anos pela indústria da construção civil para avaliação e planejamento de seus novos empreendimentos.

E também que a mesma foi atualizada recentemente (2006) onde as mudanças passaram a valer desde fevereiro de 2007 . As tabelas 2.3 e 2.4 mostram os quadros comparativos. 
Tabela 2.3 - Quadro comparativo entre as tecnologias apresentadas I

\begin{tabular}{|c|c|c|c|c|c|c|c|c|c|c|}
\hline & & \multicolumn{3}{|c|}{ Necessidade da Especialidade } & \multicolumn{3}{|c|}{$\begin{array}{l}\text { Onde AR pode ser encontrada. } \\
\text { Padrões Residencias Unifam. }\end{array}$} & \multicolumn{3}{|c|}{$\begin{array}{c}\text { Classifi- } \\
\text { cação }\end{array}$} \\
\hline \multirow[b]{5}{*}{$\begin{array}{l}\text { Tecnologias } \\
\text { Sensores }\end{array}$} & \multirow[t]{3}{*}{ Ref. } & \multicolumn{3}{|c|}{ Segundo Norma técnica NBR 5410:2004 e NR10 } & \multirow{2}{*}{\multicolumn{3}{|c|}{$\begin{array}{l}\text { Segundo Norma técnica 12721/2006 } \\
\text { CUB - Global - R-1 (R\$/m²) }\end{array}$}} & \multicolumn{3}{|c|}{ Níveis AR } \\
\hline & & \multirow{2}{*}{$\begin{array}{l}\text { Usuário } \\
\text { Cliente }\end{array}$} & \multirow{2}{*}{$\begin{array}{l}\text { Instalador } \\
\text { Eletr./Téc. }\end{array}$} & \multirow{3}{*}{\begin{tabular}{|c|} 
Projetista \\
Integr./Espec. \\
\end{tabular}} & & & & 1 & 2 & 3 \\
\hline & & & & & Baixo & Normal & Alto & & & \\
\hline & & & & & 704,42 & 869,25 & 1094,09 & & & \\
\hline & \multicolumn{4}{|l|}{ Tipo } & & & & & & \\
\hline \multirow{3}{*}{ Sensor de Presença } & PIR & & $\mathrm{x}$ & & $x$ & $\mathrm{x}$ & $\mathrm{x}$ & $\mathrm{x}$ & & \\
\hline & $\begin{array}{c}\text { Ultrasô- } \\
\text { nico }\end{array}$ & & $\mathrm{x}$ & & $\mathrm{x}$ & $x$ & $x$ & $\mathrm{x}$ & & \\
\hline & Dual & & $x$ & & $x$ & $x$ & $x$ & $x$ & & \\
\hline Fotocélula & LDR & & $\mathrm{x}$ & & $\mathrm{x}$ & $x$ & $x$ & $\mathrm{x}$ & & \\
\hline \multicolumn{11}{|l|}{ Atuadores } \\
\hline \multirow{2}{*}{$\begin{array}{l}\text { Interruptores de } \\
\text { Impulso ou } \\
\text { Minuteria }\end{array}$} & $\begin{array}{c}\text { Conven- } \\
\text { cional }\end{array}$ & & $\mathrm{x}$ & & $\mathrm{x}$ & $\mathrm{x}$ & $\mathrm{x}$ & $\mathrm{x}$ & & \\
\hline & $\begin{array}{l}\text { "inteli- } \\
\text { gente" }\end{array}$ & & $\mathrm{x}$ & & $\mathrm{x}$ & $\mathrm{x}$ & $\mathrm{x}$ & $\mathrm{x}$ & & \\
\hline \multirow[t]{2}{*}{ Dimerização } & Analó-gica & & $\mathrm{x}$ & & $x$ & $\mathrm{x}$ & $\mathrm{x}$ & $x$ & & \\
\hline & Digital & & $x$ & & $x$ & $x$ & $x$ & $\mathrm{x}$ & & \\
\hline $\begin{array}{l}\text { Automacão de } \\
\text { Cortinas }\end{array}$ & Somfy & & $\mathrm{x}$ & $\mathrm{x}$ & $x$ & $x$ & $x$ & $\mathrm{x}$ & $\mathrm{x}$ & \\
\hline Relés de Impulso & Finder & $x$ & $x$ & & $x$ & $x$ & $x$ & $\mathrm{x}$ & $\mathrm{x}$ & \\
\hline \multicolumn{11}{|l|}{$\begin{array}{l}\text { Sistemas de } \\
\text { lluminação }\end{array}$} \\
\hline \multirow{4}{*}{$\begin{array}{l}\text { Controle de } \\
\text { lluminaçao }\end{array}$} & Lutron & & & $\mathrm{x}$ & & $x$ & $x$ & $\mathrm{x}$ & $\mathrm{x}$ & \\
\hline & $\begin{array}{l}\text { Home- } \\
\text { works }\end{array}$ & & & $\mathrm{NE}^{*}$ & & & $x$ & $x$ & $x$ & \\
\hline & $\begin{array}{l}\text { Home- } \\
\text { serve }\end{array}$ & & & $\mathrm{NE}^{*}$ & & & $x$ & $\mathrm{x}$ & $\mathrm{x}$ & \\
\hline & Radio RA & & & $\mathrm{NE}^{*}$ & & & $x$ & $x$ & $\mathrm{x}$ & \\
\hline \multicolumn{6}{|c|}{$\mathrm{NE}^{*}=$ Não Encontrado Instalado } & \multicolumn{4}{|c|}{ Data Base: Junho 2007} & \\
\hline
\end{tabular}


Tabela 2.4 - Quadro comparativo entre as tecnologias apresentadas II

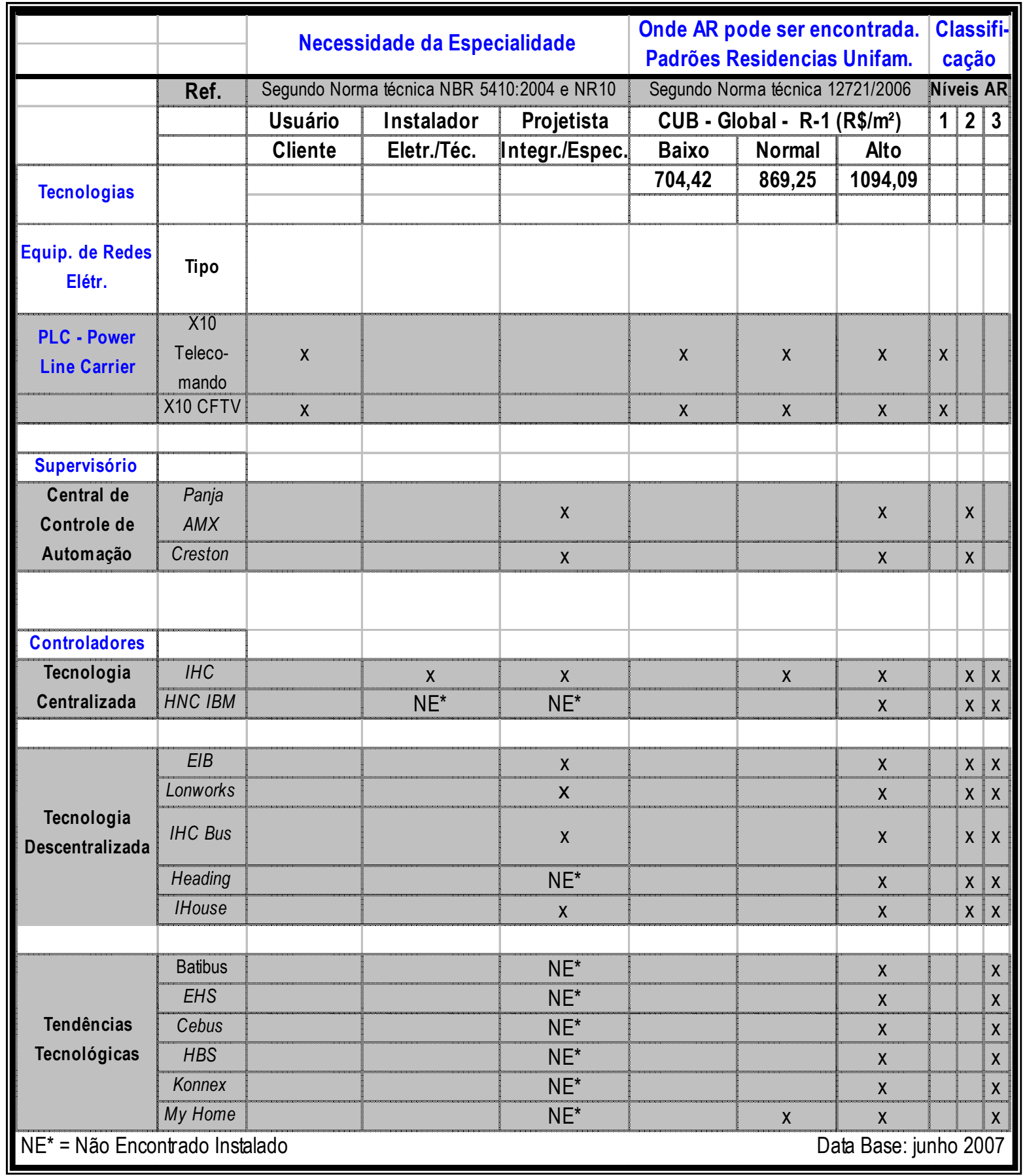

Analisando os quadros comparativos nas tabelas 2.3 e 2.4 verifica-se que, quanto maior o nível tecnológico (nível 3), maior a necessidade de especialistas integradores de AR atuarem no processo de projeto e de execução.

Outra consideração é de que os únicos que investem na aplicação de um maior nível de tecnologia nas residências ou prédios residenciais, são os padrões 
definidos como alto, pelo Sinduscon. Existem raras exceções, pois atualmente começam a aparecer algumas alternativas com custos menores e que por serem modulares permitem a aquisição gradativa.

Contudo, o que se percebe é de que para algumas tecnologias, e que atenderiam os níveis 1 e 2 de automação residencial, existem fortes evidências de que existem várias oportunidades entre necessidades de usuários e possibilidades existentes, o que aponta para a falta de uma metodologia de auxílio em projetos e implementação da automação residencial.

Portanto, foi com esse propósito que este trabalho de pesquisa apresenta uma metodologia denominada MAEAR - Metodologia para Auxílio da Engenharia em Automação Residencial.

Uma outra análise complementar a se fazer é de que comparando automação predial e residencial o que se verifica é que as características das aplicações residenciais não têm aspectos corporativos e sim particulares ou ainda, individuais, confirmando, sutilmente dessa forma, a principal diferença entre ambas. Ou seja, em uma residência existe a necessidade da customização, ou tornar o ambiente do lar adaptado aos costumes e hábitos particulares de cada usuário ou grupo familiar, diferentemente das necessidades de um edifício comercial, que deverá também ser customizado, porém aos anseios e necessidades corporativos.

Para efeito de comparação com os níveis da automação industrial, cabe citar ainda a possibilidade da existência de situações mesmo de aplicações residenciais ou prediais, que se enquadre em alguns dos respectivos da automação industrial, figura 2.7. Em um condomínio residencial de alto padrão ou comercial, os objetivos dos sistemas de automação que podem ser escolhidos focando melhorar a qualidade de serviços oferecidos, por meio de maior segurança, conforto e economia são atingidos naturalmente e inicialmente em áreas de interesses comuns, para posterior atendimento personalizado. Por exemplo; o sistema de controle de acesso, o sistema de refrigeração dos ambientes, a logística de suprimentos, entre outros.

Apresentados as definições, classificações, tecnologias, e os principais conceitos da automação residencial, por meio das tabelas de sistematização/classificação e outras abordagens correlacionadas, todas a fim de contribuir ao entendimento das características gerais dos sistemas de AR, é apresentado na seqüência a fundamentação teórica e a conceituação da Metodologia para Auxílio da Engenharia em Automação Residencial - MAEAR. 


\section{FUNDAMENTAÇÃO TEÓRICA E APRESENTAÇÃO DA METODOLOGIA MAEAR - METODOLOGIA PARA AUXÍLIO DA ENGENHARIA EM AUTOMAÇÃO RESIDENCIAL}

\subsection{INTRODUÇÃO}

Tradicionalmente o processo de projeto de edificações residenciais com algum nível de automação tem sido realizado de modo geral seguindo um método empírico, ou seja, de acordo com as experiências dos profissionais e integradores de sistemas envolvidos.

Para integrar os processos de projeto e execução é importante desenvolver uma metodologia que represente um procedimento para auxiliar na tomada de decisão. A análise metodológica para a tomada de decisão do processo de projeto contribui na identificação das oportunidades para auxiliar o desenvolvimento de uma solução apropriada.

Um conhecimento das soluções definidas provê um bom ponto de partida para a integração do projeto no processo de execução. A melhoria dos processos de projeto e de execução pode minimizar o desperdício de tempo e auxiliar a correta tomada de decisão por parte dos envolvidos no processo.

A integração entre o processo de projeto e execução depende muito da tradução da comunicação da informação do projeto na informação da execução. $\mathrm{O}$ correto fluxo de informação é uma das chaves do sucesso da integração dos dois processos.

Na maioria dos casos a transição de projeto para execução envolve uma troca de responsabilidades entre os envolvidos. Com a MAEAR é possível avaliar as escolhas realizadas e também analisar e estruturar as etapas de implementação do projeto. 


\subsection{FLUXOGRAMA DA METODOLOGIA MAEAR}

A metodologia MAEAR teve origem em estudos realizados a partir de:

- análise de diversos cursos e treinamentos sobre automação residencial e predial praticados no mercado brasileiro;

- entrevista com projetistas e integradores de empresas de pequeno, médio e grande porte que atuam na área de automação predial e residencial;

- análise de trabalhos apresentados em palestras e congressos, visitas técnicas em prédios comerciais e residenciais com algum nível de automação implementada;

- desenvolvimento de trabalhos relacionados em instituições de ensino;

- estudos comparativos em dissertações e pesquisas correlacionadas; e

- $\quad$ estudos de caso para compreensão e validação da metodologia.

A figura 12 ilustra em formato de fluxograma a MAEAR - Metodologia para Auxilio da Engenharia em Automação Residencial. 


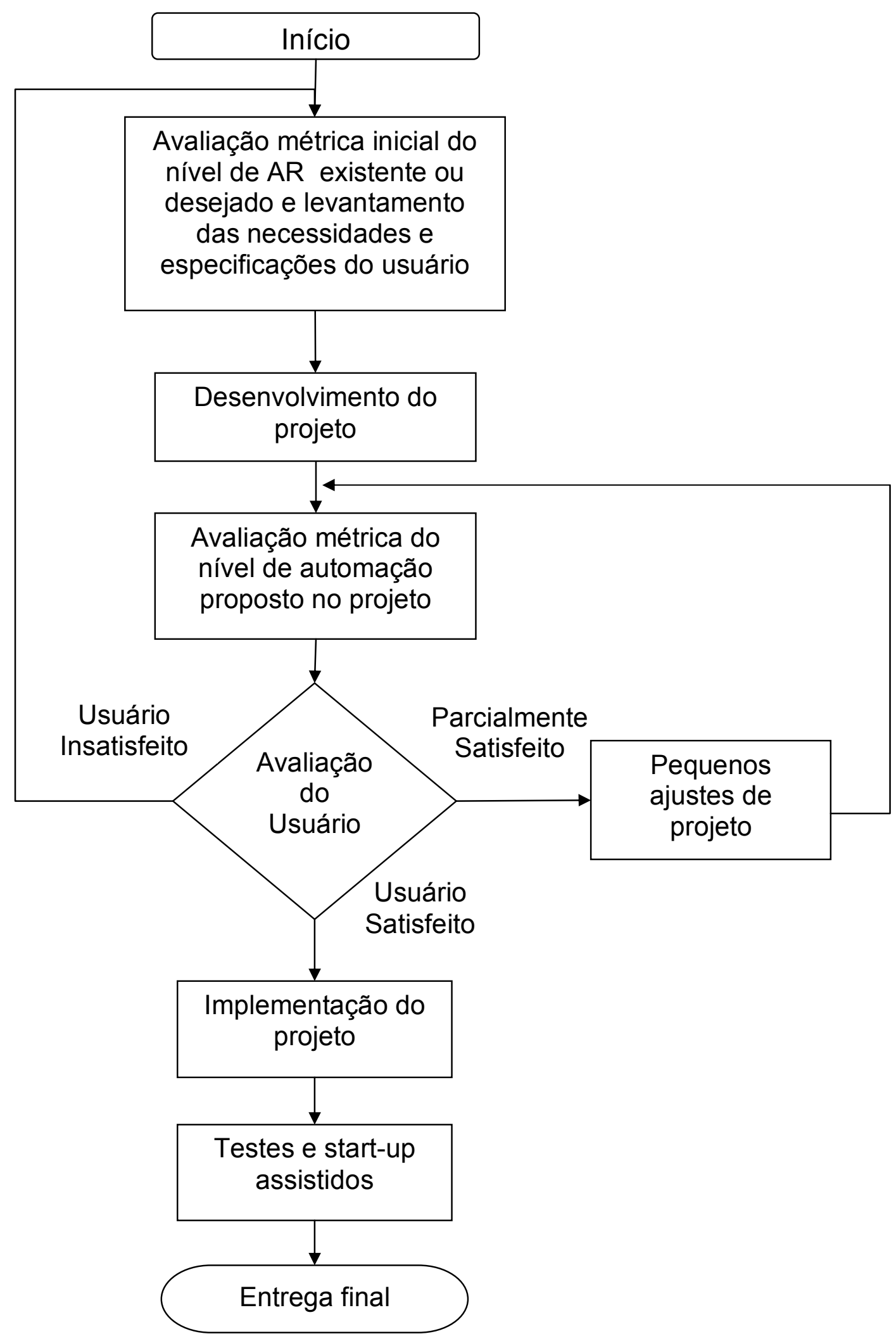

Figura 3.1 - Fluxograma da Metodologia para Auxílio da Engenharia em Automação Residencial - MAEAR 


\subsubsection{Descrição da metodologia MAEAR}

A MAEAR é composta de sete etapas:

a) Realização da avaliação inicial do nível de automação presente no projeto ou na edificação definindo o nível desejado pelo usuário e também de suas reais necessidades presentes e futuras. Nesta etapa é realizada a apresentação dos níveis de automação, a exposição dos conceitos envolvidos e as possibilidades da AR. Conseqüentemente realiza-se uma avaliação métrica inicial do nível de automação/integração presente no projeto ou na edificação. Por meio da avaliação padrão proposta dos níveis de automação versus sistemas de integração (tabela 3.1), podem-se analisar dispositivos, sistemas e os níveis de automação, permitindo assim a análise das definições escolhidas levando ao preenchimento da avaliação personalizada (tabela 3.2);

b) Desenvolvimento do projeto. Nesta etapa conforme entendimento e análise da etapa anterior realizam-se o projeto e o memorial descritivo, desenvolvendo também as previsões e/ou estimativas de custos necessários, bem como os prazos das próximas etapas;

c) Avaliação métrica do nível de automação/integração proposto no projeto. Nesta etapa a avaliação é realizada seguindo a mesma metodologia aplicada na primeira etapa, porém após especificações do projeto. Também nesta etapa, poderão ser analisadas, por meio de estudo comparativo entre outras edificações similares ou não similares, suas avaliações métricas. Esse procedimento pode permitir uma visualização das definições escolhidas no projeto e auxílio na tomada de decisão pelo projetista;

d) Avaliação do usuário. Nesta etapa o cliente avalia e verifica se suas expectativas foram atingidas ou não. Nesta, podem ser realizadas novas considerações em relação ao projeto, podendo gerar pequenas alterações no projeto $\mathrm{e}$ conseqüentemente conduzir a uma nova avaliação métrica;

e) Implementação do projeto. Nesta etapa executa-se o planejado.

f) Testes e start-ups assistidos. Nesta etapa, executa-se a realização de testes e se necessário, treinamento ao usuário;

g) Entrega final com acompanhamento por tempo determinado ou conforme contrato, preestabelecido. 
A metodologia MAEAR tem como proposta, portanto, auxiliar a engenharia em desenvolver projetos de automação residencial. Para melhor compreensão da avaliação métrica proposta na metodologia MAEAR é apresentada na seqüência sua fundamentação teórica.

\subsubsection{Avaliação métrica do nível de automação}

Para determinar, portanto, o grau de integração do sistema de automação, Arkin e Paciuk et al, (1997) apud J. Yang, H. Peng, (2001) propuseram um índice (MSIR) para avaliação e comparação da integração dos sistemas em alguns edifícios comerciais existentes e que podem ser adaptados a edificações residenciais.

A MAEAR emprega o método de avaliação métrica proposto por Arkin e Paciuk et al, (1997) apud J. Yang, H. Peng, (2001). Neste método existem dois índices que são calculados e três valores de referência que são estipulados pelo cliente e pelos integradores.

O primeiro índice $\mathrm{MSI}$ reflete a magnitude do sistema de integração da instalação. O cálculo do mesmo é efetuado segundo a fórmula 1. O segundo índice MSIR reflete o índice normalizado para a medição da integração dos sistemas de serviços na edificação. O cálculo do mesmo é efetuado segundo a fórmula 2.

Onde:

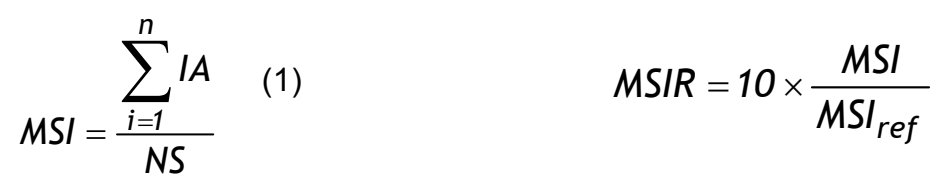

MSI Magnitude do Sistema de Integração;

MSIR Índice para a medição da integração dos sistemas de serviços na edificação;

$\mathrm{MSI}_{\text {ref }}$ Índice de referência para a medição da integração dos sistemas de serviços na edificação. Para adotar esse índice deve-se considerar a realidade nacional; 
NS Número de itens a serem avaliados do sistema de serviço da edificação;

IA Índice de Avaliação - Padrão atribuído para as características dos sistemas de serviços na edificação (ref. tabela 3.1).

A tabela 3.1 é a tabela de referência proposta neste trabalho de pesquisa para o auxílio na avaliação métrica, levantamento de necessidades e tomada de decisão.

Tabela 3.1 - Tabela de referência para avaliação métrica proposta dos níveis de automação versus sistemas de integração

\begin{tabular}{|c|c|c|c|}
\hline $\begin{array}{l}\text { Nível de } \\
\text { Automação }\end{array}$ & Tipo de Integração & Atributos e descrição & $\begin{array}{l}\text { Índice de } \\
\text { Avaliação } \\
\quad \text { (IA) }\end{array}$ \\
\hline \multirow{4}{*}{1} & \multirow{4}{*}{$\begin{array}{l}\text { Sistemas de } \\
\text { automação elou de } \\
\text { proteção } \\
\text { independentes: } \\
\text { - Sem integração direta }\end{array}$} & $\begin{array}{l}\text { Convencional sem aterramento e sem infra- } \\
\text { estrutura para (antena/telefonia e rede) }\end{array}$ & -2 \\
\hline & & $\begin{array}{l}\text { Convencional com aterramento e com infra- } \\
\text { estrutura para (antena/telefonia e rede) }\end{array}$ & 1 \\
\hline & & Convencional com DR ou IDR & 2 \\
\hline & & Convencional com DR ou IDR e DPS & 3 \\
\hline \multirow{5}{*}{2} & \multirow{5}{*}{$\begin{array}{l}\text { Sistemas integrados, } \\
\text { porém cada sistema } \\
\text { opera de acordo com } \\
\text { sua fabricação: } \\
\\
\text { - Malha Aberta, } \\
\text { Controle Manual ou } \\
\text { Automação } \\
\text { Programada }\end{array}$} & Relés de Impulso & 4 \\
\hline & & $\begin{array}{l}\text { Sensores de presença, Minuterias e/ou } \\
\text { Dimerização }\end{array}$ & 5 \\
\hline & & Automação de Cortinas e/ou Portões & 6 \\
\hline & & Sistema PLC - Power Line Carrier & 7 \\
\hline & & Sistemas de Controle de lluminação & 8 \\
\hline \multirow[b]{2}{*}{3} & \multirow{2}{*}{$\begin{array}{l}\text { Integração total dos } \\
\text { sistemas: } \\
\\
\text { - Controle Manual, } \\
\text { Automação } \\
\text { Programada ou } \\
\text { Automação Total }\end{array}$} & Central de Controle de Automação & 9 \\
\hline & & $\begin{array}{l}\text { Controladores Descentralizados e passíveis de } \\
\text { integração com outros dispositivos }\end{array}$ & 10 \\
\hline
\end{tabular}


Onde:

DR Disjuntor Diferencial Residual

IDR Interruptor Diferencial Residual

DPS Dispositivo de Proteção contra Surtos

IA Índice de Avaliação - Padrão atribuído para as características dos sistemas de serviços na edificação

Nota-se que os níveis de automação propostos na tabela diferem em parte daqueles apresentados e ilustrados na figura 2.8 pela HAA - Home Automation Association.

Trata-se de uma adequação necessária considerando a maioria dos projetos e execuções das instalações elétricas residenciais nacionais.

Foram adicionados ao nível 1 de automação da classificação realizada pela $H A A$, itens de proteção automática e de infra-estrutura, como IDR (Interruptor Diferencial Residual) ou DR (Disjuntor Diferencial Residual), DPS (Dispositivo de Proteção contra Surtos), sistema de aterramento e ainda, planejamento para antena, telefonia e rede de informática.

Apesar de não serem itens conectados a sistemas automáticos de controle, a avaliação métrica propõe a visão de que estes dispositivos e tubulações são indiretamente partes da integração de uma instalação elétrica segura, cômoda e com recursos disponíveis.

Aos Índices de Avaliação (IA's) estabelecidos, foram atribuídos valores de -2 a 10, conforme os níveis de automação e das tecnologias mais disponíveis no Brasil, além da inserção de itens importantes de segurança e de itens básicos de infraestrutura, conforme também as considerações anteriores.

Essas atribuições foram adotadas neste trabalho de pesquisa conceitualmente assim como, no trabalho citado por Arkin e Paciuk et al, (1997) apud J. Yang, H. Peng, (2001)

Portanto, a proposta da avaliação métrica está fundamentada sob alguns aspectos:

- adequação à realidade nacional da definição do nível 1 de automação residencial apresentada pela $H A A$. Este é o nível que se aplicam equipamentos individuais ou subsistemas que provêem funções independentes que não se relacionam diretamente com outros equipamentos ou subsistemas; 
- confronto com as normas vigentes nacionais, que impõe por questões de segurança, a instalação de dispositivos como o IDR e o DPS;

- necessidade e importância do planejamento de uma infra-estrutura mínima distribuindo pontos de acesso necessários para uma residência nos dias atuais;

- condições econômicas e culturais sobre o investimento em projetos e execuções das instalações elétricas e possibilidades da AR;

- determinação de índices de magnitude do sistema de integração da instalação, segundo método científico; e

- possibilidade de comparação dos índices de magnitude entre edificações similares ou não similares para auxílio na tomada de decisão.

Ao somar os Índices de Avaliação (IA's) e dividir pelo número de sistemas avaliados (NS), ou por um número fixo, que pode ser estabelecido como um mínimo aceitável de itens em uma residência, determina-se a Magnitude do Sistema de Integração (MSI), conforme Equação (1).

No caso de haver diversos sistemas similares na edificação, cada qual com um equivalente índice de avaliação para a integração, deve-se ponderar um valor de 0 a $100 \%$ do índice de avaliação. Por exemplo: se houver um sistema de controle por presença de parte da iluminação em uma residência e a mesma em algum outro ponto seja acionado por outro sensor de presença independente, deve ser considerado e preferencialmente justificado o valor mais apropriado ao índice de avaliação (IA) e ao número de sistemas avaliados (NS).

Já para o caso de haver diferentes sistemas devem ser considerados e aplicados a Equação (1), devendo-se também ponderar os índices escolhidos.

Os valores obtidos utilizando a Equação (1) e aplicados na Equação (2) determinam o MSIR, índice para a medição da integração dos sistemas de serviços na edificação, e podem ser considerados conforme o contexto de cada edificação, como tipo, padrão ou uso.

Por exemplo, ao examinar uma residência construída aproximadamente há 30 anos, mas que passou por reforma recentemente, obtiveram-se, após avaliação, os resultados apresentados na tabela 3.2.

Note que o índice de referência para a medição da integração dos sistemas de serviços na edificação $\left(\mathrm{MSI}_{\text {ref }}\right)$ foi adotado em 5 , pois trata-se de um índice médio considerado neste trabalho como coerente conforme embasamento da própria pesquisa realizada. 
Tabela 3.2 - Tabela resumo para determinar a magnitude e o índice de integração em edificações residenciais.

\section{Itens Descrição ou Comentários/Justificativa}

IA

Na mesma não havia sistema de aterramento e nem infra-estrutura para dados, mas foi instalada na parte reformada da mesma.

Na mesma não havia DR ou IDR, mas foi instalado na parte reformada da residência.

3 Na mesma não havia DPS, mas foi instalado após a reforma. residência, podendo ser acionado de três ou mais pontos distintos.

Foi instalado após reforma um sensor de presença com fotoelétrico em uma
determinada parte da residência. NS

S

Aplicando a Equação (1) MSI 2,6

Considerando as condições nacionais brasileiras, MSI Ref 5

Aplicando a Equação (2)

MSIR

5,2

Portanto, analisando o exemplo estudado, conclui-se que existe a possibilidade em se adotar a instalação de um sistema considerado integrado, ou ao menos com um nível mínimo de dispositivos "inteligentes" e/ou recursos, para uma edificação residencial.

É importante esclarecer novamente que no caso estudado foi atribuído um MSI ref. = 5 e um NS = 5, onde $M S I$ ref. é o índice para a medição da integração dos sistemas de serviços na edificação de referência, (considerando a realidade nacional), e NS é o número de itens a serem avaliados do sistema de serviço da edificação (considerado 5 itens).

Pode-se notar também que para o item 2 foi atribuído um IA = 1, (poderia ser até 2 , conforme tabela 3.1), mas a justificativa apresentada na tabela 3.2 mostra que o dispositivo IDR foi instalado somente em parte da residência. Já no item 5 , o valor atribuído foi $I A=4$, (poderia ser até 5, conforme tabela 3.1), pois apesar da instalação de sensor de presença com fotoelétrico, existe oportunidade em outra parte da residência. 
Assim sendo, a residência estudada, mesmo com 30 anos de construção foi avaliada, segundo os critérios apresentados, e obteve 5,2 pontos no índice normalizado para a medição da integração dos sistemas de serviços na edificação, (MSIR), ou seja, acima 0,2 pontos da atribuída à $\mathrm{MSI}$ ref., o que se pode considerar como uma boa média aos padrões estudados.

Embora para a realização da avaliação métrica do nível de automação residencial e da atribuição de valores aos índices de avaliação (IA's), possa ser considerada uma aproximação simplificada para quantificar um sistema de integração, a mesma pode ser utilizada para desenvolver um índice que retrata a magnitude desses sistemas de integração (MSI), que pode ser uma estratégia de comparação entre várias residências.

Mesmo que haja algum questionamento nas atribuições aos índices sugeridos, como no exemplo apresentado, se forem utilizados os mesmos critérios pelos profissionais para as escolhas em todos os casos estudados e desenvolvidos permitirá a realização de um quadro comparativo que pode auxiliar na visualização e definição do sistema mais apropriado.

Contudo, cabe ainda salientar que o enfoque considerado no estudo apresentado para definição do índice de medição da integração, está delimitado em partes do sistema elétrico, podendo ser desenvolvido similarmente o mesmo método em outros sistemas como, por exemplo, de segurança ou daqueles que podem contribuir ao meio ambiente, como sistema com coletores solares para aquecimento da água, ou outros sistemas, como o de aproveitamento das águas pluviais. 


\section{APLICAÇÃO DA METODOLOGIA MAEAR - METODOLOGIA PARA AUXÍLIO DA ENGENHARIA EM AUTOMAÇÃO RESIDENCIAL}

\subsection{INTRODUÇÃO}

Conforme apresentado anteriormente o conceito de uma edificação inteligente não significa somente ser sofisticada e repleta de alta tecnologia. A tomada de decisão adequada apoiada nas reais necessidades dos usuários e nas possibilidades tecnológicas existentes são as metas para edificações com este propósito.

Assim sendo, este capítulo apresenta um estudo comparativo, por meio do uso da ferramenta de engenharia para auxílio na tomada de decisão, intitulada MAEAR - Metodologia para Auxílio da Engenharia em Automação Residencial, servindo também como princípio do processo de validação da mesma.

A metodologia pesquisa-ação utilizada baseia-se na investigação cooperativa entre cliente e pesquisador para os casos em que houve a aplicação da MAEAR e na investigação participativa para os casos em que houve visita técnica ou estudo para ampliação do conhecimento de conceitos e das possibilidades tecnológicas.

A pesquisa-ação é caracterizada como um método de investigação de natureza qualitativa que procura resolver problemas específicos, dentro de um grupo ou organização, Peralta apud Gil (2002).

\subsection{CONSIDERAÇÕES INICIAIS}

Um processo genérico de AR pode ser efetuado segundo três seqüências distintas. A figura 4.1 ilustra as possibilidades. 


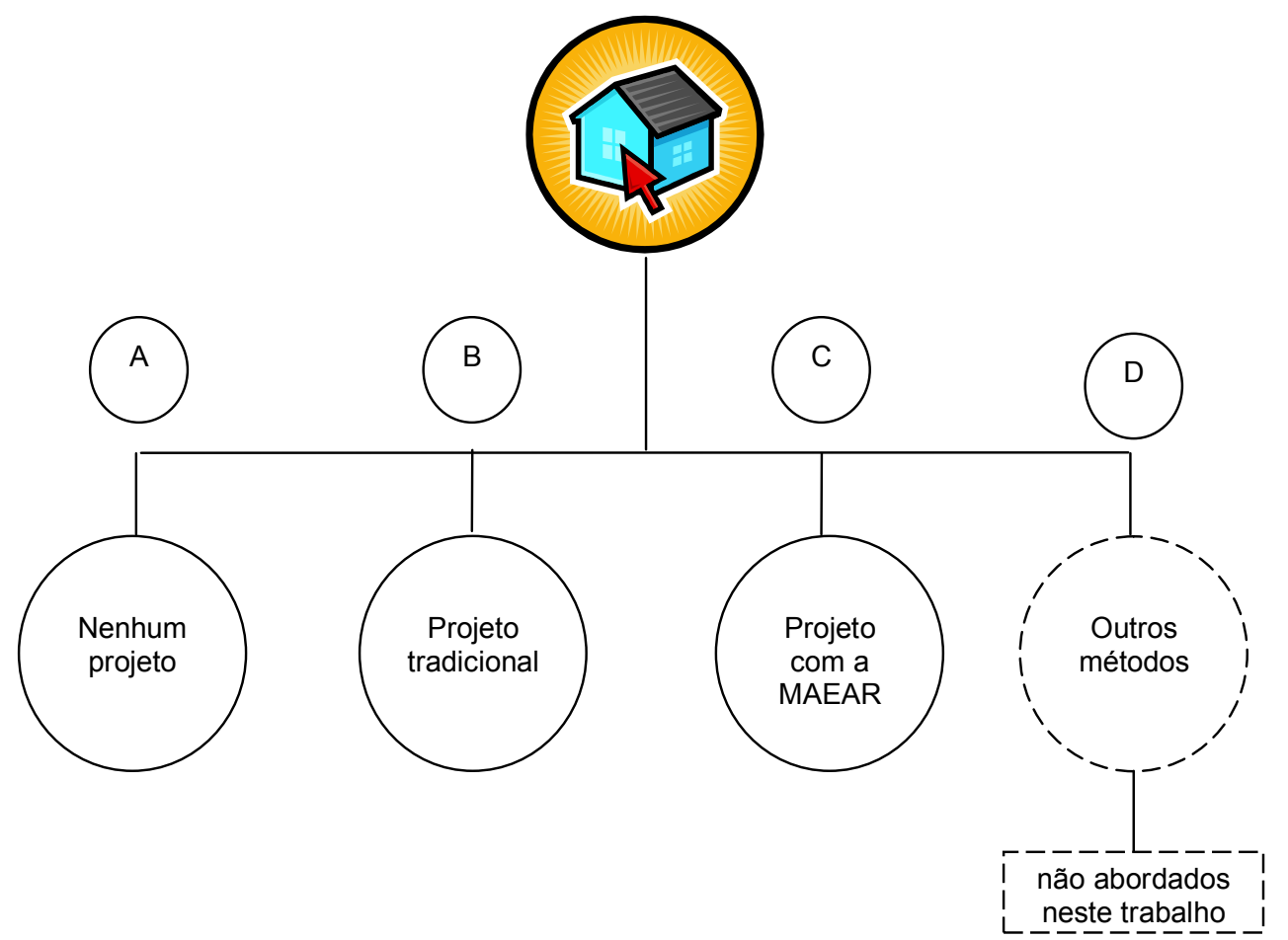

Figura 4.1 - Possibilidades de metodologia para a implantação de projetos residenciais com AR

Entre os caminhos A e B e A e C não há como efetuar comparações em relação ao emprego de alguma metodologia. Entretanto, entre os caminhos $\mathrm{B}$ e $\mathrm{C}$ é que este trabalho se propõe a demonstrar a eficiência da metodologia MAEAR.

O processo de decisão do consumidor depende de diversos fatores dos quais muitos não fazem parte do objeto de estudo deste trabalho.

Contudo, partindo-se das expectativas iniciais do consumidor os objetivos da AR somente serão plenamente atingidos quando o produto final atender as expectativas de desempenho desejadas inicialmente pelo próprio consumidor aliadas a critérios de eficiência e também de custo.

Geralmente o consumidor é leigo com relação às possibilidades e também aos níveis de investimento necessários para implantação de AR.

É claro que o mesmo pode ou não ter suas expectativas atendidas ou ter um alto grau satisfação quer o processo de efetivação do projeto siga o caminho B ou C.

Entretanto, uma metodologia como a MAEAR que inclui nas suas etapas métodos científicos de sistematização, informação e identificação das reais necessidades do cliente certamente contribuirá para evitar retrabalho e desperdícios difíceis de serem previstos. 
Assim sendo, não é plenamente possível fazer uma comparação quantitativa entre os caminhos B e C porque os mesmos são mutuamente excludentes para cada caso.

E não se podem comparar casos distintos porque os consumidores e também residências são distintas.

Contudo, este trabalho propõe como continuação da pesquisa que se faça um estudo com vários grupos sociais de diferentes regiões e rendas para que se possa obter uma média relativa que reflita com razoável grau de acerto uma comparação quantitativa entre $\mathrm{B}$ e $\mathrm{C}$.

Assim sendo, nesta fase do trabalho os estudos e pesquisas são focados no emprego da MAEAR - Metodologia para Auxílio da Engenharia em Automação Residencial.

\subsection{ESTUDOS REALIZADOS PARA VALIDAÇÃO DA MAEAR}

Para validação da metodologia MAEAR foram realizados estudos de caso. Ao todo foi objeto de estudo sete residências e um showroom (Projeto Conectar), sendo que quatro foram visitas técnicas, um estudo técnico e três implementações de projetos utilizando a metodologia MAEAR.

As residências que fizeram parte do estudo são apresentadas de forma não cronológica na tabela 4.1. 
Tabela 4.1 - Tabela de relação das residências que serviram de objeto de estudo

\begin{tabular}{|c|c|c|c|c|c|c|c|}
\hline \multirow{3}{*}{$\begin{array}{l}\text { Residências } \\
\text { Unifamiliares }\end{array}$} & \multicolumn{4}{|c|}{ Caracterização Geral } & \multicolumn{3}{|c|}{ Método de pesquisa } \\
\hline & \multicolumn{3}{|c|}{$\begin{array}{l}\text { Padrão segundo } \\
\text { Norma Técnica } \\
12721 / 2006\end{array}$} & $\begin{array}{l}\text { Área } \\
\text { Cons- } \\
\text { truída } \\
\left(\mathrm{m}^{2}\right)\end{array}$ & \multirow[t]{2}{*}{$\begin{array}{l}\text { Estudo } \\
\text { Técnico }\end{array}$} & \multirow[t]{2}{*}{$\begin{array}{l}\text { Visita } \\
\text { Técnica }\end{array}$} & \multirow[t]{2}{*}{$\begin{array}{c}\text { Implantação } \\
\text { de Projeto } \\
\text { com a } \\
\text { MAEAR }\end{array}$} \\
\hline & Baixo & Normal & Alto & & & & \\
\hline $\begin{array}{l}\text { 1.Casa Autônoma em } \\
\text { Brasília. Edificação n } 1 .\end{array}$ & & & $x$ & 320 & $x$ & & \\
\hline $\begin{array}{l}\text { 2.Casa Habitar } 2002 \text { na } \\
\text { Zona Norte de São Paulo. } \\
\text { Edif. } n^{\circ} 2\end{array}$ & & & $x$ & 300 & & $x$ & \\
\hline $\begin{array}{l}\text { 3.Projeto Conectar na } \\
\text { Zona Oeste de São } \\
\text { Paulo.Edif. } n^{\circ} 3\end{array}$ & & & $x$ & NA & & $x$ & \\
\hline $\begin{array}{l}\text { 4. Edificação na Zona } \\
\text { Norte de São Paulo. Edif. } \\
n^{\circ} 4\end{array}$ & & $\mathrm{x}$ & & 240 & & $x$ & \\
\hline $\begin{array}{l}\text { 5. Apartamento } \\
\text { Residencial de Alto } \\
\text { Padrão no Itaim Bibi em } \\
\text { São Paulo. Edif. } n^{\circ} 5\end{array}$ & & & $x$ & 220 & & $x$ & \\
\hline $\begin{array}{l}\text { 6. Edificação em Conjunto } \\
\text { Habitacional Jd.Giovana } \\
\text { em Guarulhos - São Paulo } \\
-\mathrm{n}^{\circ} 6\end{array}$ & & $x$ & & 128 & & & $x$ \\
\hline $\begin{array}{l}\text { 7. Edificação na Zona } \\
\text { Leste de São Paulo - } \\
\text { Parque Santa Rita - Edif. } \\
n^{\circ} 7\end{array}$ & & $x$ & & 120 & & & $x$ \\
\hline $\begin{array}{l}\text { 8. Edificação na Zona } \\
\text { Leste de São Paulo - São } \\
\text { Miguel Pta - Edif. nº } 8\end{array}$ & & $x$ & & 120 & & & $x$ \\
\hline NA = Não se Aplica & & & & & & & \\
\hline
\end{tabular}


Pelo exposto, para demonstração da aplicação da metodologia MAEAR proposta neste trabalho será apresentado na seqüência o estudo realizado na residência $n^{\circ} 6$, intitulada Edificação 6.

Essa escolha se deve pelo fato de que neste estudo poderão ser verificadas todas as etapas da implantação de um projeto considerando a utilização da metodologia MAEAR em sua totalidade. E que também se tornaria redundante apresentar todos os estudos e aplicações realizados com a ferramenta.

\subsubsection{Considerações iniciais ao projeto por meio da MAEAR}

O estudo partiu da necessidade do desenvolvimento de um projeto elétrico de uma residência localizada no Jardim Giovana, na cidade de Guarulhos no estado de São Paulo - Brasil.

Havia o terreno com aproximadamente $150 \mathrm{~m}^{2}$ e o projeto arquitetônico da edificação, tipo sobrado, com aproximadamente $125 \mathrm{~m}^{2}$ de área construída prevista.

A propósito, deve-se considerar que os proprietários romperam um primeiro paradigma, pois buscaram a contratação de um profissional de projetos da construção civil para realização do projeto arquitetônico.

Em geral não é comum essa consulta aos moradores da região. Fato este constatado por meio de pesquisa informal a outras obras também em fase inicial nas proximidades do empreendimento.

Desta maneira, convenceram-se também, a buscar a orientação de profissional da área da engenharia elétrica, proporcionando a oportunidade de aproveitar tal procedimento para aplicar a metodologia MAEAR - Metodologia para Auxílio da Engenharia em Automação Residencial.

Assim, deve-se salientar a importância da iniciativa dos proprietários, que mesmo sendo de origem simples e dando início a uma obra com padrão normal (segundo o critério do Sinduscon apresentado no capítulo anterior) demonstraram estar dispostos e decididos a serem orientados por profissionais.

Contudo, iniciou-se o processo de esclarecimentos primários e agendamento de reuniões para apresentação da metodologia. 


\subsubsection{Início da aplicação da metodologia MAEAR}

Cumprindo o agendamento citado foram realizadas duas reuniões antes de iniciar efetivamente o projeto.

Conforme apresentado no capitulo 3 , deu-se início à primeira etapa para a aplicação da metodologia, sendo para este caso, a realização da avaliação inicial do nível de automação a fazer parte do projeto, definindo o nível desejado pelo usuário e também de suas reais necessidades presentes e futuras.

Antes ainda da apresentação da metodologia procurou-se em primeiro momento, por meio de questionamento informal e observação, examinar sobre quais eram as reais condições e anseios dos proprietários inicialmente.

A partir das impressões verificadas, apresentou-se a tabela de referência proposta neste trabalho para o auxílio na avaliação métrica, levantamento de

necessidades e tomada de decisão, como forma de resumir as possibilidades e contribuir nas argumentações a respeito da AR.

Para facilitar a apresentação dessa fase do estudo, a tabela 3.1 será reapresentada. 
Tabela 3.1 - Tabela de referência para avaliação métrica proposta dos níveis de automação versus sistemas de integração

\begin{tabular}{|c|c|c|c|}
\hline $\begin{array}{c}\text { Nível de } \\
\text { Automação }\end{array}$ & Tipo de Integração & Atributos e descrição & $\begin{array}{l}\text { Índice de } \\
\text { Avaliação } \\
\text { (IA) }\end{array}$ \\
\hline \multirow{4}{*}{1} & \multirow{4}{*}{$\begin{array}{l}\text { Sistemas de } \\
\text { automação e/ou de } \\
\text { proteção } \\
\text { independentes: } \\
\text { - Sem integração } \\
\text { direta }\end{array}$} & $\begin{array}{l}\text { Convencional sem aterramento e sem infra- } \\
\text { estrutura para (antena/telefonia e rede) }\end{array}$ & -2 \\
\hline & & $\begin{array}{l}\text { Convencional com aterramento e com infra- } \\
\text { estrutura para (antena/telefonia e rede) }\end{array}$ & 1 \\
\hline & & Convencional com DR ou IDR & 2 \\
\hline & & Convencional com DR ou IDR e DPS & 3 \\
\hline \multirow{5}{*}{2} & \multirow{5}{*}{$\begin{array}{l}\text { Sistemas } \\
\text { integrados, porém } \\
\text { cada sistema opera } \\
\text { de acordo com sua } \\
\text { fabricação: } \\
\text { - Malha Aberta, } \\
\text { Controle Manual ou } \\
\text { Automação } \\
\text { Programada }\end{array}$} & Relés de Impulso & 4 \\
\hline & & $\begin{array}{l}\text { Sensores de presença, Minuterias e/ou } \\
\text { Dimerização }\end{array}$ & 5 \\
\hline & & Automação de Cortinas e/ou Portões & 6 \\
\hline & & Sistema PLC - Power Line Carrier & 7 \\
\hline & & Sistemas de Controle de lluminação & 8 \\
\hline \multirow[b]{2}{*}{3} & \multirow{2}{*}{$\begin{array}{l}\text { Integração total dos } \\
\text { sistemas: } \\
\text { - Controle Manual, } \\
\text { Automação } \\
\text { Programada ou } \\
\text { Automação Total }\end{array}$} & Central de Controle de Automação & 9 \\
\hline & & $\begin{array}{l}\text { Controladores Descentralizados e passíveis de } \\
\text { integração com outros dispositivos }\end{array}$ & 10 \\
\hline
\end{tabular}

Por meio da tabela de referência citada foi realizada a apresentação dos níveis de automação, a exposição dos conceitos envolvidos e as possibilidades da AR.

Conseqüentemente realizou-se uma avaliação métrica inicial do nível de automação/integração presente no projeto ou na edificação levando ao preenchimento da avaliação personalizada e apresentada na tabela 4.1. 
Note que, assim como exposto no capítulo 3, o índice de referência para a medição da integração dos sistemas de serviços na edificação ( $\mathrm{MSI}_{\text {ref }}$ ) foi adotado em 5, pois trata-se de um índice médio considerado neste trabalho como coerente conforme embasamento durante a própria pesquisa-ação realizada.

Outro coeficiente adotado foi o NS $=5$, que é o número de itens a serem avaliados do sistema de serviço da edificação. Foram considerados 5 itens conforme também embasamento durante a própria pesquisa-ação realizada.

Outra consideração importante é o fato da utilização do software Microsoft Excel para a determinação dos índices de magnitude, representados nas equações 1 e 2 (Capítulo 3).

A realização da avaliação métrica, por meio do software Microsoft Excel contribuiu para tornar dinâmico e prático a obtenção do índice de magnitude, podendo ser utilizado para qualquer caso.

Apresentado a tabela com todos os conceitos da AR e considerações necessárias, obteve-se, por decisão consensual entre pesquisador e proprietários os resultados apresentados na tabela 4.2 . 
$\stackrel{\infty}{\circ}$

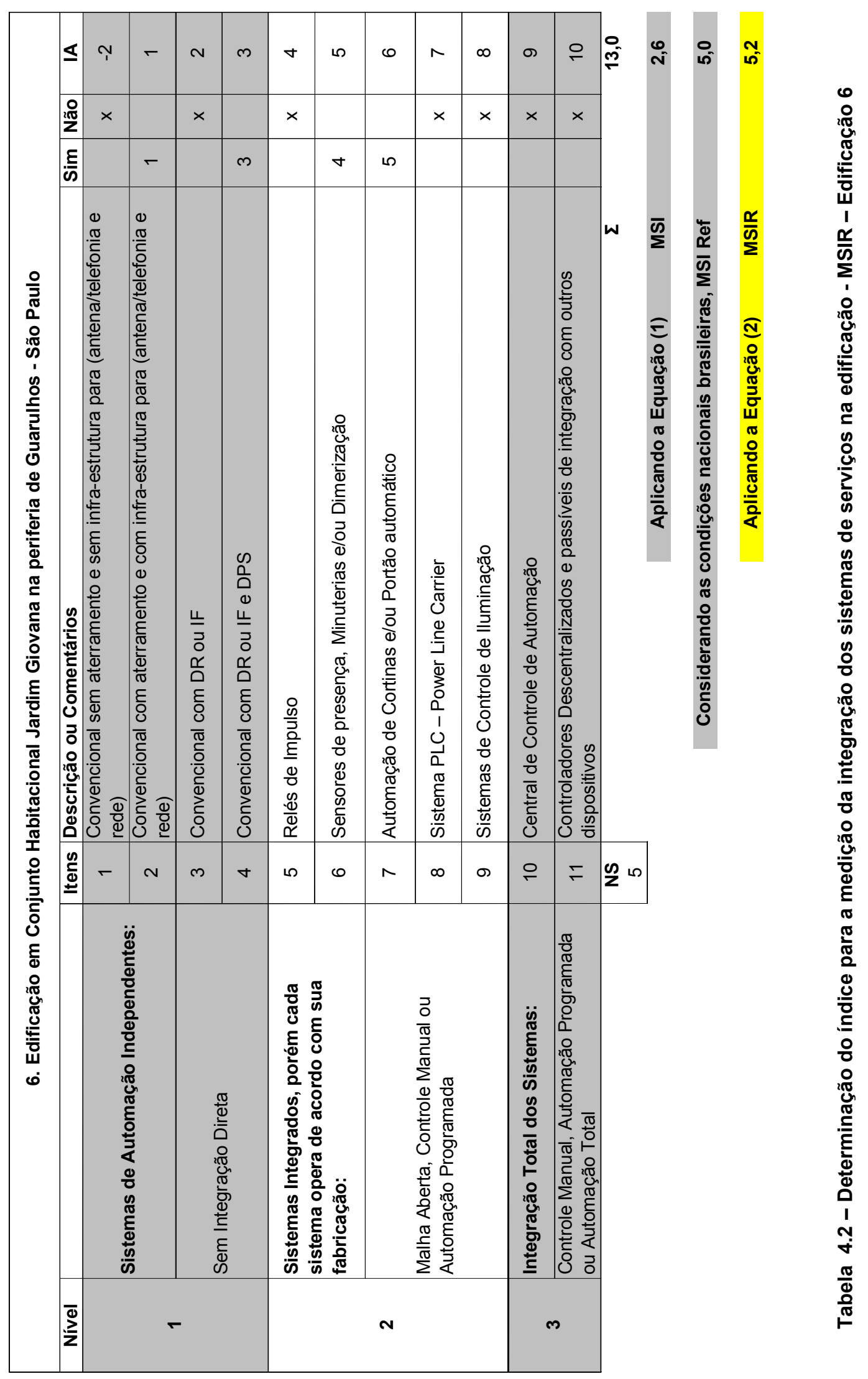


O índice MSIR da Edificação Jd. Giovana como se pode verificar, ficou em 5,2 pontos, ou seja, acima do índice $\mathrm{MSI}_{\text {Ref }}$ - Índice de referência, adotado em 5 pontos.

Para enfatizar, índice esse estabelecido em função das experiências adquiridas durante a pesquisa, da realidade nacional brasileira e da própria proposta do trabalho considerando os níveis de automação adaptados e reapresentados.

Portanto, ficando acima 0,2 pontos do índice de referência $\mathrm{MSI}_{\text {Ref }}$ sugerido. Assim, o índice de 5,2 pode ser considerado excelente em comparação, por exemplo, a outro estudo como a Edificação 8 (tabela 4.15 - apêndice), que foi de 1,2 pontos, ou seja, um índice baixo, demonstrando uma instalação ultrapassada para os dias atuais.

Todavia, se torna evidente de que os custos de investimento são maiores com a adoção dos sistemas escolhidos, e da busca por orientação profissional, mas o retorno em relação à segurança da instalação e o conforto de ter os pontos de acesso necessários nos espaços planejados podendo levar à integração dos sistemas, justificam tal acréscimo.

Fato este constatado também por meio de pesquisa informal (observação de reação) junto aos proprietários da edificação durante todo o desenvolvimento do projeto.

\subsubsection{Introdução ao desenvolvimento do projeto baseado na metodologia MAEAR}

A utilização da primeira etapa da metodologia MAEAR permitiu que tanto projetista quanto proprietário tivesse a oportunidade de enxergar todas as possibilidades tecnológicas versus reais necessidades para aplicar ao desenvolvimento do projeto, assim como, realizar uma avaliação métrica inicial das decisões tomadas.

De posse das decisões anteriores, das quais resumem-se em prever no projeto, os sistemas de automação escolhidos foram:

- convencional com aterramento e com infra-estrutura para (antena/telefonia e rede); 
- convencional com DR ou IF e DPS (para este caso; IF e DPS);

- $\quad$ sensores de presença, minuterias e/ou dimerização (para este caso; sensores de presença inicialmente em dois pontos e dimerização em dois);

- automação de cortinas e/ou portão automático (para este caso; portão automático).

Contudo, deu-se início ao desenvolvimento do projeto. Assim sendo, o projeto a ser desenvolvido deverá estar em acordo com as informações e decisões tomadas por intermédio da MAEAR.

\subsubsection{Desenvolvimento do Projeto - Características gerais}

A intitulada Edificação 6, está distribuída da seguinte maneira:

- $\quad$ Terreno: $149,95 \mathrm{~m}^{2}$

- Pavimento Térreo: $62,24 \mathrm{~m}^{2}$

- $\quad$ Pavimento Superior: $62,24 \mathrm{~m}^{2}$

- $\quad$ Área Total Construída: $128,48 \mathrm{~m}^{2}$

- $\quad$ Área Livre: $87,71 \mathrm{~m}^{2}$

Como abordado anteriormente de posse da planta baixa devidamente planejada sob a ótica da engenharia civil e arquitetônica, deu-se início ao estudo do sistema elétrico considerando o nível 1 e até partes do nível 2 de automação residencial definidas na etapa anterior.

A seguir pode-se ver a planta baixa sem escala para visualização geral. 


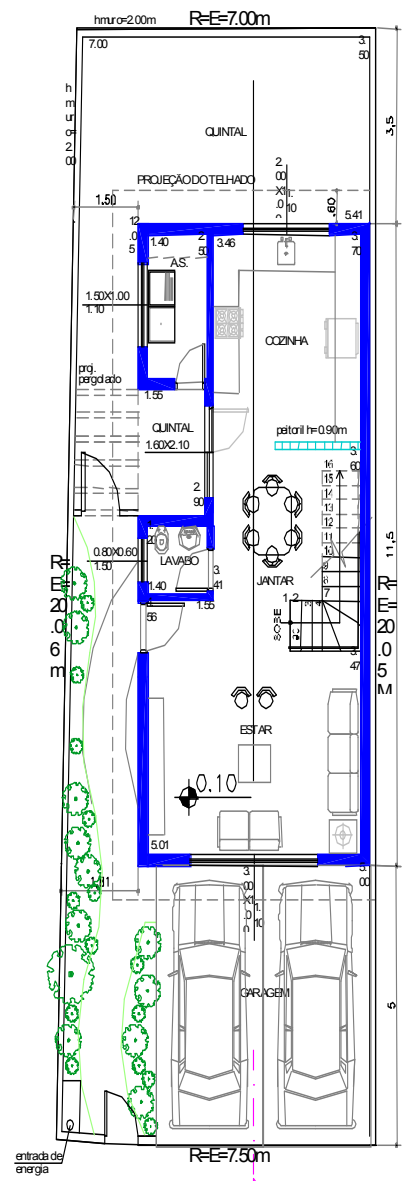

(A)

PAVMENTO

TÉRREO

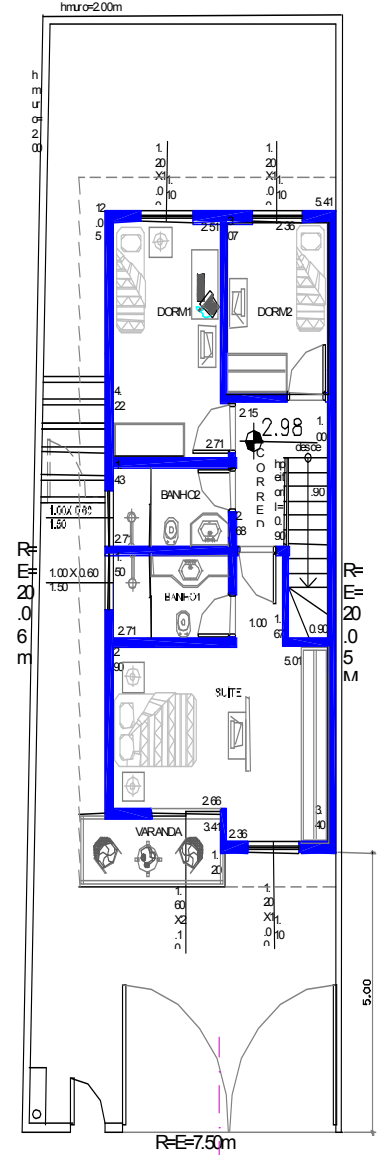

PAMMENTO

SUPEROR

Figura 4.2 - Planta baixa para simples visualização da Edificação 6

Os cômodos estão dispostos e têm suas potências distribuídas de acordo com as tabelas 4.3 a 4.6 , finalizando no dimensionamento da entrada consumidora na tabela 4.7 e 4.8 . 
Tabela 4.3 - Tabela de cargas da Edificação 6 - Pavimento Térreo

\begin{tabular}{|c|c|c|c|c|c|c|c|c|c|c|c|}
\hline \multicolumn{12}{|c|}{ Pavimento Térreo } \\
\hline \multicolumn{2}{|c|}{ Circuito } & \multirow{2}{*}{$\begin{array}{l}\text { Tensão } \\
\text { (V) }\end{array}$} & \multirow[b]{2}{*}{ Local } & \multicolumn{2}{|c|}{ Potência } & \multirow[b]{2}{*}{$\begin{array}{l}\text { Corrente } \\
\text { (A) }\end{array}$} & \multirow[b]{2}{*}{$\begin{array}{l}\mathrm{N}^{\circ} \text { de circ } \\
\text { agrupados }\end{array}$} & \multirow[b]{2}{*}{$\begin{array}{l}\text { Seção dos } \\
\text { Condutores }\end{array}$} & \multicolumn{3}{|c|}{ Proteção } \\
\hline$n^{0}$ & Tipo & & & $\begin{array}{c}\text { Qtde } x \text { Pot } \\
\text { (VA) }\end{array}$ & Total (VA) & & & & Tipo & № de pólos & IN \\
\hline \multirow{7}{*}{1} & \multirow{7}{*}{$\begin{array}{c}\text { llum Social } \\
\text { e de } \\
\text { serviço } \\
\text { Térreo }\end{array}$} & \multirow{7}{*}{127} & Sala de Estar & $1 \times 360$ & 360 & \multirow{7}{*}{8,35} & \multirow{7}{*}{4} & \multirow{7}{*}{1,5} & \multirow{7}{*}{ DTM } & \multirow{7}{*}{1} & \multirow{7}{*}{ B13A } \\
\hline & & & Sala de Jantar & $1 \times 200$ & 200 & & & & & & \\
\hline & & & \begin{tabular}{|l|} 
Cozinha \\
\end{tabular} & $1 \times 200$ & 200 & & & & & & \\
\hline & & & Lavanderia & $1 \times 100$ & 100 & & & & & & \\
\hline & & & Lavabo & $1 \times 100$ & 100 & & & & & & \\
\hline & & & \begin{tabular}{|l} 
Hall de Entrada \\
nat
\end{tabular} & $1 \times 100$ & 100 & & & & & & \\
\hline & & & & Soma & 1060 & & & & & & \\
\hline \multirow{4}{*}{2} & \multirow{4}{*}{$\begin{array}{l}\text { TUG's } \\
\text { Térreo }\end{array}$} & \multirow{4}{*}{127} & Sala de Estar & $5 \times 100$ & 500 & \multirow{4}{*}{14,17} & \multirow{4}{*}{3} & \multirow{4}{*}{2,5} & \multirow{4}{*}{ DTM } & \multirow{4}{*}{1} & \multirow{4}{*}{$\mathrm{B} 20 \mathrm{~A}$} \\
\hline & & & & $1 \times 100$ & 100 & & & & & & \\
\hline & & & \multirow{2}{*}{ Cozinha } & $2 \times 600$ & 1200 & & & & & & \\
\hline & & & & Soma & 1800 & & & & & & \\
\hline \multirow{7}{*}{3} & & & Sala de Estar & $5 \times 100$ & 500 & & & & & & \\
\hline & & & Sala de Jantar & $1 \times 100$ & 100 & & & & & & \\
\hline & & & Cozinha & $1 \times 600$ & 600 & & & & & & \\
\hline & Térreo & 121 & Cozinha & $4 \times 100$ & 400 & 14,17 & 3 & 2,5 & DTM & 1 & B20A \\
\hline & & & \begin{tabular}{|l|} 
Lavabo \\
\end{tabular} & $1 \times 100$ & 100 & & & & & & \\
\hline & & & Hall de Entrada & $1 \times 100$ & 100 & & & & & & \\
\hline & & & & Soma & 1800 & & & & & & \\
\hline & & & & $3 \times 600$ & 1800 & & & & & & \\
\hline 4 & $\begin{array}{l}\text { TUG's } \\
\text { Térreo }\end{array}$ & 127 & Lavanderia & $2 \times 100$ & 200 & 15,75 & 3 & 2,5 & DTM & 1 & $\mathrm{C} 20 \mathrm{~A}$ \\
\hline & & & & Soma & 2000 & & & & & & \\
\hline 5 & TUE & 127 & Microondas & $1 \times 1000$ & 1000 & 7,87 & 2,5 & 6,0 & DTM & 1 & $\mathrm{C} 16 \mathrm{~A}$ \\
\hline 6 & TUE & 220 & Torneira El. & $1 \times 4500$ & 4500 & 20,45 & 4,0 & 4,0 & DTM & 2 & $\mathrm{~B} 30 \mathrm{~A}$ \\
\hline & ribuição & 220 & QD & - & 7903 & 35,92 & 2 & 6,0 & IDR & 4 & $40 \mathrm{~A}$ \\
\hline & & & & & & & & & $\mathrm{N}^{\circ}$ pólos & 10 & \\
\hline
\end{tabular}

Dessa forma, por meio de quadros resumidos, pode-se definir a distribuição e a proteção adequada, conforme a Norma Brasileira NBR 5410:2004 que trata das Instalações Elétricas em Baixa Tensão e de acordo as decisões tomadas com a utilização da metodologia MAEAR.

Vale observar que a tabela 4.3 trata da previsão de cargas do pavimento térreo, sendo sua corrente de demanda calculada em 35,92 A, conforme fatores de potência e de demanda definidos na tabela 4.4. 
Tabela 4.4 - Fatores de Demanda e Potência da Casa Edificação 6 - Pavimento Térreo

\begin{tabular}{|c|c|c|c|c|c|c|}
\hline \multicolumn{7}{|l|}{ Pavimento Térreo } \\
\hline \multicolumn{7}{|c|}{ Fator de Potência } \\
\hline Potência de lluminação em VA & 1060 & 0,8 & 1 & Pot. de llum. em W & 1060 & Potência Demandada (W) \\
\hline \multirow[t]{12}{*}{ Potência TUG's em VA } & 5600 & \multicolumn{2}{|c|}{$\begin{array}{l}\text { Fator de Potência Médic } \\
\qquad 0,9\end{array}$} & Potência TUG's em W & 4480 & \\
\hline & & & & Pot. llum + TUG's & 5540 & 2493 \\
\hline & & \multicolumn{2}{|c|}{ Fatores de Demanda } & & & \\
\hline & & llum.+ Tug's & TUE's & \multirow[t]{2}{*}{ Potência TUE's em W } & 5500 & \multirow[t]{3}{*}{4620} \\
\hline & & 0,45 & 0,84 & & & \\
\hline & & & & \multirow[t]{3}{*}{ Pot. Ativa Total em W } & 11040 & \\
\hline & & & & & Potên & a Total Demandada (W) \\
\hline & & & & & & 7113 \\
\hline & & & & \multicolumn{3}{|c|}{ Potência do Circuto Distribuição(VA) } \\
\hline & & & & \multicolumn{3}{|c|}{7903} \\
\hline & & & & & \multicolumn{2}{|c|}{ Corrente Demandada (A) } \\
\hline & & & & & \multicolumn{2}{|r|}{35.92} \\
\hline
\end{tabular}


Na seqüência é apresentada a tabela 4.5 que descreve a distribuição do pavimento superior.

Tabela 4.5 - Tabela de Cargas da Edificação 6 - Pavimento Superior

\begin{tabular}{|c|c|c|c|c|c|c|c|c|c|c|c|}
\hline \multicolumn{12}{|c|}{ Pavimento Superior } \\
\hline \multicolumn{2}{|c|}{ Circuito } & \multirow[b]{2}{*}{$\begin{array}{c}\text { Tensão } \\
\text { (V) }\end{array}$} & \multirow[b]{2}{*}{ Local } & \multicolumn{2}{|c|}{ Potência } & \multirow[b]{2}{*}{$\begin{array}{l}\text { Corrente } \\
\text { (A) }\end{array}$} & \multirow[b]{2}{*}{$\begin{array}{l}N^{0} \text { de circ } \\
\text { agrupados }\end{array}$} & \multirow[b]{2}{*}{$\begin{array}{l}\text { Seção dos } \\
\text { Condutores }\end{array}$} & \multicolumn{3}{|c|}{ Proteção } \\
\hline$n^{0}$ & Тіро & & & $\begin{array}{c}\text { Qtde } x \\
\text { Pot (VA) }\end{array}$ & $\begin{array}{l}\text { Total } \\
\text { (VA) }\end{array}$ & & & & Tipo & $\begin{array}{l}N^{\circ} \text { de } \\
\text { pólos }\end{array}$ & IN \\
\hline \multirow{9}{*}{6} & \multirow{9}{*}{\begin{tabular}{|l|} 
|lum Social \\
e de serisoo \\
Supprior
\end{tabular}} & \multirow{9}{*}{127} & Quarto Suíte & $1 \times 100$ & 100 & \multirow{9}{*}{6,30} & \multirow{9}{*}{4} & \multirow{9}{*}{1,5} & \multirow{9}{*}{ DTM } & \multirow{9}{*}{1} & \multirow{9}{*}{ B10A } \\
\hline & & & Hall Quarto S. & $1 \times 100$ & 100 & & & & & & \\
\hline & & & Banho 1 & $1 \times 100$ & 100 & & & & & & \\
\hline & & & Corredor & $1 \times 100$ & 100 & & & & & & \\
\hline & & & Banh.2 & $1 \times 100$ & 100 & & & & & & \\
\hline & & & Dormitório 1 & $1 \times 100$ & 100 & & & & & & \\
\hline & & & Dormitório 2 & $1 \times 100$ & 100 & & & & & & \\
\hline & & & Escada & $1 \times 100$ & 100 & & & & & & \\
\hline & & & & Soma & 800 & & & & & & \\
\hline \multirow{4}{*}{7} & \multirow{4}{*}{ Tug's } & \multirow{4}{*}{127} & Quarto Suíte & $6 \times 100$ & 600 & \multirow{4}{*}{14,17} & \multirow{4}{*}{4} & \multirow{4}{*}{2,5} & \multirow{4}{*}{ DTM } & \multirow{4}{*}{1} & \multirow{4}{*}{$\mathrm{B} 20 \mathrm{~A}$} \\
\hline & & & Banh.1 & $1 \times 600$ & 600 & & & & & & \\
\hline & & & Banh.2 & $1 \times 600$ & 600 & & & & & & \\
\hline & & & & Soma & 1800 & & & & & & \\
\hline \multirow{5}{*}{8} & \multirow{5}{*}{ TUG's } & \multirow{5}{*}{127} & Dormitório 1 & $6 \times 100$ & 600 & \multirow{5}{*}{9,45} & & & & & \\
\hline & & & Dormitório 2 & $4 \times 100$ & 400 & & & & & & \\
\hline & & & Corredor & $1 \times 100$ & 100 & & 4 & 2,5 & DTM & 1 & B20A \\
\hline & & & Escada & $1 \times 100$ & 100 & & & & & & \\
\hline & & & & Soma & 1200 & & & & & & \\
\hline 9 & TUE & 220 & Chuveiro 1 & $1 \times 6500$ & 6500 & 29,55 & 1 & 6,0 & DTM & 2 & C35A \\
\hline 10 & TUE & 220 & Chuveiro 2 & $1 \times 7500$ & 7500 & 34,09 & 2 & 6,0 & DTM & 2 & C35A \\
\hline & buição & 220 & $\begin{array}{l}\mathrm{QD} \\
\mathrm{QM}\end{array}$ & - & 10560 & 48,00 & 2 & 10,0 & IDR & 4 & $50 \mathrm{~A} / 30 \mathrm{~mA}$ \\
\hline & & & & & & & & & ${ }^{\circ}$ pólos & 11 & \\
\hline
\end{tabular}


Seguindo o mesmo raciocínio, a tabela 4.6 apresenta fatores de demanda, de potência e respectivamente os cálculos de previsão de cargas do pavimento superior.

Tabela 4.6 - Fatores de Demanda e Potência da Edificação 6 - Pavimento Superior

\begin{tabular}{|c|c|c|c|c|c|c|}
\hline \multicolumn{7}{|l|}{ Pavimento Superior } \\
\hline & \multicolumn{3}{|c|}{ Fator de Potência } & \multirow[b]{2}{*}{ Pot. de llum. em W } & & \\
\hline Potência de lluminação em VA & 800 & 0,8 & 1 & & 800 & Potência Demandada (W) \\
\hline \multirow[t]{13}{*}{ Potência TUG's em VA } & 3000 & \multirow{2}{*}{\multicolumn{2}{|c|}{$\begin{array}{l}\text { Fator de Potência Médio } \\
0,9\end{array}$}} & Potência TUG's em W & 2400 & \\
\hline & & & & & & \\
\hline & & & & Pot. llum + TUG's & 3200 & 1664 \\
\hline & & \multicolumn{2}{|c|}{ Fatores de Demanda } & & & \\
\hline & & Ilum. + Tug's & TUE's & Potência TUE's em W & 14000 & 7840 \\
\hline & & 0,52 & 0,56 & & & \\
\hline & & & & Pot. Ativa Total em W & 17200 & \\
\hline & & & & & Potên & a Total Demandada (W) \\
\hline & & & & & & 9504 \\
\hline & & & & \multicolumn{3}{|c|}{ Potência do Circuto Distribuição(VA) } \\
\hline & & & & \multicolumn{3}{|c|}{10560} \\
\hline & & & & & \multicolumn{2}{|c|}{ Corrente Demandada (A) } \\
\hline & & & & & \multicolumn{2}{|c|}{48,00} \\
\hline
\end{tabular}

Para o dimensionamento da entrada consumidora, a tabela 4.7 apresenta os resultados obtidos.

Tabela 4.7 - Dimensionamento da Entrada Consumidora

\begin{tabular}{|c|c|c|c|c|c|c|c|c|c|c|c|}
\hline \multicolumn{2}{|c|}{ Circuito } & \multirow{2}{*}{$\begin{array}{c}\text { Tensão } \\
(\mathrm{V})\end{array}$} & \multirow[b]{2}{*}{ Local } & \multicolumn{2}{|c|}{ Potência } & \multirow{2}{*}{$\begin{array}{l}\text { Corrente } \\
\text { (A) }\end{array}$} & \multirow{2}{*}{$\begin{array}{l}N^{0} \text { de circ } \\
\text { agrupados }\end{array}$} & \multirow[b]{2}{*}{$\begin{array}{l}\text { Seção dos } \\
\text { Condutores }\end{array}$} & \multicolumn{3}{|c|}{ Proteção } \\
\hline$n^{0}$ & Tipo & & & $\begin{array}{l}\text { Qtde } \\
\text { x Pot }\end{array}$ & $\begin{array}{l}\text { Total } \\
\text { (VA) }\end{array}$ & & & & Tipo & $\begin{array}{l}N^{0} \text { de } \\
\text { pólos }\end{array}$ & IN \\
\hline Dist & uição & 220 & \begin{tabular}{|l|} 
QD \\
QM
\end{tabular} & - & 13022 & 59,19 & 2 & 16,0 & $\begin{array}{l}\text { IDR } \\
\text { DTM }\end{array}$ & 4 & $\begin{array}{c}63 \mathrm{~A} 30 \mathrm{~mA} \\
70 \mathrm{~A}\end{array}$ \\
\hline
\end{tabular}

Onde:

- QD é o Quadro de Distribuição;

- QM é o Quadro de Medição;

- IDR é o Interruptor Diferencial Residual, e;

- DTM é o Disjuntor Termomagnético. 
Para também expor os fatores de demanda e potência utilizados aos pavimentos térreo e superior unificados e conseqüentemente os cálculos de dimensionamento do circuito de distribuição da entrada consumidora, apresenta-se a tabela 4.8 .

Tabela 4.8 - Fatores de Demanda e Potência da Edificação 6 - Dimensionamento da Entrada Consumidora

\begin{tabular}{|c|c|c|c|c|c|c|}
\hline \multicolumn{7}{|c|}{ Pavimento Térreo + Superior } \\
\hline \multicolumn{7}{|c|}{ Fator de Potência } \\
\hline Potência de lluminação em VA & 1860 & 0,8 & 1 & Pot. de llum. em W & 1860 & Jotência Demandada (W) \\
\hline \multirow[t]{12}{*}{ Potência TUG's em VA } & 8600 & \multicolumn{2}{|c|}{$\begin{array}{c}\text { Fator de Potência Médio } \\
0,9\end{array}$} & Potência TUG's em W & 6880 & \\
\hline & & & & Pot. Ilum + TUG's & 8740 & 2360 \\
\hline & & \multicolumn{2}{|c|}{ Fatores de Demanda } & & & \\
\hline & & Ilum.+ Tug's & TUE's & \multirow[t]{2}{*}{ Potência TUE's em W } & 19500 & 9360 \\
\hline & & 0,27 & 0,48 & & & \\
\hline & & & & \multirow[t]{3}{*}{ Pot. Ativa Total em W } & 28240 & \\
\hline & & & & & Potência & Total Demandada (W) \\
\hline & & & & & & 11720 \\
\hline & & & & \multicolumn{3}{|c|}{ Potência do Circuto Distribuição(VA) } \\
\hline & & & & \multicolumn{3}{|c|}{13022} \\
\hline & & & & & \multicolumn{2}{|c|}{ Corrente Demandada (A) } \\
\hline & & & & & \multicolumn{2}{|c|}{59,19} \\
\hline
\end{tabular}

\subsubsection{Avaliação métrica do nível de automação/integração proposto no projeto}

Tendo em vista que durante a execução do projeto aconteceram diversas consultas nas decisões tomadas na etapa anterior e de que também não tenham surgido novas propostas adicionais, não houve alteração do índice de magnitude. 
Portanto, após análise e a consideração mencionada foi dado prosseguimento na metodologia MAEAR, ou seja, a apresentação do projeto aos proprietários para que pudessem avaliar as propostas do projeto.

\subsubsection{Apresentação da proposta de projeto ao usuário para avaliação}

Conforme a metodologia MAEAR, nesta etapa o usuário verifica se suas expectativas estão sendo atendidas, podendo gerar pequenas alterações no projeto e conseqüentemente conduzir a uma nova avaliação métrica.

Porém, neste caso, os usuários demonstraram satisfação em relação às suas expectativas, permitindo dar prosseguimento à próxima etapa.

\subsubsection{Implementação do projeto e considerações}

Assim, após o desenvolvimento de todas as etapas previstas na metodologia MAEAR e dos dimensionamentos apresentados, foi realizada a previsão de toda a distribuição da tubulação necessária em atendimento ao projeto elétrico e de dados.

Desta forma, no que diz respeito ao sistema elétrico de uma edificação inteligente, deve-se acrescentar também, conforme apresentado aos proprietários por meio da MAEAR, a especificação para instalação do Dispositivo de Proteção contra Surtos - DPS, determinação essa exigida desde março de 2005 pela Norma Brasileira NBR 5410/2004.

E fornecer também as devidas orientações sobre a importante instalação do sistema de aterramento adequado para a residência, pois somente uma única haste tradicionalmente exigida por concessionárias pode não ser eficaz para proteger toda instalação contra possíveis surtos.

Para os sistemas de antena, telefone, interfone e rede de informática, denominados neste trabalho, de simplesmente dados, deve-se prever e realizar, também como discutido na metodologia MAEAR, toda a infra-estrutura necessária, assim como definido no índice de avaliação IA da metodologia. 
Isso quer dizer que deve-se atender aos itens discutidos na metodologia MAEAR conforme as decisões tomadas na etapa anterior e definido os pontos de acesso em planta-baixa.

O ideal é realizar no mínimo dois diagramas de infra-estrutura, um para o sistema elétrico e outro para o sistema de dados, até porque os dois sistemas devem ser separados, segundo normas internacionais (Obs.: Não existem normas brasileiras específicas para sistemas de dados, normalmente orienta-se pelas normas internacionais).

A experiência, porém demonstra que mesmo quando existem dois diagramas, a maioria das vezes, não podem ser precisamente seguidos, devido principalmente à impossibilidade de prever em projeto todas as condições físicas para construção, levando a aproximações e condições e/ou situações comum ocorridas em uma construção, como por exemplo, o encontro com vigas, colunas ou outras razões correlacionadas.

A sugestão para este caso é a realização da distribuição das tubulações no próprio local, embasada nas informações do dimensionamento elétrico e dos pontos de acesso de dados definidos anteriormente e obrigatoriamente em conjunto com o responsável da construção civil, e se possível até mesmo com a presença dos proprietários.

Outro fator importante e imprescindível para o sucesso de um projeto, principalmente sob os conceitos discutidos, é de que todos os envolvidos devem respeitar as etapas da construção, buscando esclarecer as informações de status da obra a todos constantemente.

Aliás, a gestão da comunicação entre os envolvidos é um dos fatores bastante significativos. Por exemplo: Imagine iniciar a discussão sobre a infraestrutura, ou seja, a distribuição da tubulação de dados, somente após a construção das lajes estarem terminadas.

Contudo, também vale ressaltar a importância da utilização de tubulações de no mínimo 3/4" de diâmetro, podendo e de preferência adotando tubulações com diâmetros adequados para cada trecho.

Se necessário com diâmetros de, 1",1 e 1/2", 2", etc. E que também sejam resistentes a pressões externas. É comprovado de que economias extremas nesta fase da obra trazem prejuízos futuros. 
Outro fator interessante é o de prever um número, um tamanho e um padrão de qualidade adequado às caixas de passagem, pois a falta de critério nestes itens tem as mesmas características das tubulações, no que diz respeito aos possíveis prejuízos futuros.

Logo, estas observações estão relacionadas com o custeio do ciclo de vida dos produtos utilizados em uma construção, assim como, deve-se sempre ponderar todos os outros materiais necessários no decorrer da obra e na manutenção da edificação.

\subsubsection{Testes e start-up assistido do projeto de estudo de caso}

A partir do projeto implantado são realizados todos os testes necessários que devem ser confrontados com as decisões definidas anteriormente.

Esta etapa permite verificar se existe a necessidade de instruções ou treinamentos específicos aos usuários.

No estudo em questão houve a orientação com relação ao teste mensal do IDR sugerido pelo fabricante e do procedimento de identificação de circuitos caso venha a ocorrer desarmes indesejados, ou provocados por alguma fulga de corrente no mesmo dispositivo.

Também nesta etapa que se realizam todas as demarcações necessárias em toda a instalação para facilitar uma possível manutenção futura.

\subsubsection{Entrega final do projeto de estudo de caso}

Após todas as etapas consideradas se realiza a entrega final do projeto, acompanhado de uma verificação final de testes e anotações em quadros, tomadas e/ou outros dispositivos que se julgarem necessários. É também nesta etapa que se entra em acordo com relação à necessidade de acompanhamento por período predeterminado ou se deseja realizar um contrato de manutenção e acompanhamento. 


\subsubsection{Considerações finais da implantação do projeto de estudo de caso}

Uma constatação interessante que o estudo apresentou é de que uma vez bem desenvolvido os conceitos discutidos na MAEAR, os proprietários e os executores, ficam pré-dispostos e atentos em oportunidades de melhorias, pois durante a execução da obra surgem idéias e questionamentos diversos de possibilidades de se ampliar ou aperfeiçoar os itens escolhidos anteriormente.

O fato é de que quando há integração entre todos os envolvidos uma cumplicidade é gerada, contribuindo para uma edificação não repleta de tecnologia, mas, sim com sistemas integrados, que apesar não interagirem tecnologicamente entre si, se complementa.

Isto é, se existe, por exemplo, no momento certo um projeto e orientação para a instalação da infra-estrutura, ou seja, uma tubulação preparada para os mais diversos serviços, e os responsáveis pela construção os seguem, leva a uma satisfação conjunta, pois também evidencia e valoriza a importância de seus conhecimentos e ações em cada etapa. E quando todos reconhecem seus futuros benefícios que traz tal planejamento, unem-se ainda mais.

A metodologia MAEAR é uma proposta de iniciar uma conscientização seguida de ações, que tem em seu princípio um embasamento de uma pesquisa científica e uma realidade:

Projetos "inteligentes" geram edifícios, máquinas, processos e também edificações residenciais "inteligentes".

Também é necessário compreender e ponderar novamente sobre os níveis de automação citados nesta pesquisa, pois existem cada vez mais tecnologias que realmente se interagem fazendo de uma residência uma Casa Conectada como é chamada por uma respeitada empresa de tecnologia.

Existem também cada vez mais empresas e profissionais buscando aperfeiçoamento nesse campo do conhecimento, basta navegar brevemente na Internet para comprovar tal afirmação.

Neste início da validação da metodologia MAEAR, defendeu-se os níveis 1 e 2 da Automação, como sendo uma forma diferenciada de visualizar o significado de uma Edificação Inteligente, como por exemplo estes que acabaram de ser expostos neste capítulo, buscando romper inclusive o paradigma da relação, normalmente 
divulgada, de que automação residencial esteja somente associada a alta tecnologia.

Entretanto, durante o período de pesquisa constatou-se diversas outras situações, condições, exemplos e realidades diferentes, que deixaram claras evidências da existência real das inúmeras e empolgantes possibilidades e abrangências que a automação residencial pode alcançar com a alta tecnologia, porém níveis esses no Brasil, acessíveis somente para a classe de alto padrão.

Contudo, pode-se concluir ao implementar a metodologia MAEAR em projetos de AR que a mesma independe do nível de automação ou do padrão social, pois a mesma pode ser utilizada em qualquer situação.

No apêndice são apresentadas as tabelas dos outros estudos realizados. Apenas para visualização dos processos das edificações inteligentes a figura 4.3 apresenta um gráfico comparativo entre os índices encontrados em cada caso.

Conforme afirmado anteriormente não se deseja realizar comparações quantitativas e sim qualitativas, no que diz respeito à utilização da AR em busca de conforto, segurança, entretenimento, ou outros benefícios difíceis de serem medidos ou equiparados.

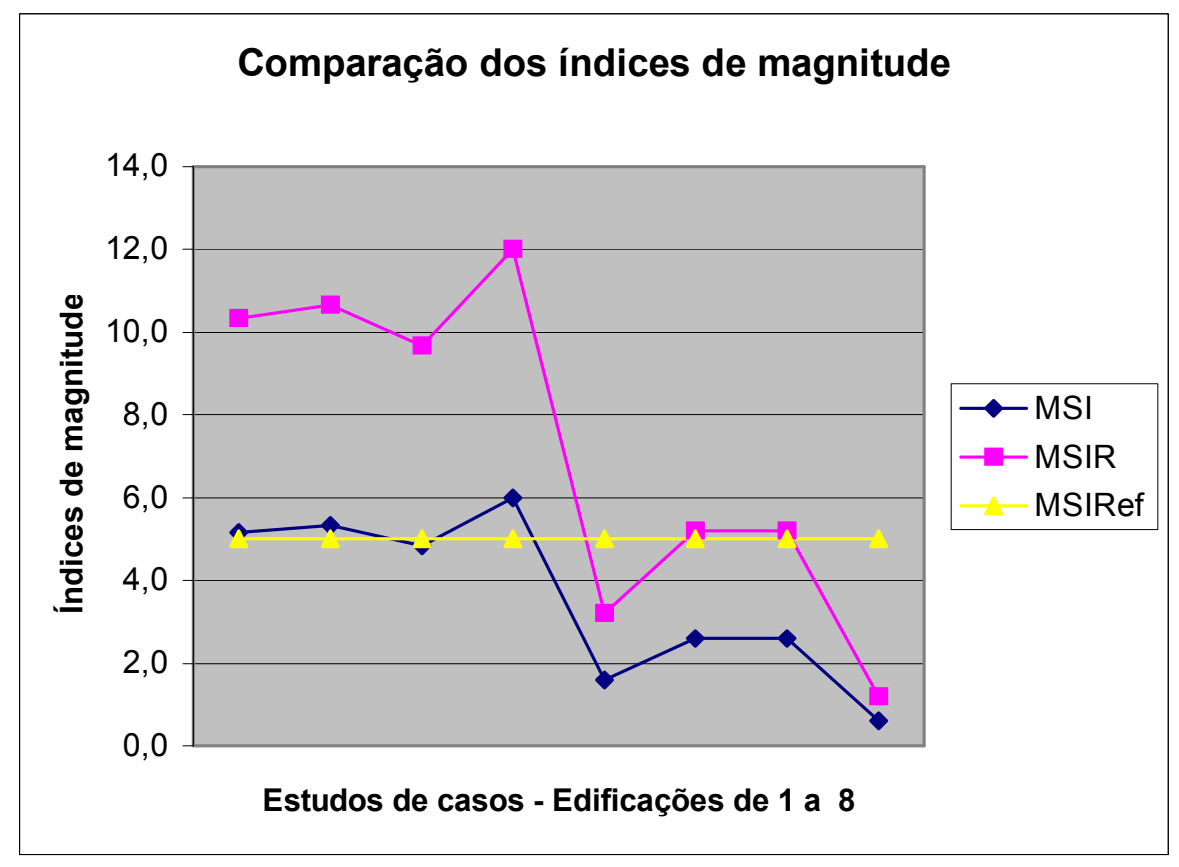

Gráfico 4.1 - Comparação dos índices de magnitude para visualização dos processos de edificações residenciais inteligentes 


\section{CONCLUSÃO}

\subsection{Análise Global}

Conforme mostrado neste trabalho de pesquisa a metodologia MAEAR é uma poderosa ferramenta de engenharia para análise de desenvolvimento de projetos de automação residencial (AR).

A mesma permite que haja uma melhor identificação das demandas imaginárias e as reais necessidades dos clientes e usuários de AR.

Também permite a elaboração de uma documentação clara sobre o relacionamento empresa/cliente e, portanto contribui para a eliminação de conflitos e quebra de expectativas.

Uma outra contribuição significativa da metodologia MAEAR é a adaptação dos níveis de automação residencial inserindo ao nível 1, itens de proteção automática como DR, IDR e DPS, contribuindo com as exigências normativas do setor elétrico.

Contribui também estimulando, por meio da MAEAR, a visualização da possibilidade da inserção de itens de infra-estrutura para sistemas de dados, como a previsão de tubulação para antena, telefonia, redes de informática, TV a cabo, entre outros.

Contudo a MAEAR, permite também flexibilidade, pois não está condicionada a nenhuma tecnologia especificamente.

Assim sendo pode-se concluir que o emprego da MAEAR poderá contribuir para o desenvolvimento e aprimoramento do mercado de automação residencial.

\subsection{Sugestões para trabalhos futuros}

Este trabalho propõe como continuidade das pesquisas efetuadas os seguintes tópicos: 
- Aprofundar a metodologia MAEAR realizando pesquisa que se faça um estudo com vários grupos sociais de diferentes regiões e rendas para que se possa obter uma média relativa que reflita com razoável grau de acerto uma comparação quantitativa entre projetos tradicionais versus projetos por meio da MAEAR;

- Examinar a possibilidade de ampliar a abrangência da metodologia MAEAR considerando aos níveis e sistemas de automação, equipamentos, dispositivos, materiais e custos que contribuam ao meio ambiente;

- Realizar novos estudos com a MAEAR considerando os portadores de necessidades especiais;

- Confrontar os conceitos da gestão de projetos da indústria da construção civil, ou da logística empresarial, com os conceitos relacionados à implantação de projetos de automação residencial;

- Verificar se existe interesse no mercado de AR a respeito do desenvolvimento de ferramenta iterativa de $\mathrm{TI}$ (Tecnologia da Informação) que facilite a determinação e especificação de equipamentos, dispositivos e sistemas de automação. 
Referências Bibliográficas

ABNT. NBR 5410:2004 Instalações elétricas de baixa tensão.

ARAÚJO M. W., LUZ J. M., AGUILAR A.. C. Instalações elétricas automatizadas descentralizadas versus instalações convencionais. ELETRICIDADE MODERNA, São Paulo, v.29, n. 329, p.148-161, agosto 2001.

ARKIN H., PACIUK M. Evaluation intelligent building according to level of service systems integration. Automation in Construction 1997;6(5/6):471-9.

BOLZANI, C. A. M., Desenvolvimento de um simulador de controle de dispositivos residenciais inteligentes: Uma introdução ao sistema domótico, Dissertação de mestrado, São Paulo, 2004, Escola Politécnica da Universidade de São Paulo.

CAMARGO I. M. de T. Noções básicas de engenharia econômica: aplicações ao setor elétrico. Brasília, FINATEC, 1998.

CAPUANO A., DELL'LSOLA M., MASSAROTTI N., VANOLI L. A metrological analysys of a (Direct Digital Control) DDC - based air conditioning system.

CEGELEC ENGENHARIA S.A. Sistemas de cabeamento estruturado. São Paulo, 1994. 47p.

DUARTE R., MARTINS A.G. Estratégias de controle automático de iluminação em edificações. ELETRICIDADE MODERNA, São Paulo, v.29, n. 324, p.62-71, março 2001.

ECHELON CORPORATION LonWorks ${ }^{\mathrm{TM}}$ - Power line SCADA systems. LonWorks Marketing Bulletin Number REV A., 2000.

ELKADI $\mathrm{H}$. Ecological approach for the evaluation of intelligence energy features in a building's skin. RENEWABLE AND 
SUSTAINABLE ENERGY REWIEWS ELSEVIER SCIENSE LTD., v4, p. 91-103, 2000.

ENERGY AND BUILDINGS ELSEVIER SCIENSE S.A., v29, p. 155-166, 1999.

GARCIA D. A. de A. Desenvolvimento de medidor eletrônico de energia elétrica de custo competitivo associado a estudos de medições de energia elétrica. São Paulo, 2000. Dissertação de Mestrado. Escola Politécnica da Universidade de São Paulo. Departamento de Engenharia e Automação Elétrica.

GIBSON D. O cabeamento estruturado aplicado a residências. ELETRICIDADE MODERNA, São Paulo, v.29, n. 324, p.142-151, março 2001.

GONÇALVES A. P. C. Proposta de Arquitetura Aberta de Central de Atendimento. São Paulo, 2001. Dissertação de Mestrado. Escola Politécnica da Universidade de São Paulo. Departamento de Engenharia de Computações e Sistemas Digitais.

HARTKOPF V., LOFTNESS V., MAHDAVI A, LEE S., SHANKAVARAM J.S. An integrated approach to design and engineering of intelligent buildings - The Intelligent Workplace at Carnegie Mellon Univesity. AUTOMATION IN CONSTRUCTION ELSEVIER SCIENSE B.V., v6, 401-415, 1997.

HIRST E., O'HARA F. M. Energy efficient in buildings - Building Energy Conservation - USA, 1986.

KALLENBORN R. A tecnologia PLC e os métodos da análise da transmissão. ELETRICIDADE MODERNA, São Paulo, v.29, n. 325, p.206-217, abril 2001.

KEEGAN W. J., MARK C. G. Princípios de Marketing Global. São Paulo, Saraiva, 1999. 476p. 
KUA H. W., Lee S. E., Demonstration intelligent building - a methodology for the promotion of total sustainability in the built environment. AUTOMATION CONSTRUCTION IN ELSEVIER SCIENSE LTD., v37, p. 231-240, 2002.

LAMBERTS R., DUTRA L., PEREIRA F. O. R. Eficiência Energética na Arquitetura. São Paulo: PW, 1997. 192p. il.

LI H. W. D., LAM J. C. Evaluation of lighting performance in office buindings with daylighting controls. ENERGY AND BUILDINGS ELSEVIER SCIENSE B.V., v33, p. 793-803, 2001.

MARTE, C. L. Automação predial - a Inteligência distribuída nas edificações. Carthago e Forte, 1995.

MOORE G. A. Dentro do Furacão. São Paulo, Futura, 1996. 272 p.

MORAES C. C., CASTRUCCI P. de L. Engenharia de Automação Industrial. São Paulo, LTC, 2001. 295p.

NICOLÓSI M.. Arquitetura predial e técnicas de arquitetura podem otimizar consumo de energia. CLIMATIZAÇÃO RPA EDITORIAL, São Paulo, p. 10-20, agosto 2001.

PARASURAMAN A. Marketing para Produtos Inovadores. São Paulo, ARTMED, 2002. $157 \mathrm{p}$.

PERALTA, A. C. Um modelo do processo de edificações, baseado na engenharia simultânea, em empresas construtoras incorporadoras de pequeno porte. Florianópolis: Universidade Federal de Santa Catarina, 2002. 143 p.

PEREIRA, S. L., GUNDIM, R. S., Tecnologia e tendências dos sistemas de automação residencial, Eletricidade Moderna, V. 373, 2005, p. 66-87.

PEREIRA, S. L., GUNDIM, R. S., Proposta de metodologia para auxílio da engenharia em projetos de automação residencial e tendências tecnológicas, Congresso ISA SHOW 2007, 2007. 
PINTO J. R. Utilização racional de energia elétrica em instalações elétricas comerciais empregando sistemas de automação. São Paulo, 2000. Dissertação de Mestrado. Escola Politécnica da Universidade de São Paulo. Departamento de Engenharia e Automação Elétrica.

SIEMENS AUTOMAÇÃO. Técnica inteligente de gerenciamento de instalações elétricas prediais e residenciais. CD ROOM. 2001.

SMITH S.. The Integration of communications netwoks in the intelelligent building. AUTOMATION IN CONSTRUCTION ELSEVIER SCIENSE B.V., v6, 511-527, 1997.

T. DEREK J. CLEMENTS. What do we mean by intelligent buildings?. AUTOMATION IN CONSTRUCTION ELSEVIER SCIENSE B.V., v6, n p. 395-400, 1997.

TSANG P. W. M., WANG R. W. C. Development of a distributive lighting control system using local operation network. IEEE TRANSACTION ON CONSUMER ELETRONICS, v40, n. 4, p. 879-889. November 1994.

VARGAS A. A., Pereira C. A., Lages W. F., Carro L., Comunicação de dados através da rede elétrica, UFRS, Porto Alegre, p.70, 2004.

XIE C. , PU J. S., MOORE P. R. A case study on the development of intelligent actuador components for distributed control systems using LONWORKS neuron chips. MECHATRONIS ELSEVIER SCIENSE LTD., v08, p. 103-119, 1998.

YANG J, PENG H. Decision support to the application of intelligent buindilng technologies. RENEWABLE ENERGY ELSEVIER SCIENSE Ltd., v.22, p. 67-77, 2001. 


\section{Páginas da Internet (Referências Complementares)}

Homepage da Lemos Britto Multimídia Congressos e Feiras;

$<$ http://www.lemosbritto.com.br/predio-inteligente/> acessado em junho de 2005.

Homepage da European International Business Academy; <http://www.eiba.com/> acessado em julho de 2006.

Homepage da Casa Inteligente Lda; <http://www.acasainteligente.com> acessado em julho de 2006.

Homepage do Projeto Casa Autônoma;

<http://www.casaautonoma.com.br/> acessado em setembro de 2006.

Homepage do Sindicato da Indústria da Construção Civil do Estado de São Paulo; <http://www.sindusconsp.com.br/> acessado em junho de 2007.

Homepage da Continental Automated Buildings Association;

<http://www.caba.org/index.html> acessado em junho de 2007.

Homepage da Continental Automated Buildings Association;

$<$ http://www.building-iq.com/biq/index.html> acessado em junho de 2007.

Homepage da Continental Automated Buildings Association (LCC);

< http://www.caba.org/lifecycle/> acessado em junho de 2007.

Homepage da iHomes \& Buildings Magazine;

<http://www.caba.org/ihomesandbuildings/> acessado em set. de 2007.

Homepage da CABA's Internet Home Alliance Research Council;

<http://www.caba.org/iha/> acessado em setembro de 2007

Homepage da Associação Brasileira de Automação Residencial

<http://www.aureside.org.br/> acessado em outubro de 2007.

Homepage da Siemens do Brasil;

<http://w1.siemens.com/answers/pt/br/> acessado em outubro 2007. 


\section{APÊNDICE A - DESCRIÇÃO EXEMPLO DE UMA CASA INTELIGENTE}

Aconteceram diversos congressos, feiras tecnológicas, e eventos correlacionados à automação residencial. Um dos que merece destaque pela abrangência das aplicações foi o projeto intitulado "CASA INTELIGENTE” em 2002. Nela foram desenvolvidas variadas funções para uma edificação residencial. Implementada no evento denominado Habitar 2002 em uma exposição realizada em 2002 em São Paulo, teve na ocasião, como objetivo divulgar e estimular a adoção de tecnologias de automação residencial no país. A mesma compunha de vários sistemas, entre elas:

- portas, janelas, cortinas e toldos da CASA eram controlados com um toque no controle remoto;

- controle de luminosidade interna em função da luminosidade externa;

- o acesso à CASA se deu por meio de sistemas de biometria. Para entrar, a pessoa era identificada pela leitura digital ou da íris;

- todas as luzes, internas e externas, foram acionadas a partir de um único controlador digital, podendo, ainda, serem programadas várias funções, tais como, horário diurno, noturno, festas, exibições no home theater, dentre outras;

- os sistemas de telefonia e intercomunicação foram totalmente integrados, possibilitando que o morador atendesse a campainha ou acessasse sua secretária eletrônica a partir de qualquer telefone instalado dentro da casa;

- o sistema de irrigação permitiu criar zonas de irrigação e dosar a quantidade de água de acordo com a necessidade de cada planta. Esse sistema também permitia ser programado para funcionar em horários preestabelecidos ou na falta prolongada de chuva;

- o sistema de áudio integrado possibilitou que o som instalado em cada um dos ambientes fosse monitorado a partir de qualquer local da CASA;

- o sistema de climatização permitiu que a temperatura dentro da CASA fosse controlada a distância ou passasse a ser programada para aquecer ou resfriar em determinados horários do dia;

- os locais mais frios da casa contaram com o sistema de aquecimento de piso. $O$ mesmo permitia ser acionado de modo que, quando o morador acordasse ou chegasse a casa, o chão já estivesse aquecido; 
- o sistema de segurança, que possuíam detectores conectados a sensores de presença e botões de pânico, garantiam o total controle dos acessos à CASA. Como parte desse sistema uma pequena câmera estava discretamente posicionada próxima à porta, permitindo que o visitante fosse visto em qualquer um dos televisores dentro da residência. Pelo mesmo método, foi possível monitorar aposentos específicos, como o quarto das crianças. Este sistema pode ser usado, ainda, para acionar as luzes, televisores e rádio para fazer com que a CASA pareça estar ocupada enquanto o morador estiver ausente;

- um outro recurso disponibilizado pelo sistema de segurança, permitia que os pais fossem avisados, com uma luz piscando, quando simuladamente seu filho, chegasse a casa;

- no home theater, a integração dos sistemas de telefonia, segurança e iluminação permitiam que o usuário, com um toque no controle remoto, ligasse o sistema de projeção com o seu filme preferido e, automaticamente, fosse ajustada a iluminação mais adequada ao momento. Se a campainha ou o telefone tocasse, as luzes do ambiente se ascendiam e o filme, de imediato parava, com uma mensagem chamando a atenção para atender ao telefone ou receber a visita;

- as fechaduras de algumas portas funcionaram de três formas: através de senha, cartão magnético ou cartão de aproximação. Dotada de memorização, o sistema tinha capacidade para armazenar informações como data e horário, checando e controlando o acesso aos diferentes ambientes da CASA;

- o controle periférico, que substituiu a cerca elétrica, foi equipado com um sistema emissor de infravermelho, que, se fosse interrompido, fazia disparar o alarme;

- um painel interativo para jogos foi colocado no quarto dos jovens. Ligado ao computador, foi possível mover as peças de um jogo, com as mãos, ao invés de usar o mouse ou o teclado do computador;

- até mesmo o cofre era eletrônico. Além de ser aberto por meio de um teclado digital, ele foi equipado com um sistema que registrou a data e o horário da sua abertura;

- as camas foram articuladas e ajustadas, por controle remoto, de acordo com a posição que o morador desejasse; 
- a banheira com massageador automático foi adaptada com um sistema que tornou a água ozonizada. Esse sistema, cujos jatos da água são acionados automaticamente, tem efeito terapêutico;

- o protetor de surto, que também estava nos ambientes, impedia que os problemas da rede elétrica fossem transferidos para os equipamentos eletroeletrônicos;

- a piscina foi equipada com o sistema de auto-limpeza, que, assim como os demais, podiam ser programados para funcionar em determinados horários, sem que o usuário tivesse que se deslocar até o local.

- o purificador de ar, instalado na cozinha, detectava a qualidade do ar e ligava, automaticamente, se fosse preciso;

- o sistema de reaproveitamento e filtragem de água permitia que a água de chuva ou aquela que foi utilizada uma única vez, pudesse ser filtrada e posteriormente reutilizada, por exemplo, para lavar o chão ou na irrigação do jardim;

- o PDA, um equipamento eletrônico portátil, foi usado para receber e-mail, ascender as luzes ou, mesmo, conectar-se à Internet visualizando, por meio das câmeras instaladas e de um sistema de comunicação sem fio (wireless) o sistema de segurança de vídeo;

- a central de aspiração a vácuo, localizada numa área restrita, "sugava" o ar, por uma tubulação, sem ruídos e sem que fosse necessário deslocar o aspirador de pó.

Estas foram algumas das possibilidades de aplicação da automação residencial implementadas na CASA INTELIGENTE em São Paulo no evento Habitar 2002, com o intuito de divulgar e estimular a adoção de tecnologias de automação residencial no país. Fica evidenciado que eventos como estes também são formas para atacar nichos do mercado de automação residencial a fim de combater o "abismo", mencionado por Geoffrey Moore e apresentado no Capítulo 1.

Com relação aos sistemas de automação implementados nesta CASA devido serem múltiplos sistemas integrados entre si, mas que entretanto determinados sistemas ou equipamentos operavam de acordo com sua fabricação, melhor enquadra-se no nível 2 de automação, segundo a HAA - Home Automation Association. 


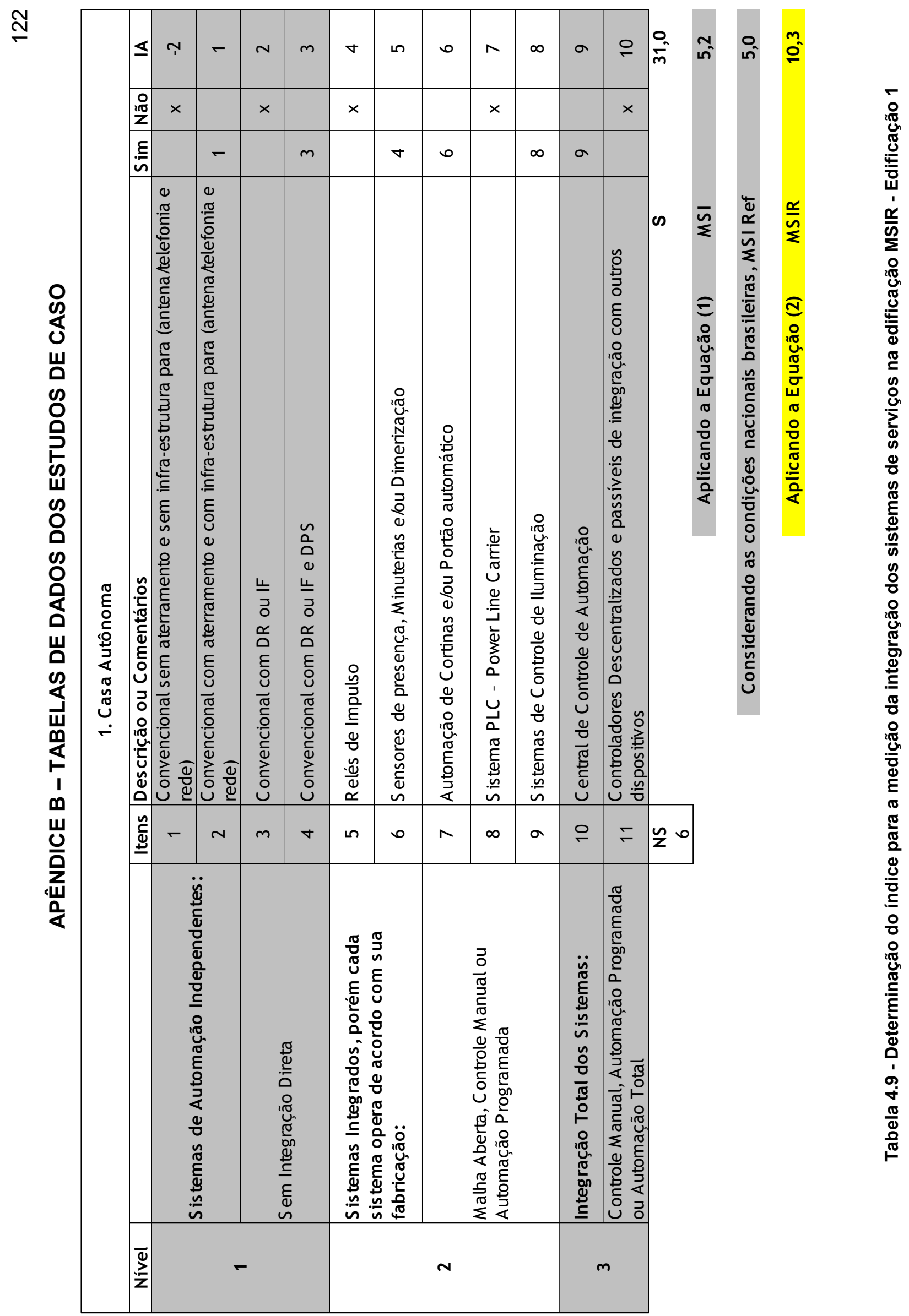


$\stackrel{乛}{\sim}$

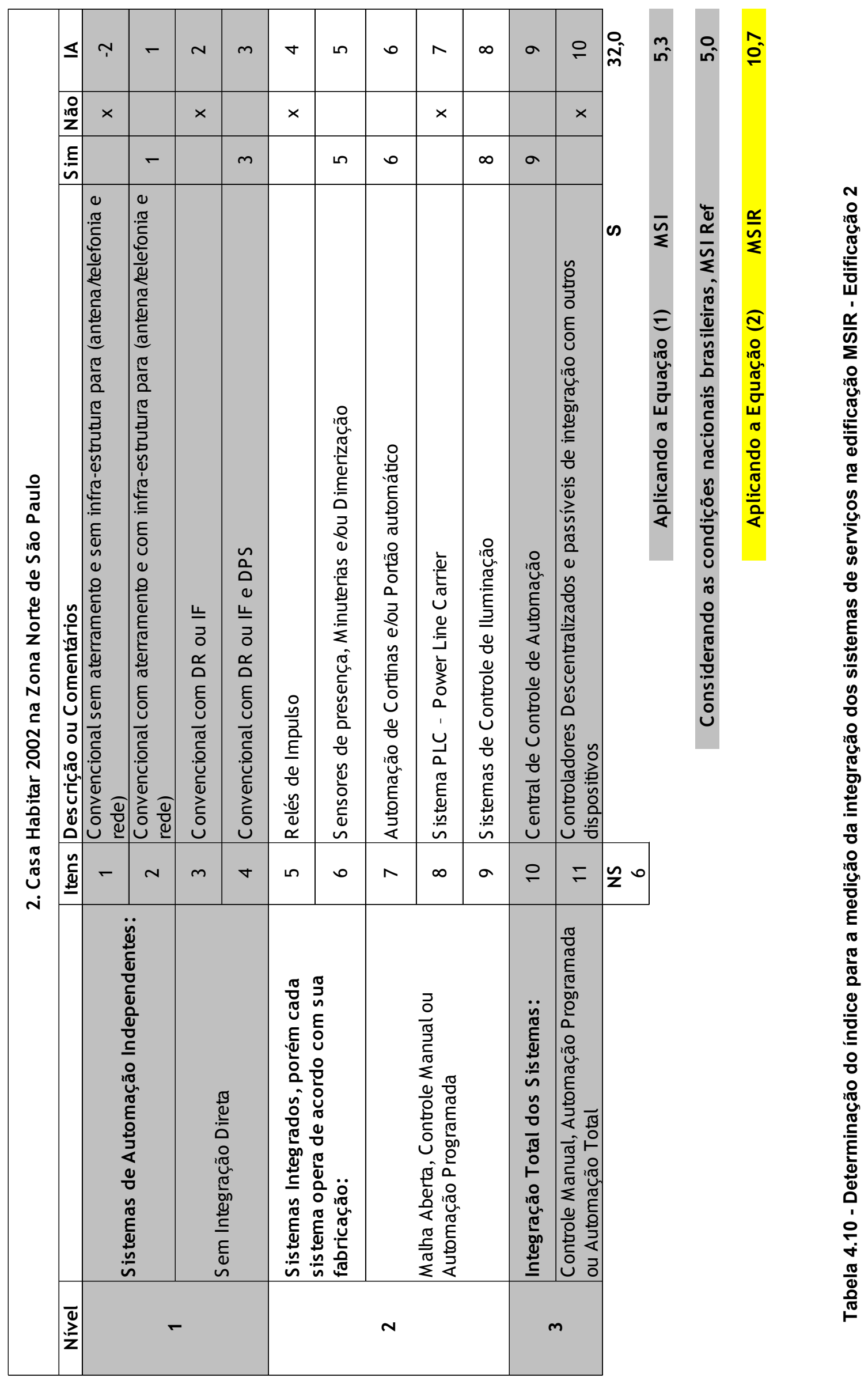


$\stackrel{ \pm}{\check{I}}$

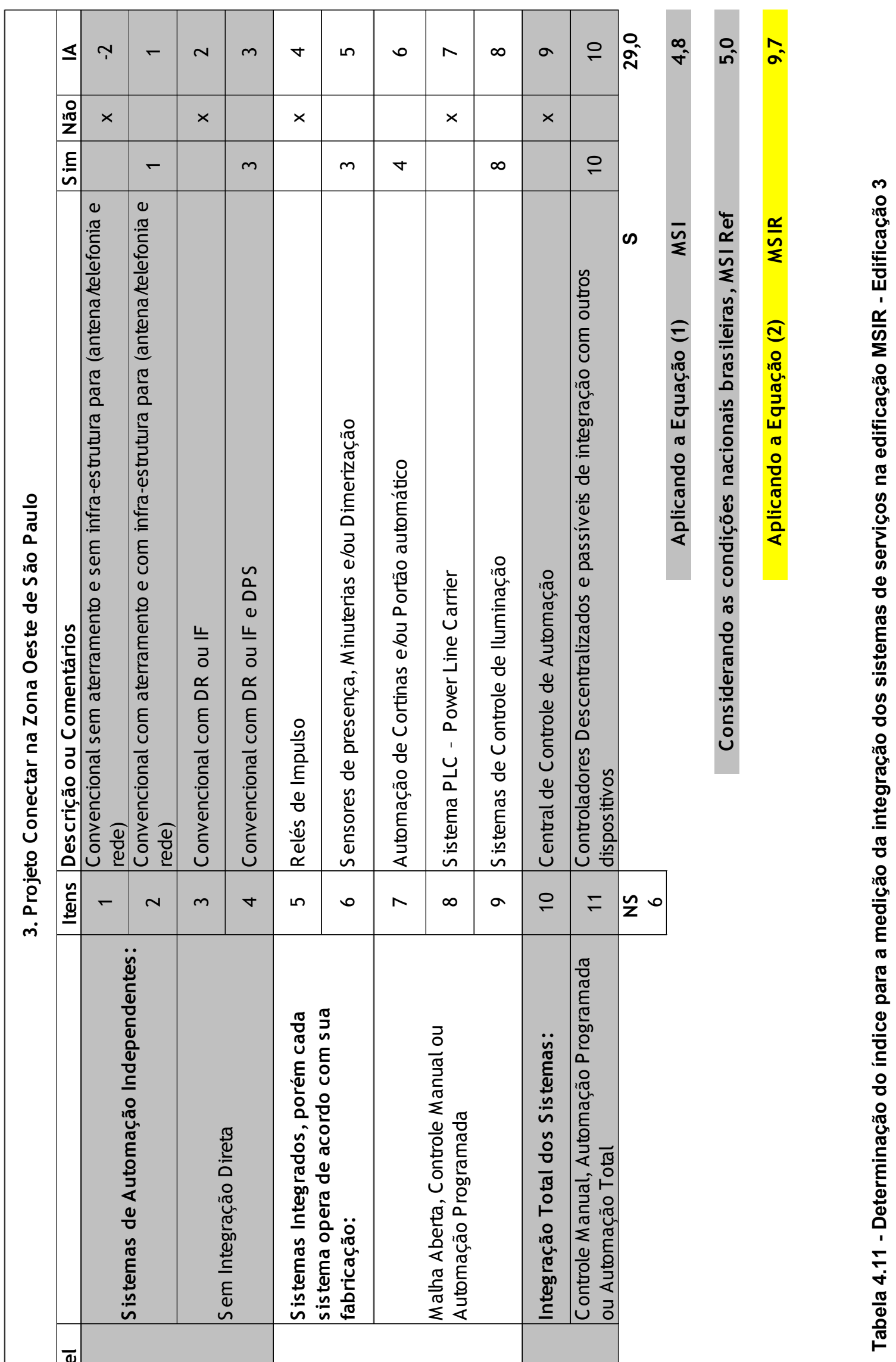




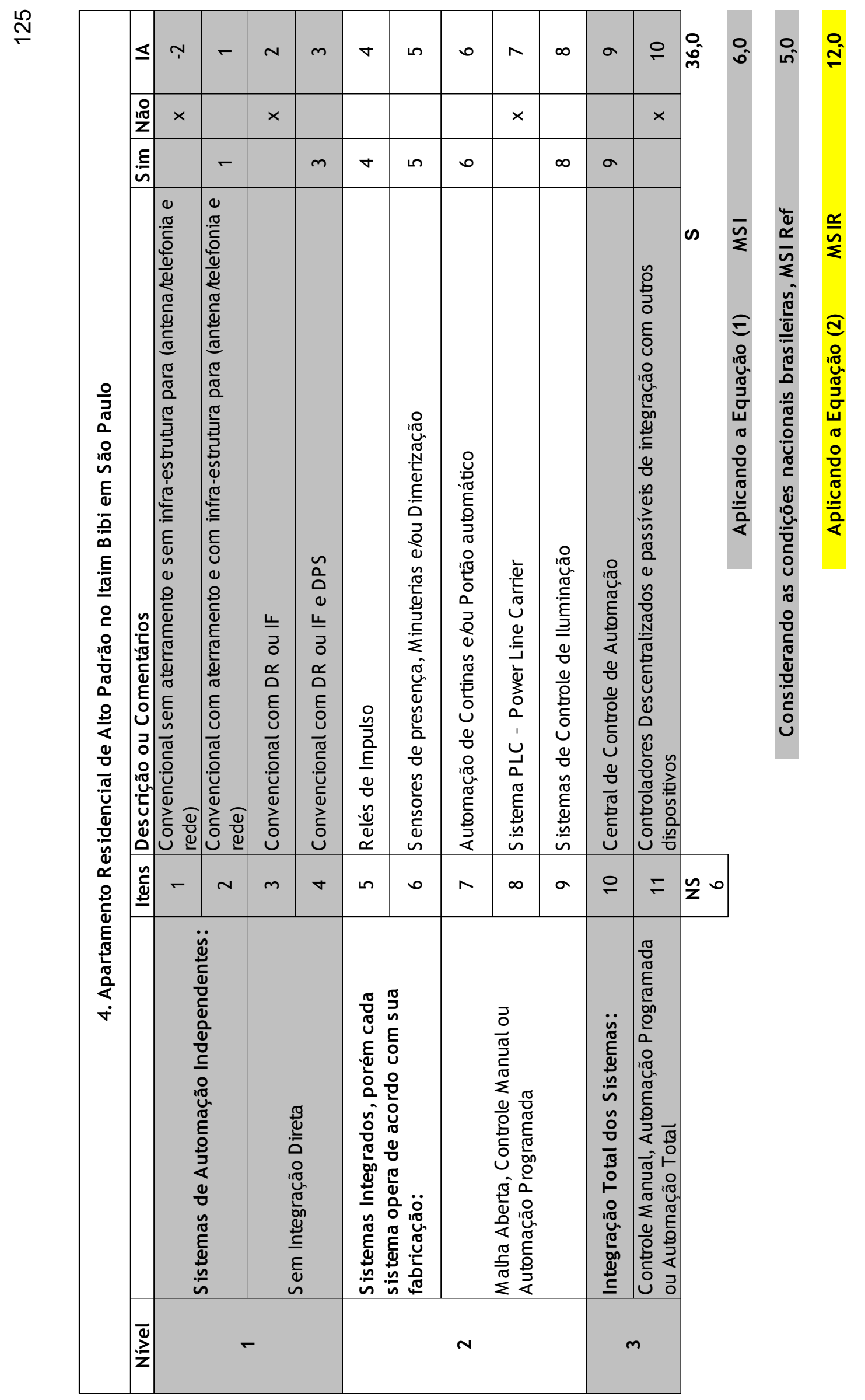

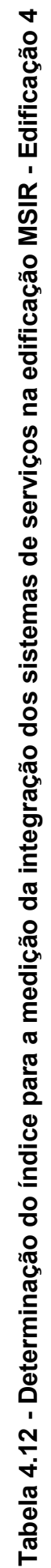


$\stackrel{ }{\sim}$

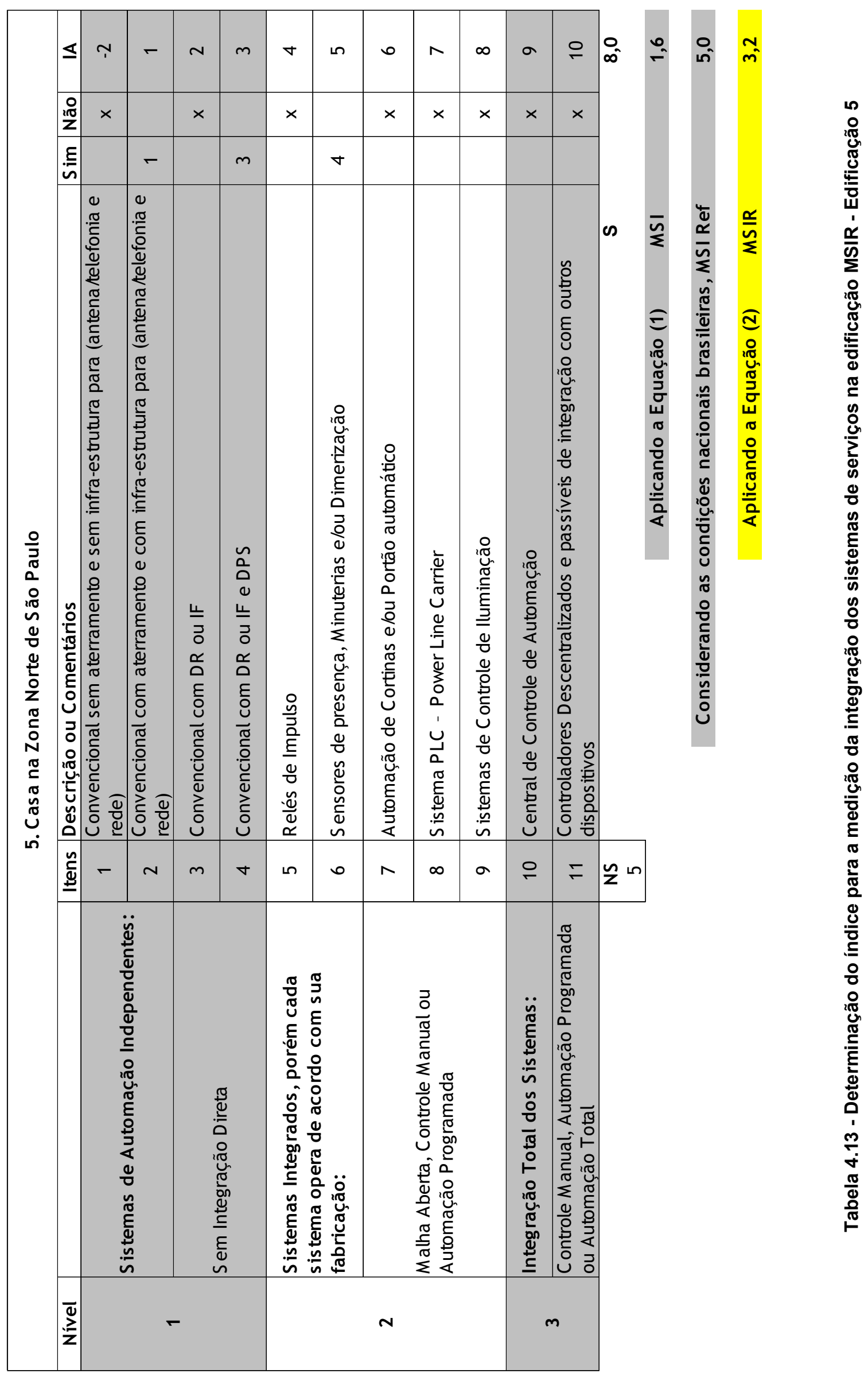




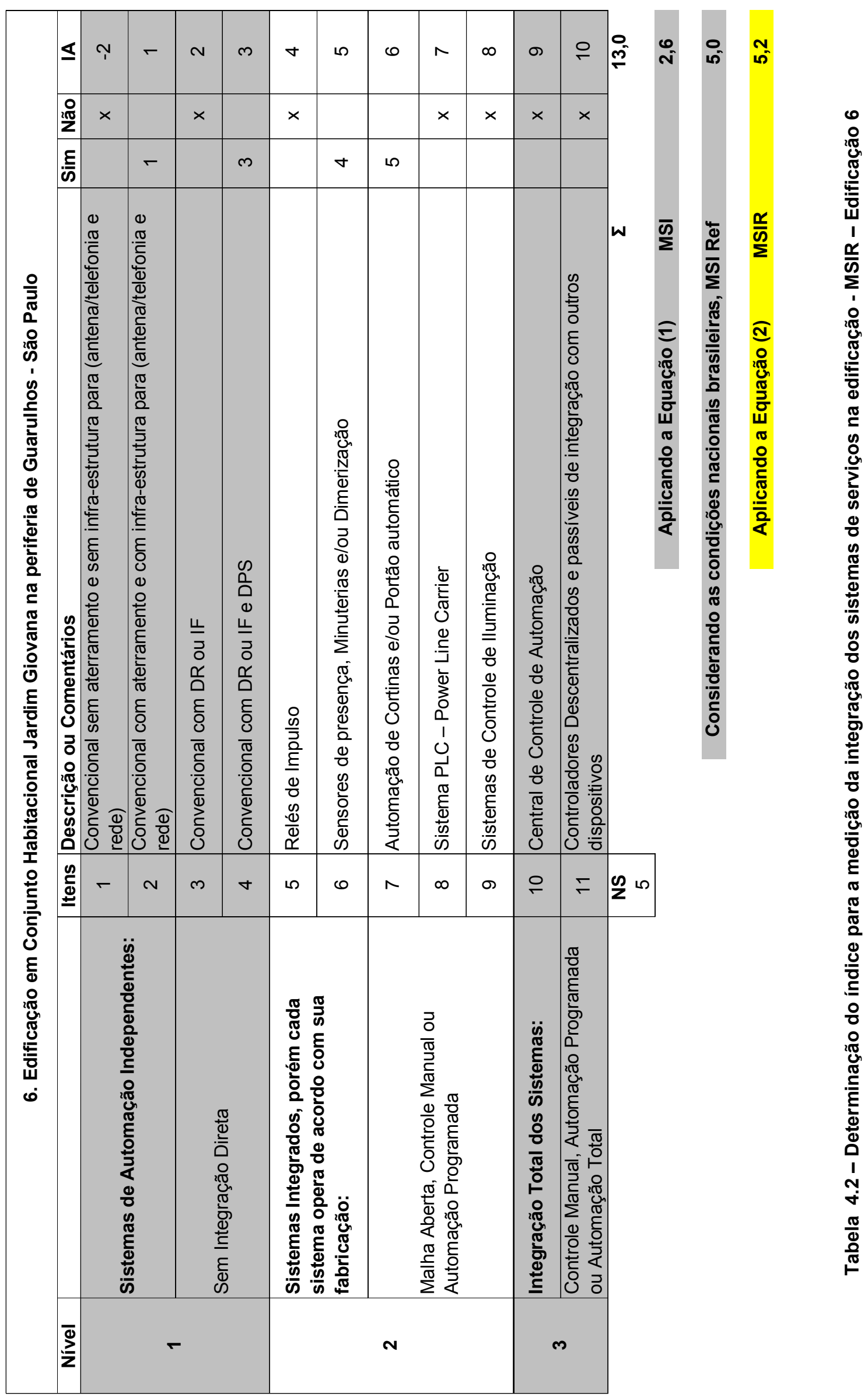




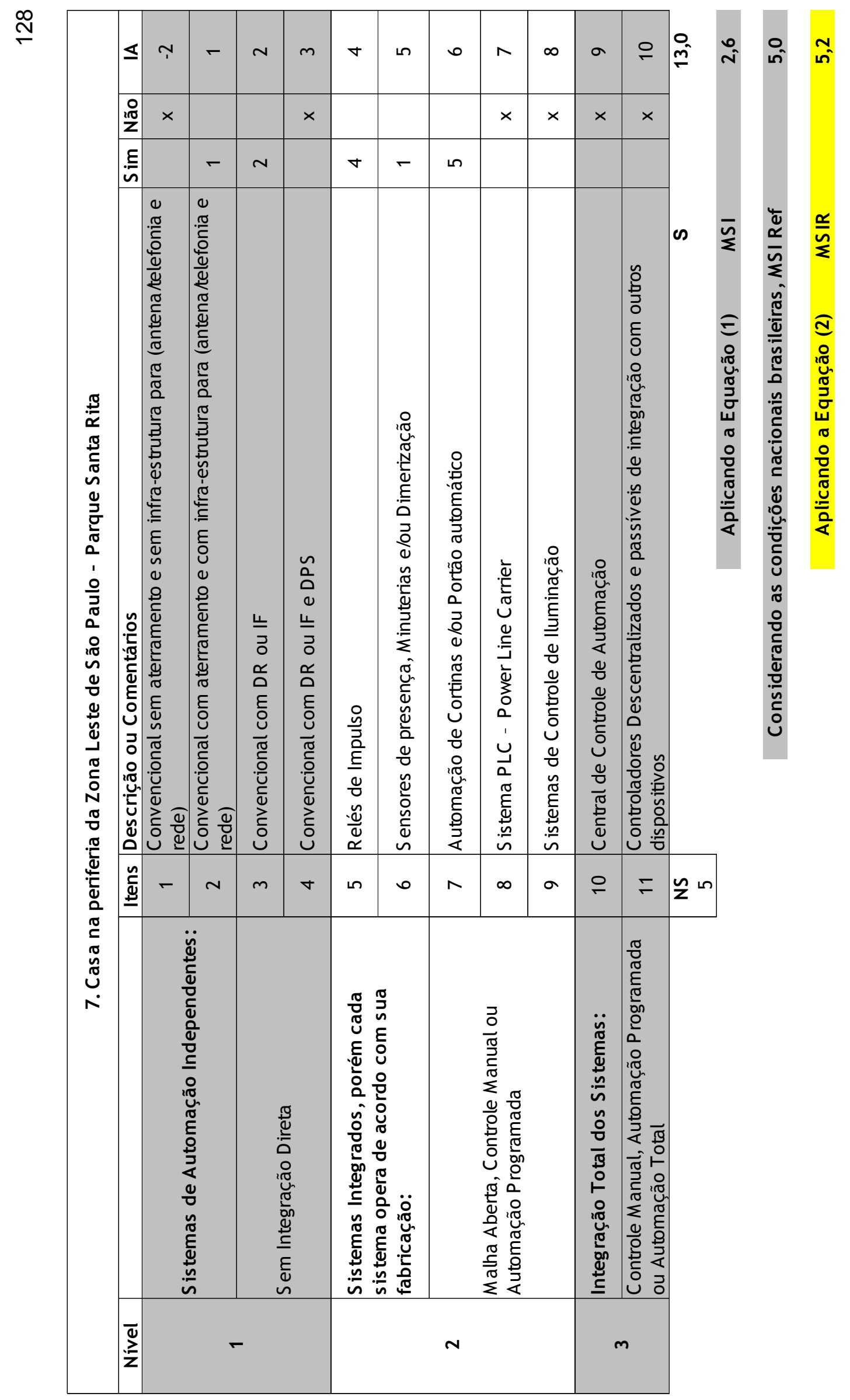

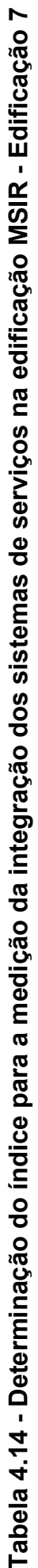




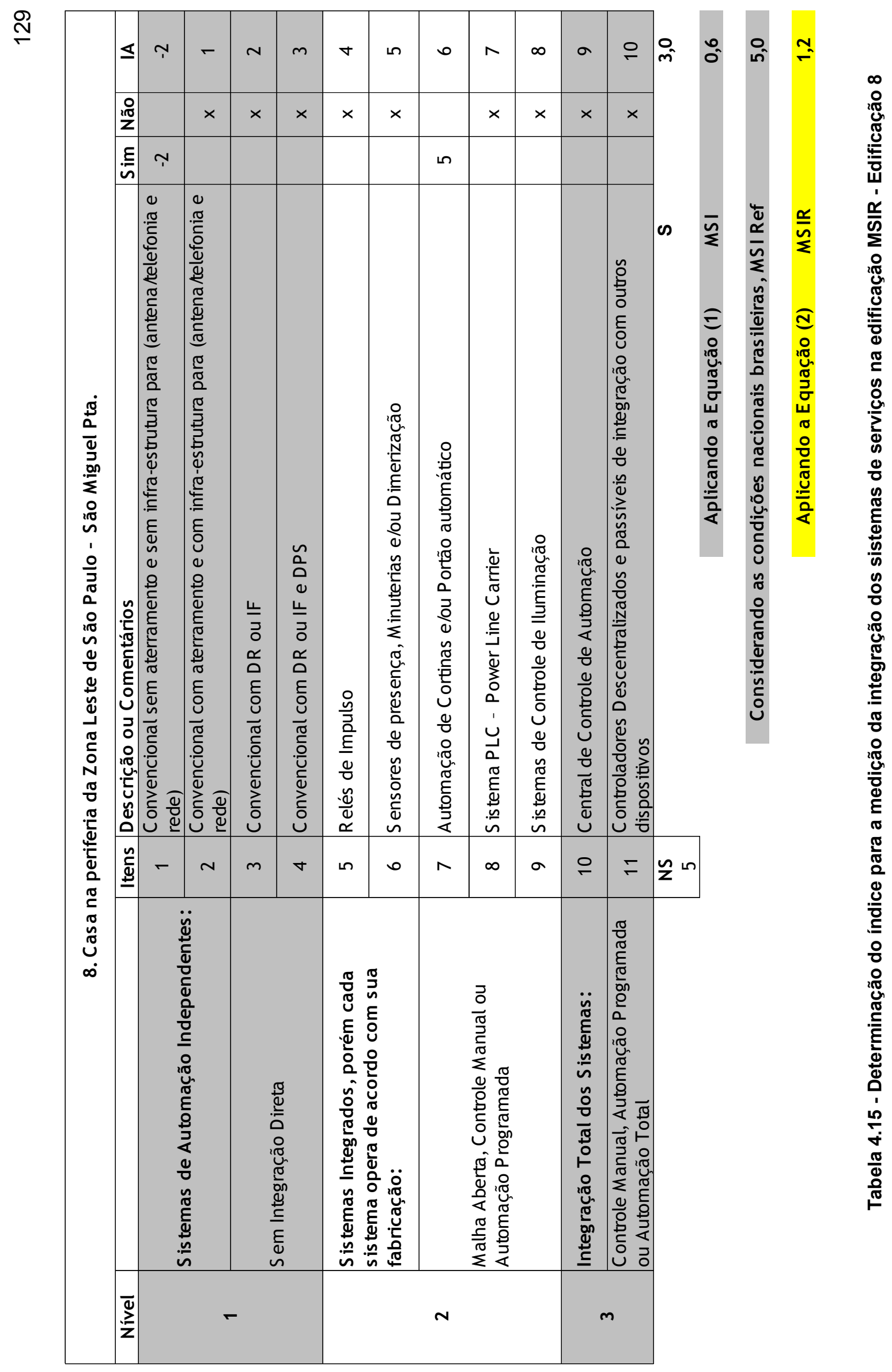





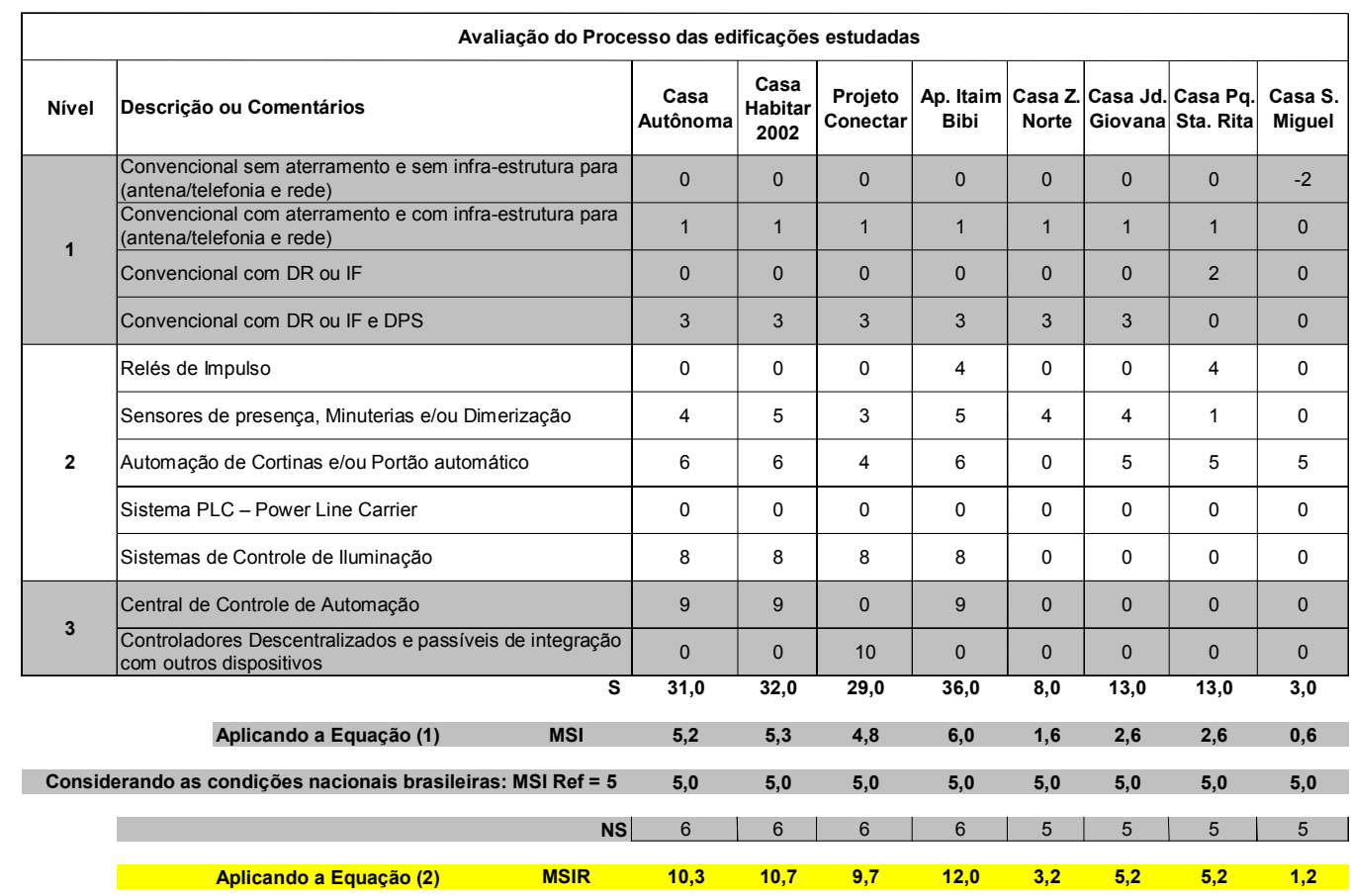

Tabela 4.16 - Tabela integrada para comparação das edificações residenciais inteligentes

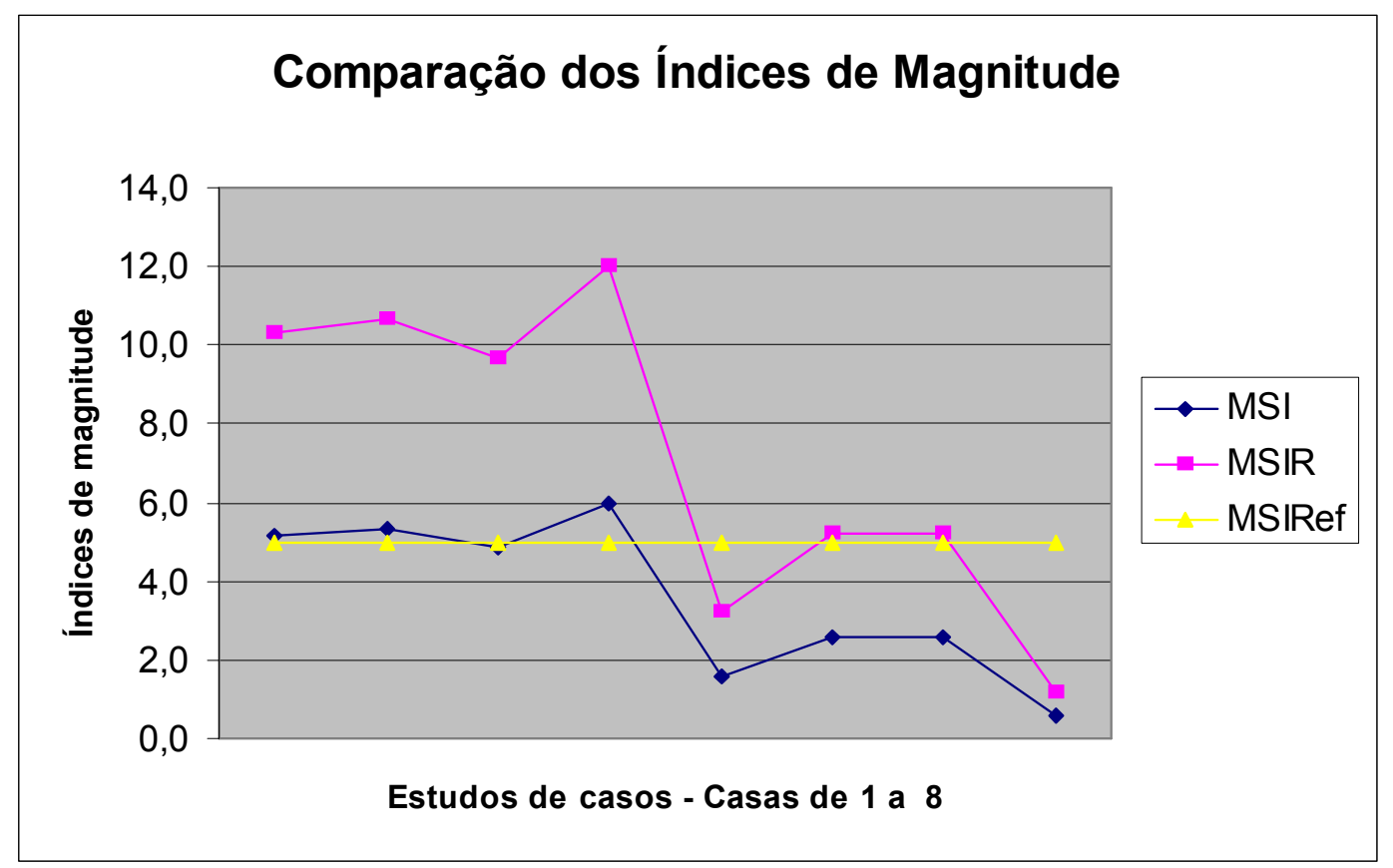

Gráfico 4.1 - Comparação dos Índices de Magnitude para avaliação dos processos de edificações residenciais inteligentes 